UNIVERSIDAdE DE SÃo PAUlo

INSTITUTO DE FÍsICA

\title{
Efeitos da Desordem Temporal Aperiódica em Transições de Fase Fora do Equilíbrio
}

\section{Ariel Yssou Oliveira Fernandes}

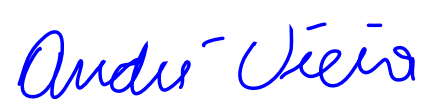

Orientador: Prof. Dr. André de Pinho Vieira

Dissertação de mestrado apresentada ao Instituto de Física da Universidade de São Paulo, como requisito parcial para a obtenção do título de Mestre em Ciências.

Banca Examinadora:

Prof. Dr. André de Pinho Vieira - Orientador (USP)

Profa. Dra. Suani Tavares Rubim de Pinho (UFBA)

Prof. Dr. José Abel Hoyos Neto (UFSCar) 


\section{FICHA CATALOGRÁFICA}

\section{Preparada pelo Serviço de Biblioteca e Informação}

do Instituto de Física da Universidade de São Paulo

\begin{tabular}{|l} 
Fernandes, Ariel Yssou Oliveira \\
Efeitos da desordem temporal aperiódica em transições de fase \\
fora do equilíbrio. São Paulo, 2020. \\
Dissertação (Mestrado) - Universidade de São Paulo. Instituto de \\
Física. Depto. de Física Geral \\
Orientador: Prof. Dr. André de Pinho Vieira \\
Área de Concentração: Física Estatística. \\
Unitermos: 1. Universalidade; 2. Processo de contato; 3. Transição \\
de fase. \\
USP/IF/SBI-052/2020
\end{tabular}


UNIVERSITY OF SÃo PAULO

INSTITUTE OF PHYSICS

\title{
Effects of Aperiodic Temporal Disorder on Nonequilibrium Phase Transitions
}

\section{Ariel Yssou Oliveira Fernandes}

\author{
Supervisor: Prof. Dr. André de Pinho Vieira
}

Dissertation submitted to the Physics Institute of the University of São Paulo in partial fulfillment of the requirements for the degree of Master of Science.

Examining Committee:

Prof. Dr. André de Pinho Vieira - Supervisor (USP)

Profa. Dra. Suani Tavares Rubim de Pinho (UFBA)

Prof. Dr. José Abel Hoyos Neto (UFSCar)

São Paulo 

Para aqueles que, mesmo em tempos de preconceito, ousam ser quem são. 


\section{Agradecimentos}

Esta dissertação não teria sido escrita sem a paciência, compreensão e amor que recebi de muitas pessoas. Devo primeiramente os meus mais sinceros agradecimentos ao Prof. André de Pinho Vieira. Sua orientação me ajudou a me tornar o profissional que sou hoje e sua paixão pela ciência tem sido uma inspiração. Devo também agradecer seu carinho e compreensão que me ajudaram a aguentar períodos difíceis em minha vida e me motivaram à continuar lutando pelos meus sonhos.

Gostaria também de agradecer à Profa. Carmen Pimentel Prado por me apresentar à física estatística e servir como inspiração como pesquisadora e como professora. Ao meu professor e amigo Guilherme "Turma" Magalhães por todo o apoio e carinho através dos anos, por me apresentar à ciência e acreditar em mim. Devo agradecer também aos diversos professores que tive durante minha vida. Sem eles não teria chegado aonde cheguei.

Agradeço também aos meus amigos, que sempre estiveram ao meu lado: Júlia Najar Duarte, por ser a pessoa mais forte e incrível que conheço. Lucas Camargo, por ser extremamente insuportável e um amigo que irei levar no coração por toda vida. Gabriel Julião, por todas as aventuras que tivemos desde crianças até hoje. Pedro Eduardo Harunari e Pedro de Castro Portugal, cuja ajuda e companheirismo me ajudaram a chegar até aqui. Liza Caetano, minha outra metade de sereia. Vinícius Teixeira, por tudo que enfrentamos. A todos amigos que fiz no Instituto de Física, em especial ao pessoal do CEFISMA, que sacrificaram muito para tornar o instituto um lugar melhor para todos. A todos que não citei nominalmente, porém compõe minha história e coração.

Agradeço a minha família por todo o sacrifício, amor e carinho. Agradeço especialmente a minha mãe Joice. Sem seu amor, carinho e sacrifício não teria me tornado quem sou hoje.

Por fim agradeço ao Conselho Nacional de Desenvolvimento Científico e Tecnológico pelo apoio financeiro. 
Buried deep within you, beneath all the years of pain and anger, there is something that has never been nurtured: the potential to make yourself a better man. And that is what it is to be human. To make yourself more than you are.

Oh, yes - I know you. There was a time you looked at the stars and dreamed of what might be.

Jean-Luc Picard 



\section{Resumo}

Nesta dissertação estudamos o efeito da desordem determinística aperiódica temporal no comportamento crítico do processo de contato e em sua solução de campo médio, a equação logística. Adaptamos o critério de Harris-Luck para desordens aperiódicas temporais e estabelecemos um novo valor limite para o expoente de flutuação $\omega$, que determina se a criticalidade será afetada. Introduzimos desordem temporal nos modelos tratados fazendo com que os parâmetros do sistema oscilassem de acordo com a sequência generalizada de Fibonacci, caracterizada por um fator $k$, que controla a intensidade das flutuações da sequência. Com o auxilio de teoria de grupo de renormalização, simulações de Monte Carlo e argumentos de escala, estudamos o comportamento crítico desses sistemas e verificamos as previsões do critério de estabilidade, que se provaram

compatíveis com os resultados numéricos. Apresentamos, também, esforços para uma formulação de um tratamento de grupo de renormalização para o processo de contato com desordem temporal aperiódica.

Palavras-chaves: Processo de contato; desordem temporal; transições de fase; universalidade; simulações de Monte Carlo. 


\begin{abstract}
In this dissertation we have studied the effect of aperiodic temporal disorder on the critical behavior of the contact process and its mean field solution, the logistic equation. We adapted the Harris-Luck criterion to temporal aperiodic disorder and established a new threshold for the fluctuation exponent $\omega$, that determines if the criticality will be affected. Aperiodic temporal disorder was introduced in the aforementioned models by considering that the system parameters oscillate according to the generalized Fibonacci sequence, characterized by a parameter $k$ that controls the strength of the oscillations within the sequence. Using renormalization group theory, Monte Carlo simulations and scaling arguments, we studied the critical behavior of these systems and verified the predictions of the stability criterion, which were compatible with our numerical results. We also provide efforts towards a renormalization group approach to the contact process with temporal aperiodic disorder.
\end{abstract}

Keywords: Contact Process; temporal disorder; nonequilibrium phase transitions; universality; Monte Carlo simulations. 


\section{Conteúdo}

1 Introdução $\quad 13$

2 Aperiodicidade Determinística e Universalidade 15

2.1 Sequência Generalizada de Fibonacci ～. . . . . . . . . . . . . . . . . . . . 17

2.2 Universalidade e a Percolação Direcionada . . . . . . . . . . . . . . . . . . . . . . . . . 19

2.2 .1 Percolação Direcionada . . . . . . . . . . . . . . . . . . . . . . 20

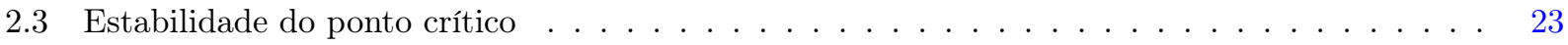

2.3 .1 Desordem espacial e o critério de Harris-Luck . . . . . . . . . . . . . . . . . . 23

2.3.2 Desordem temporal e a generalização do critério de Harris . . . . . . . . . . . . . . . . 24

3 Modelos $\quad 27$

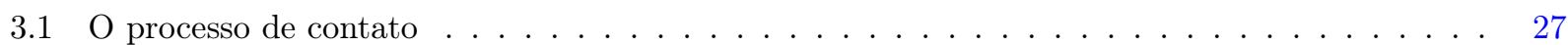

3.1 .1 Aproximação de campo médio e a equação logística . . . . . . . . . . . . . . . . . . . 30

3.2 Desordem . . . . . . . . . . . . . . . . . . . . . . . . . . . . 31

$3.2 .1 \quad$ Desordem Espacial . . . . . . . . . . . . . . . . . . . . . . . . . . 32

3.2 .2 Desordem Temporal . . . . . . . . . . . . . . . . . . . . . . . . . 34

4 Equação Logística com Aperiodicidade Temporal $\quad 37$

4.1 Grupo de renormalização . . . . . . . . . . . . . . . . . . . . . . . 39

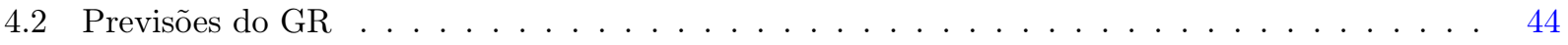

4.3 Fluxo do Grupo de Renormalização . . . . . . . . . . . . . . . . . . . . . . . . . 45

4.4 Previsões explícitas do Grupo de Renormalização . . . . . . . . . . . . . . . . . . . . . . 46

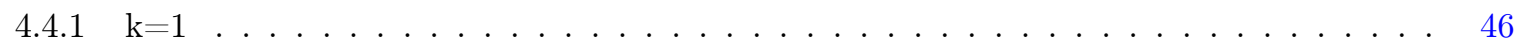

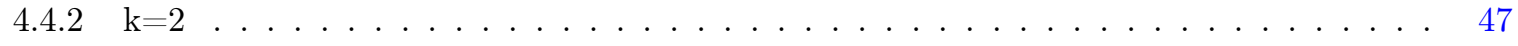

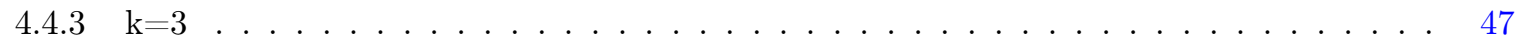

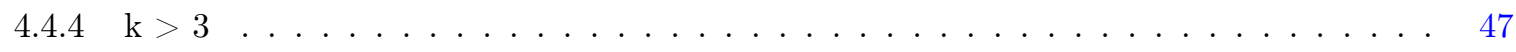

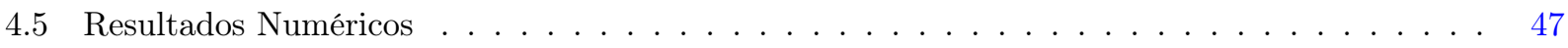

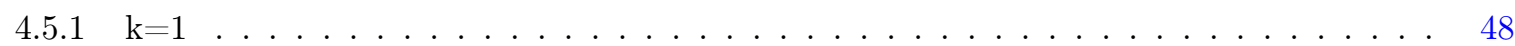




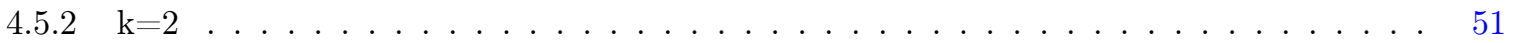

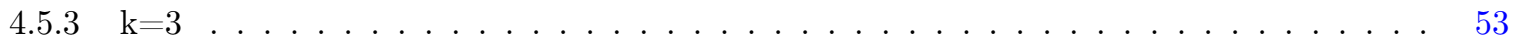

5 Processo de Contato com Aperiodicidade Temporal $\quad 57$

5.1 Grupo de Renormalização . . . . . . . . . . . . . . . . . . . . . . . . 58

5.1 .1 Adaptação do GR . . . . . . . . . . . . . . . . . . . . . . . . . 59

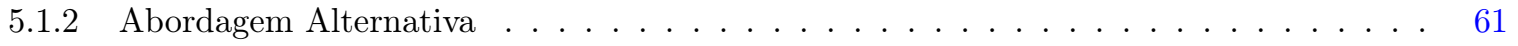

5.2 Simulações de Monte Carlo . . . . . . . . . . . . . . . . . . . . . . . . . . 62

$5.2 .1 \quad$ Algoritimos e Metodologia . . . . . . . . . . . . . . . . . . . . . 62

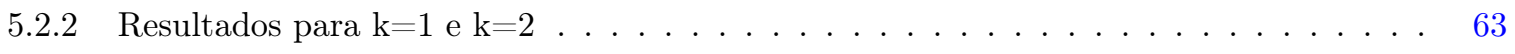

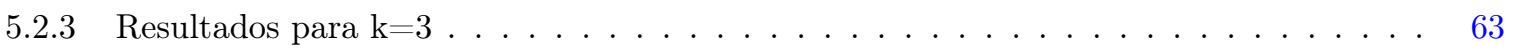

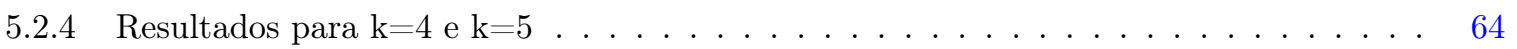

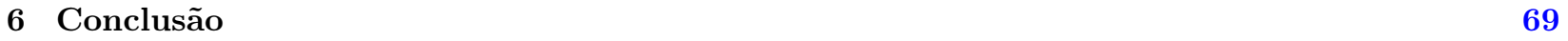

Apêndices

$\begin{array}{ll}\text { A Renormalização da equação logística para desordem determinística } & 73\end{array}$

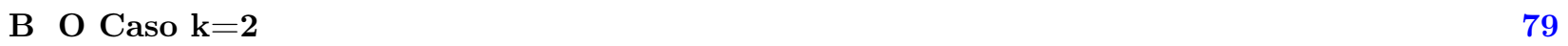

B.1 Adaptação do GR . . . . . . . . . . . . . . . . . . . . . . . . . 79 


\section{Capítulo 1}

\section{Introdução}

Cotidianamente observamos diversos sistemas físicos transitando entre diferentes fases, como um volume de água em uma chaleira que começa a evaporar indo da fase líquida para a fase gasosa. O estudo de transições de fase tem sido um tópico muito ativo em física, abrangendo desde a condensação de Bose-Eintein até a formação de supercondutores, e possui ramificações que se estendem até outras áreas do conhecimento, como biologia [1], química [2] e até mesmo sociologia (no processo de formação de opiniões [3], por exemplo).

Vários sistemas que podem apresentar transições de fase exibem efeitos exóticos e fascinantes no ponto crítico (onde ocorre a transição), como quebra espontânea de simetria, não analiticidades na energia livre, entre outros [4]. Porém, apesar do grande conhecimento acumulado, ainda há vários aspectos desconhecidos sobre diferentes tipos de transições de fase, que permanece um tópico intensamente estudado em diferentes áreas da física.

Um dos aspectos mais interessantes sobre sistemas com transições de fase é que podemos agrupar diferentes modelos (inclusive de outras áreas como biologia e economia) através de seu comportamento crítico em uma "classe de universalidade". Há um grande interesse em elencar os mecanismos fundamentais que caracterizam uma classe de universalidade e que regem todos os modelos nela agrupados, e ver como mudanças nesses mecanismos (ou até mesmo a introdução de novas dinâmicas) podem afetar o comportamento crítico de um sistema.

Para ilustrar a pluralidade de modelos que possuem transições de fase podemos tomar como um primeiro exemplo um tópico pouco usual para a física: a evolução de uma população biológica. Neste caso temos que o sistema pode transitar entre a sobrevivência e a extinção de sua população e separando essas fases existe um ponto crítico, onde as taxas de nascimento e morte dos indivíduos são tais que o sistema se encontra no limiar entre a sobrevivência e a morte da população. Em termos de mecânica estatística esse sistema possui uma fase com estados ativos, onde a população não se extingue e apenas flutua no tempo, e uma fase inativa, com um estado onde a população se extinguiu. Esse tipo de transição é chamado na literatura de transição de fase absorvente, onde há um ou mais estados dos quais o sistema não pode escapar (uma população extinta não pode voltar espontaneamente à vida). Modelos com transições de fase absorventes 
aparecem em áreas da física como propagação de rachaduras [5], turbulência [6], reações em superfícies [7], vórtices supercondutores [8], entre outras.

Outra faceta interessante que podemos explorar é a análise não só do comportamento crítico de um sistema mas também do que pode perturbá-lo e que tipos de pertubações são relevantes. No exemplo da população biológica é possível introduzir indivíduos imunes, locais mais férteis, infecções que dependem do tempo, entre outras mudanças. O efeito dessas novas dinâmicas no comportamento crítico pode ou não ser relevante: se colocarmos um indivíduo levemente mais resistente a uma doença em uma população imunodeficiente não iremos afetar fundamentalmente o comportamento do sistema como um todo, porém se todos os indivíduos se tornarem resistentes o sistema irá obviamente mudar.

Na natureza são comuns pertubações aleatórias sobre um sistema, como inomogeneidades ou temperaturas oscilantes, que tem se provado ingredientes relevantes que afetam o comportamento crítico em diferentes modelos, podendo levar até à criação de novas fases e comportamentos críticos incomuns de dinâmicas extremamente lentas. Em cadeias quânticas, por exemplo, temos que a aleatoriedade pode levar a fases de Griffiths [9] e paramagnetismo quântico aleatório [10]. Estruturas e dinâmicas aleatórias são um tópico interessante em si, porém podemos considerar dinâmicas ainda mais exóticas.

Com a descoberta experimental de cristais quase-periódicos [11] foram observadas estruturas extremamente incomuns [12] que exibem simetrias proibidas pela cristalografia tradicional. Estas estruturas são aperiódicas mas não aleatórias, pois podemos descrevê-las de maneira inteiramente determinística. Elas também possuem propriedades raras que podem levar a efeitos físicos igualmente incomuns. Aperiodicidade determinística pode chegar a afetar o comportamento de um sistema de maneira diferente à aperiodicidade puramente aleatória [13] e será o tópico específico desta dissertação, onde iremos explorar as consequências sobre o comportamento crítico de alguns sistemas frente a desordem temporal determinística.

Este texto está estruturado como segue. No capítulo 2 iremos discutir mais a fundo o conceito de aperiodicidade determinística, sua motivação histórica e suas propriedades, além de discutir como aperiodicidades podem afetar a estabilidade do ponto crítico. No capítulo 3 iremos introduzir os modelos que basearam nosso estudo e o efeito de desordem sobre eles. Nos capítulos 4 e 5 finalmente discutiremos os modelos com a aperiodicidade determinística temporal. Concluímos no capitulo 6. 


\section{Capítulo 2}

\section{Aperiodicidade Determinística e Universalidade}

Sequências aperiódicas compartilham muitas propriedades com séries aleatórias, porém diferenças fundamentais as separam. A inspiração para estudar aperiodicidade determinística em sistemas físicos remete à descoberta de cristais quase-periodicos [11], que introduzem simetrias proibidas pela cristalografia tradicional. Uma manifestação da aperiodicidade desses cristais surge no espectro de difração, onde são observados picos de Bragg em um número de direções que nenhuma estrutura regular em três dimensões poderia gerar, como representado na figura (2.1). Isto implica que a estrutura cristalina é regular (uma rede de Bravais) em uma dimensão maior do que 3! A projeção de uma estrutura como essa em um plano bidimensional pode gerar um padrão aperiódico determinístico e como exemplo citamos o famoso ladrilho de Penrose (figura 2.2a), que é a projeção de uma seção de um cristal hipercúbico em 5 dimensões [14].

Da mesma forma que obtemos o ladrilho de Penrose (que é aperiódico) através de um corte e uma projeção de um objeto periódico de dimensão superior, podemos então imaginar um análogo unidimensional de um quase cristal a partir do mesmo método. Se realizarmos um corte em uma rede quadrada (periódica) em um ângulo igual à razão áurea $\phi=(1+\sqrt{5}) / 2^{1}$ e projetarmos os pontos contidos no corte em sua parte inferior iremos obter uma sequência (unidimensional) de distâncias completamente aperiódica, onde apenas duas separações são possíveis (por construção). Uma ilustração desse método está exibida na figura (2.2b).

Se denotarmos as distâncias dessa cadeia como " $A$ " e " $B$ " teremos que a sequência de distâncias é a mesma se iteramos a regra de substituição

$$
\begin{aligned}
& A \rightarrow A B \\
& B \rightarrow A,
\end{aligned}
$$

que produz a chamada "palavra de Fibonacci", onde a cada iteração o número de letras segue a sequência de

\footnotetext{
${ }^{1} \mathrm{~A}$ espessura desse corte deve ser tal que as bordas do corte tangenciem os pontos de uma célula unitária.
} 


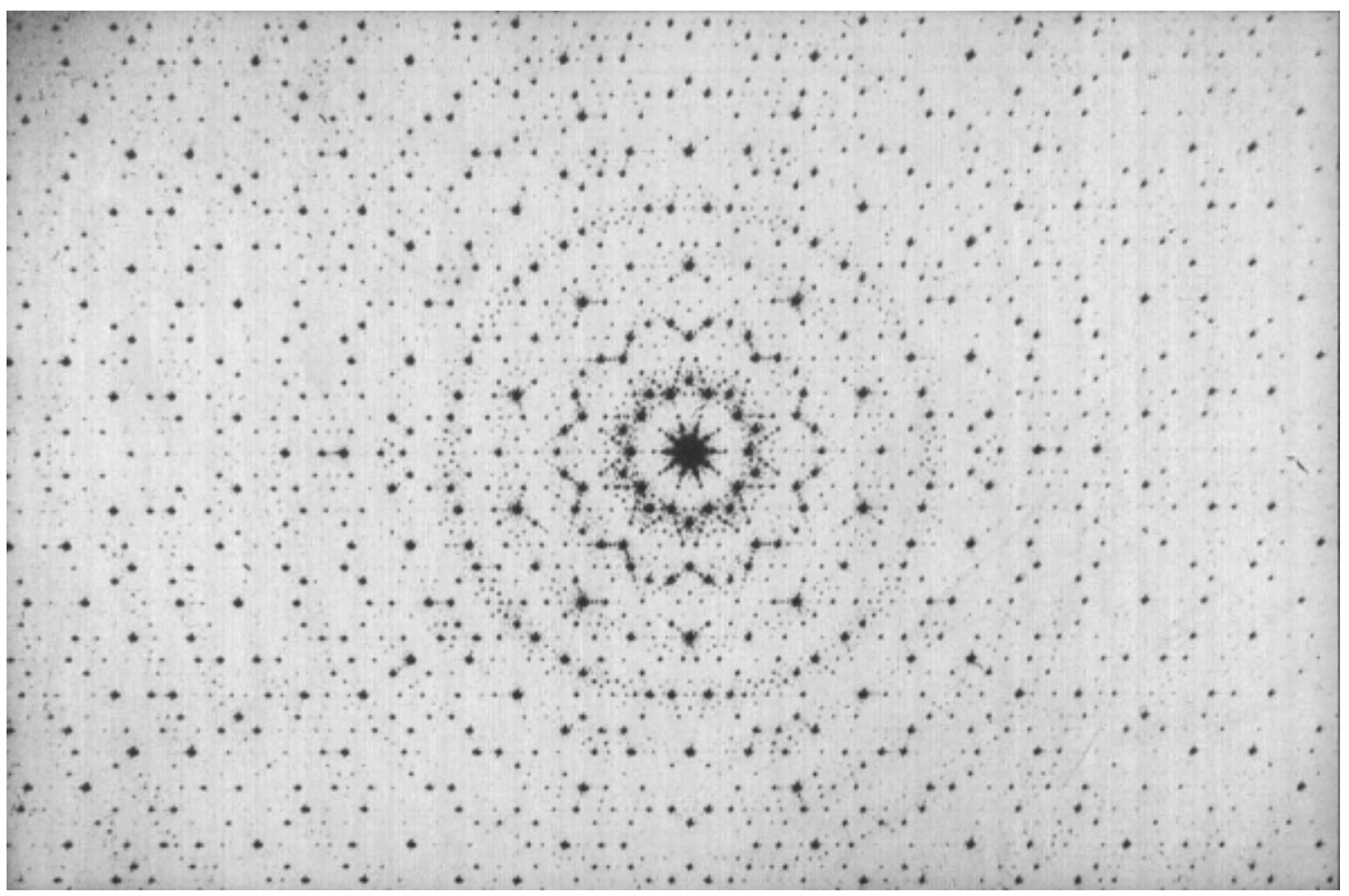

Figura 2.1: Simulação de um espectro de difração de um ladrilho de Penrose extraído da referência [15] (cores foram invertidas). Esse espectro exibe simetrias locais em 10 direções, o que seria impossível por redes regulares tridimensionais.

Fibonacci $\{1,1,2,3,5,8, \ldots\}$ :

$\begin{array}{ll}\text { B } & 1 \\ \text { A } & 1 \\ \text { AB } & 2 \\ \text { ABA } & 3 \\ \text { ABAAB } & 5 \\ \text { ABAABABA } & 8\end{array}$

Sequências como esta podem ser utilizadas para introduzir aperiodicidade determinística em um sistema. Outras sequências são possíveis definindo regras de substituição diferentes, como a sequência de RudinShapiro, que envolve quatro letras [16]. Estas sequências terão propriedades únicas, e cabe a nós decidir que tipos de propriedades queremos introduzir junto com a aperiodicidade. 


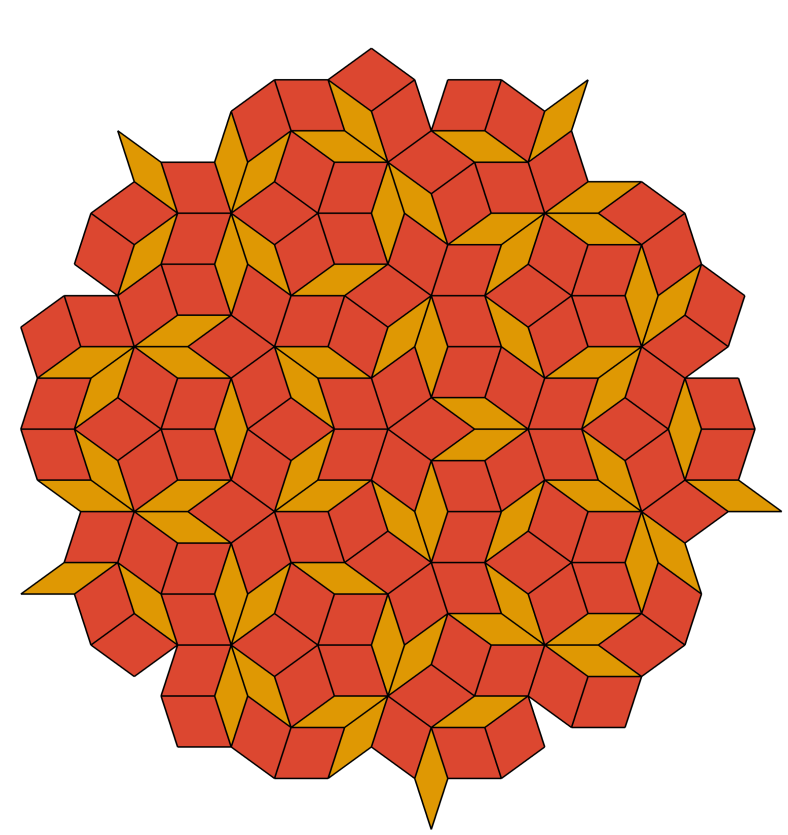

(a)

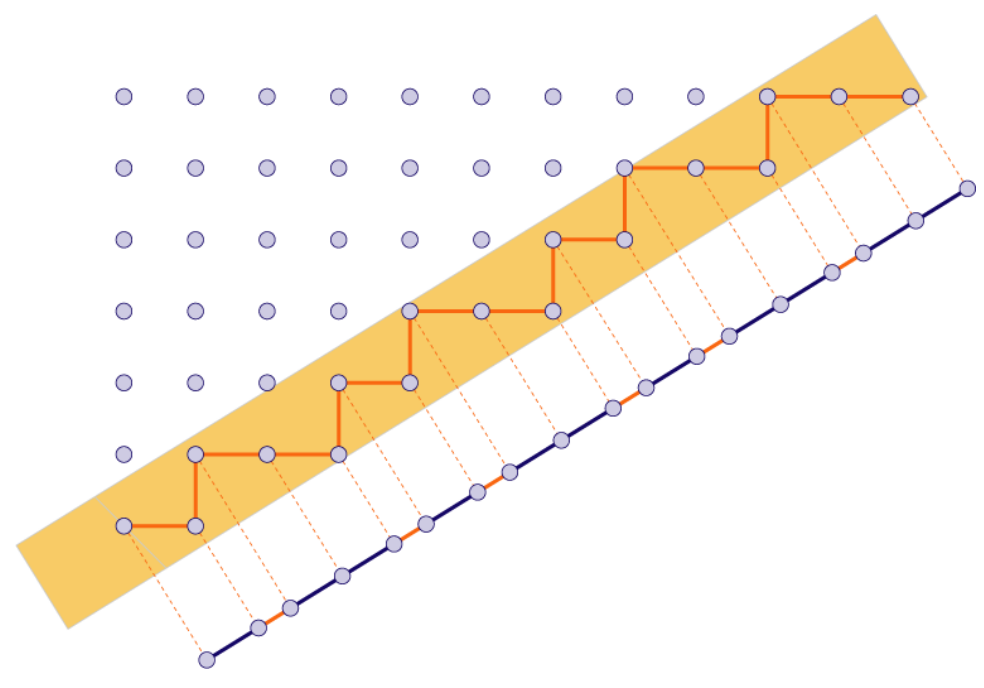

(b)

Figura 2.2: (2.2a) O ladrilho de Penrose construído com losangos. (2.2b) O método de corte-projeção para obter um análogo unidimensional de um cristal quase-periódico.

\subsection{Sequência Generalizada de Fibonacci}

Podemos gerar uma família de sequências aperiódicas com a seguinte regra de substituição [17]:

$$
\begin{aligned}
& A \rightarrow A B^{k} \\
& B \rightarrow A,
\end{aligned}
$$

onde $B^{k}$ representa uma sequência de $k$ letras $B$ e no caso $k=1$ recuperamos a sequência de Fibonacci. Iremos agora discutir algumas propriedades importantes dessa sequência. Denotando por $N_{a}(j)$ o número de letras $A$ após $j$ iterações da regra de substituição dada pela equação $(2.1), N_{b}(j)$ o número correspondente de letras $B$ e $N(j) \equiv N_{a}(j)+N_{b}(j)$ o tamanho total da sequência, podemos reescrever a regra de substituição de forma matricial:

$$
\left(\begin{array}{l}
N_{A}(j+1) \\
N_{B}(j+1)
\end{array}\right)=\left(\begin{array}{ll}
1 & 1 \\
k & 0
\end{array}\right)\left(\begin{array}{l}
N_{A}(j) \\
N_{B}(j)
\end{array}\right) \equiv \boldsymbol{M}_{k} \boldsymbol{N}_{j} .
$$

Os autovalores da matriz de substituição $\boldsymbol{M}_{k}$ são:

$$
\zeta_{ \pm}=\frac{1}{2}(1 \pm \sqrt{1+4 k})
$$

Podemos decompor $\boldsymbol{M}_{k}$ como $\boldsymbol{M}_{k}=\boldsymbol{V} \boldsymbol{D}_{k} \boldsymbol{V}^{-1}$, onde as colunas da matriz $\boldsymbol{V}$ são dadas pelos autovetores à direita de $\boldsymbol{M}_{k}$ e a matriz $\boldsymbol{D}$ é uma matriz diagonal composta pelos autovalores $\boldsymbol{D}_{k}=\operatorname{diag}\left\{\zeta_{-}, \zeta_{+}\right\}$. Isso 
nos permite escrever:

$$
\boldsymbol{N}_{j+1}=\boldsymbol{V} \boldsymbol{D}_{k}^{j} \boldsymbol{V}^{-1} \boldsymbol{N}_{j}
$$

que nos leva ao sistema de equações:

$$
\begin{aligned}
& N_{a}(j)=-\left(N_{b}(0)+\zeta_{-} N_{a}(0)\right) \zeta_{-}^{j}+\left(N_{b}(0)+\zeta_{+} N_{a}(0)\right) \zeta_{+}^{j}, \\
& N_{b}(j)=\left(\zeta_{+} N_{b}(0)-k N_{a}(0)\right) \zeta_{-}^{j}+\left(k N_{a}(0)-\zeta_{-} N_{b}(0)\right) \zeta_{+}^{j},
\end{aligned}
$$

que combinado com a equação (2.2) nos dá, no limite $j \rightarrow \infty$, as frequências de letras $A$ e $B$ na sequência infinita $x_{a, b}=\lim _{j \rightarrow \infty} N_{a, b}(j) / N(j)$ :

$$
\begin{array}{r}
\zeta_{+} x_{a}=x_{a}+x_{b}, \\
\zeta_{+} x_{b}=k x_{a},
\end{array}
$$

onde e $x_{a}+x_{b}=1$. Disso tiramos que $x_{a}=1 / \zeta_{+}$e $x_{b}=1-1 / \zeta_{+}$. Também temos que no limite de $j \rightarrow \infty$ o maior autovalor $\zeta_{+}$irá governar a forma assintótica do número total de letras $N(j)$ :

$$
N(j) \sim \zeta_{+}^{j},
$$

e a flutuação no número de letras $N_{a}(j)$ e $N_{b}(j)$ será governada pelo menor autovalor. Especificamente:

$$
\Delta N_{a}(j)=\left|N_{a}(j)-x_{a} N(j)\right| \sim\left|\zeta_{-}\right|^{j}
$$

para $j$ grande.

Dentro de cada sequência a flutuação de letras também não é homogênea, se definirmos o valor máximo da flutuação dentro de cada sequência como sendo:

$$
h_{j} \equiv \max _{n<N(j)}\left\{\left|N_{a}(n)-x_{a} n\right|\right\},
$$

onde $\Delta N_{a}(n)$ representa o número de letras $a$ até a posição $n$, podemos analisar a intensidade (máxima) das flutuações geométricas a cada passo de iteração $j$.

Temos ainda que se definirmos o expoente de flutuação geométrica $\omega$

$$
\omega \equiv \frac{\ln \left|\zeta_{-}\right|}{\ln \zeta_{+}}
$$

podemos escrever o crescimento das flutuações na sequência de Fibonacci como

$$
\Delta N_{a}(j) \sim N_{j}^{\omega}
$$

Isso nos diz que sequências aperiódicas com $\omega>0$ levam à flutuações que crescem sem limites à medida que o comprimento da sequência aumenta. Já se $\omega<0$ teremos flutuações que somem à medida que o 
comprimento cresce. Numericamente temos $\omega_{1}=-1, \omega_{2}=0, \omega_{3} \approx 0.3171$ e para $k \geq 4$ o expoente $\omega_{k}$ cresce monotonicamente até 1 . Para efeitos de comparação, uma sequência aleatória descorrelacionada de letras " $A$ " e " $B$ " tem $\omega=1 / 2$. Temos então que para $k=1,2$ as flutuações não devem aumentar (e tendem a 0 para $k=1$ ), já para $k \geq 3$ elas devem ficar cada vez mais intensas. Gráficos mostrando a evolução de $\Delta N_{a}(j)$ e $h_{j}$ estão representados, respectivamente, nas figuras (2.3a) e (2.3b) para diferentes valores de $k$.

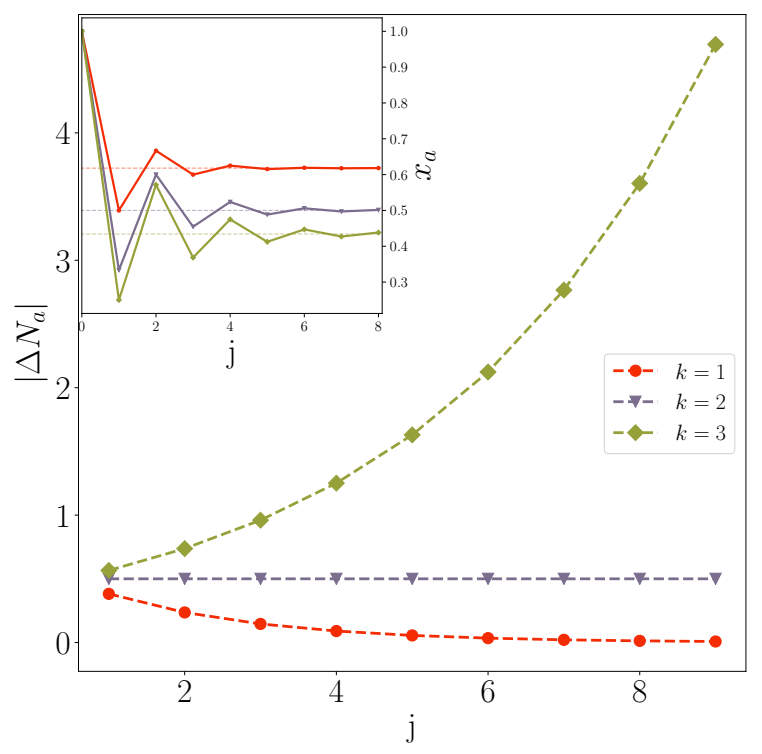

(a)

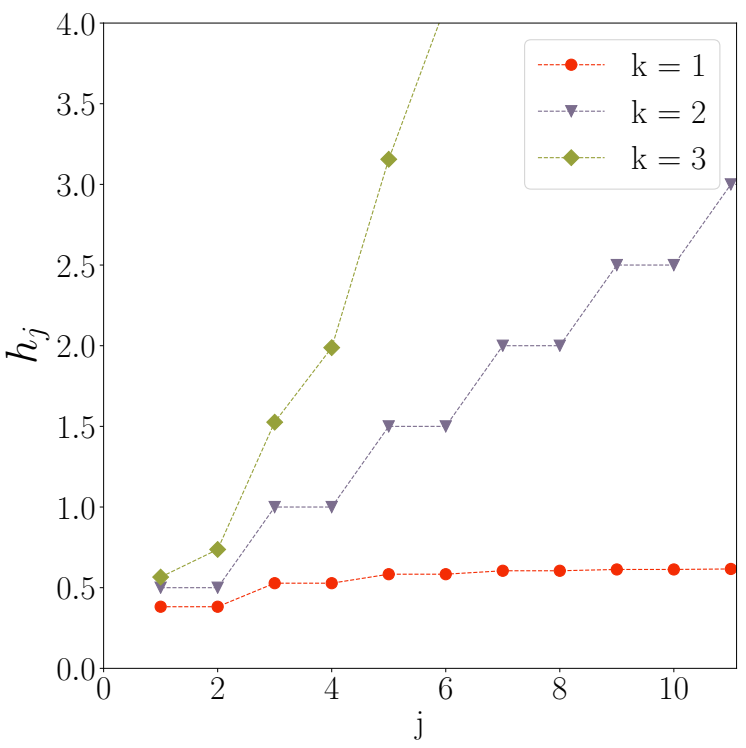

(b)

Figura 2.3: (2.3a) Flutuação no número de letras $A$ na sequência de Fibonacci após $j$ iterações da regra de substituição dada pela equação (2.1). Para $k=3$ temos que $\left|\zeta_{-}\right|>1$, logo as flutuações se tornam cada vez mais intensas. No inset está a evolução da fração $x_{a}$ de letras $A$, onde os pontilhados representam os valores que $x_{a}$ assume na sequência "infinita", quando $j \rightarrow \infty$. (2.3b) Valor máximo da flutuação de letras $A$ dentro da sequência após $j$ iterações. Por mais que para $k=2$ as flutuações não oscilem entre as iterações, elas se tornam cada vez mais intensas dentro de cada sequência.

Com isso somos capazes de produzir sequências aperiódicas com flutuações mais ou menos intensas do que a sequência puramente aleatória e que, por serem determinísticas, nos apresentam maneiras de as estudar exatamente.

\subsection{Universalidade e a Percolação Direcionada}

O comportamento de um sistema durante um transição de fase é bem característico, porém vários modelos que descrevem sistemas que aparentemente não guardam relação entre si (como formação de opiniões [3] e a formação de vórtices supercondutores em um imã [8]) podem compartilhar o mesmo comportamento crítico, o que nos permite agrupá-los em classes de universalidade. 
É recorrente que durante uma transição de fase, que pode ser descrita em termos de um parâmetro de ordem ${ }^{2}$, as grandezas do sistema (como magnetização e suscetibilidade para materiais magnéticos, por exemplo) sigam leis de potência definidas por certos expoentes, chamados de "expoentes críticos", que passam a definir com precisão uma classe de universalidade.

Modelos com transições de fase com um único estado absorvente geralmente $[18,19]$ estão agrupados na classe de universalidade da percolação direcionada (DP - Directed Percolation), que iremos discutir brevemente a seguir.

\subsubsection{Percolação Direcionada}

Considere o volume de água que botamos para esquentar em uma chaleira na introdução. Se derramarmos essa água em um filtro de café posto sobre uma mesa horizontal as moléculas de água irão se movimentar (percolar) entre os poros do papel livremente. Se esse filtro estiver inclinado a ação da gravidade irá fazer com que a percolação das partículas de água se dê majoritariamente em uma direção, uma percolação direcionada.

Formalmente a classe DP pode ser vista como uma variação da percolação isotrópica [20] e foi introduzida por Broadbent e Hammersley [21] para descrever a conectividade em uma rede aleatoriamente conectada. Um exemplo de percolação isotrópica seria um sistema definido em uma rede ocupada por partículas que podem ou não se mover entre os sítios vizinhos dependendo se há uma conexão entre eles. Percolação direcionada se dá quando a percolação pode acontecer somente entre sítios conectados e em uma única direção privilegiada. Um esquema dessas duas situações está representado na figura (2.4).

No exemplo da água no filtro de papel temos que se variarmos o nível de porosidade (conectividade) entre os sítios do papel ele pode se tornar impermeável ou permeável e entre esses regimes há um ponto crítico. Vale realçar que a transição de fase se dá puramente por razões geométricas da rede.

Existe uma dualidade interessante na interpretação no processo de percolação direcionada representado na figura (2.4b). Podemos interpretar essa dinâmica como a percolação de um líquido em um meio bidimensional ou como um modelo em uma dimensão espacial e outra temporal (em $1+1$ dimensões), onde a dinâmica só ocorre na dimensão espacial e a dimensão temporal representa a "história" do processo.

$\mathrm{Na}$ interpretação de $1+1$ dimensões temos em termos de dinâmica estatística que os sítios ativos estão sujeitos a uma dinâmica de reação-difusão e podem se tornar inativos (aniquilação), mudar de posição na rede (difusão), criar uma nova ocupação em um sítio vizinho (criação autocatalítica) ou combinar destrutivamente dois sítios ativos em um (coalescência), dependendo da conectividade entre os sítios. Aniquilação acontece quando todos os próximos sítios não estão conectados, criação quando há mais de uma conexão, difusão quando há uma conexão e coalescência quando várias ligações levam a um mesmo sítio. Dependendo da razão entre a criação e aniquilação o processo pode permanecer ativo ou alcançar um estado onde não há mais sítios ativos, do qual o sistema não pode mais escapar. Esse é o estado absorvente da percolação

\footnotetext{
${ }^{2}$ É dito parâmetro de ordem um parâmetro que vale zero em uma fase e é diferente de zero na outra (geralmente abaixo do ponto de transição).
} 


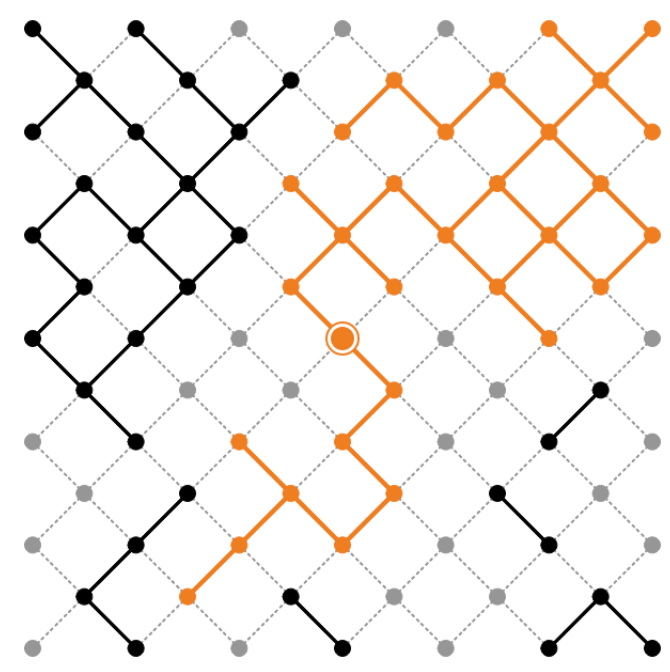

(a)

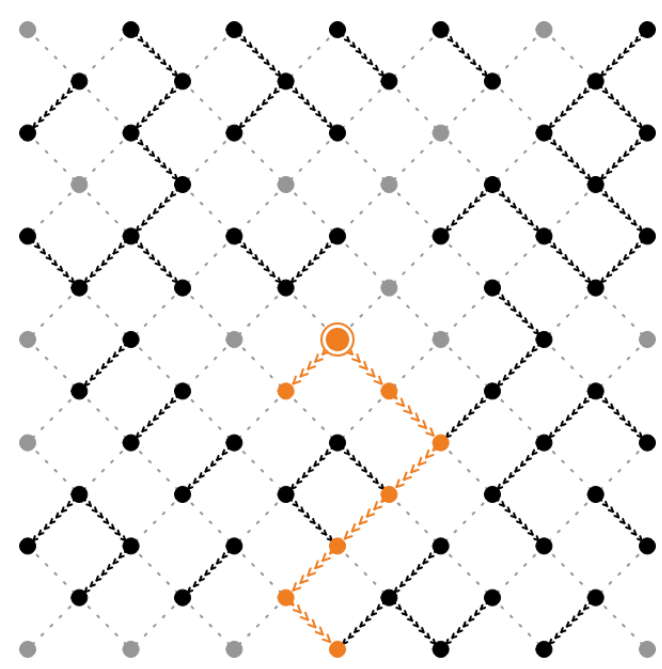

(b)

Figura 2.4: (2.4a) Representação de uma percolação isotrópica em uma rede regular em duas dimensões, onde linhas cheias representam conexões e tracejados a ausência das mesmas. Destacados em laranja estão todos os sítios diretamente conectados ao sítio central, que está destacado com um círculo. (2.4b) Uma rede bidimensional com percolação direcionada. O ponto circulado representa a origem da percolação e as setas indicam a direção da percolação. Em laranja estão os sítios conectados à origem e linhas tracejadas representam a ausência de ligação entre dois sítios.

direcionada.

Se considerarmos um rede regular onde uma partícula pode se deslocar de um sítio para outro com probabilidade $p$ e com uma direção preferencial, observamos a formação de aglomerados de sítios conectados na configuração inicial, que representa a trajetória máxima que uma partícula pode percorrer. A partir de um certo valor crítico $p_{c}$ o tamanho desses aglomerados deixa de ser finito ${ }^{3}$ e começa a poder assumir valores arbitrários (e o sistema entra na fase ativa). Nas redondezas do ponto crítico as grandezas do sistema começam a seguir leis de potência definidas por expoentes críticos. A densidade de sítios ativos serve como parâmetro de ordem e, no ponto crítico, segue uma lei de potência em termos do tempo $t$ :

$$
\rho \sim t^{-\delta} .
$$

$\mathrm{Na}$ fase ativa, porém nas proximidades do ponto crítico, temos que a densidade estacionária de sítios ativos segue

$$
\rho_{\text {est }} \sim\left(p-p_{c}\right)^{\beta},
$$

\footnotetext{
${ }^{3}$ Para a percolação direcionada o parâmetro de ordem é a probabilidade de podermos observar um aglomerado de sítios de tamanho arbitrariamente grande $P_{\infty}$, que deixa de ser 0 para valores de $p>p_{c}$.
} 
e além disso os comprimentos de correlação espacial $\xi$ e temporal $\xi_{t}$ também divergem como

$$
\begin{aligned}
& \xi \sim\left|p-p_{c}\right|^{-\nu_{\perp}}, \\
& \xi_{t} \sim\left|p-p_{c}\right|^{-\nu_{\|}} .
\end{aligned}
$$

A interpretação física dos comprimentos de correlação é a distância típica, espacial ou temporal, que precisamos percorrer para que dois sítios deixem de ter correlação entre si. Na figura (2.5) estão ilustradas as interpretações físicas de $\xi_{\perp}$ e $\xi_{\|}$nos diferentes regimes de um processo $(1+1)$ dimensional que pertence à DP. Na fase inativa (painéis $A$ e $B$ ) as distâncias de correlação podem ser relacionadas aos tamanhos, espacial e temporal, da rede ativa. Já para a fase ativa (painel $C$ ) a ocupação se propaga em um cone, cuja abertura depende da razão $\xi_{\perp} / \xi_{\|}$. Outra maneira de interpretar os tamanhos de correlação na fase ativa é observando as dimensões típicas de "ilhas" de sítios inativos (painel $D$ ) [22].
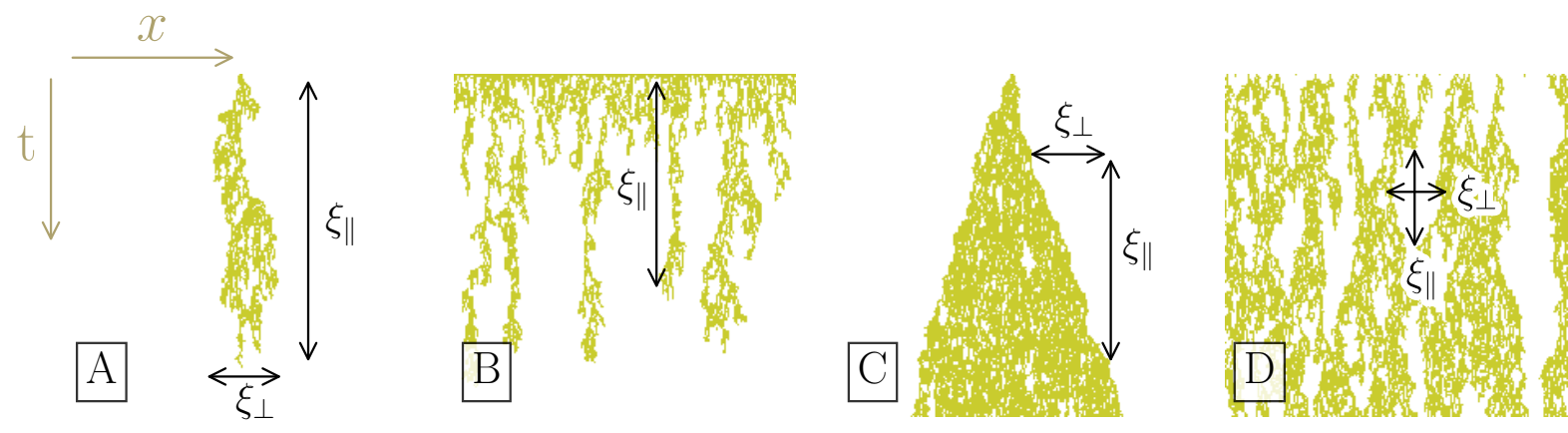

Figura 2.5: Interpretação física dos tamanhos de correlação $\xi_{\perp}$ e $\xi_{\|}$em um processo $(1+1)$ dimensional que pertence à classe da DP. Nos painéis $A$ e $B$ estão representadas as evoluções temporais de dois sistemas na fase inativa, um partindo de um único sítio ativo (painel $A$ ) e outro partindo de uma rede que estava completamente ativa inicialmente (painel $B$ ). Nos painéis $C$ e $D$ está a evolução temporal desses mesmos sistemas só que na fase ativa.

Os expoentes $\beta, \nu_{\perp}$ e $\nu_{\|}$descrevem univocamente a classe da DP e regem a dinâmica de todos os modelos aquilatados nessa classe de universalidade. A DP é particularmente interessante pois é extremamente robusta [23], no sentido que são necessárias mudanças drásticas na dinâmica do sistema para afetar seu comportamento crítico. Além disso foi conjecturado por Janssen e Grassberger $[18,19]$ que qualquer modelo irá pertencer a classe da DP se:

- as interações forem de curto alcance,

- o parâmetro de ordem for escalar,

- houver uma transição de fase de uma fase ativa para outra absorvente (com um único estado), 
- nenhuma outra simetria, aleatoriedade congelada ou lei de conservação existir.

Por mais que o modelo da DP pareça simples, ainda não há uma solução exata para ele. Porém podemos extrair os expoentes críticos numericamente. Apresentamos na tabela (2.1) os valores numéricos dos expoentes críticos mencionados até esse ponto.

\begin{tabular}{ccccc}
\hline Expoente & $d=1[24]$ & $d=2[25]$ & $d=3[26]$ & $d \geq 4$ \\
\hline$\beta$ & $0.276486(8)$ & $0.584(4)$ & $0.81(1)$ & 1 \\
$\nu_{\perp}$ & $1.096854(4)$ & $0.734(4)$ & $0.581(5)$ & $1 / 2$ \\
$\nu_{\|}$ & $1.733847(6)$ & $1.295(6)$ & $1.105(5)$ & 1 \\
$\delta$ & $0.15947(3)$ & $0.4505(10)$ & $0.730(4)$ & 1 \\
\hline
\end{tabular}

Tabela 2.1: Expoentes críticos para a percolação direcionada. Para $d \geq 4$ os valores são da aproximação de campo médio. Os valores para o expoente $\delta$ foram extraídos da referência [27].

\subsection{Estabilidade do ponto crítico}

Sistemas físicos reais geralmente têm heterogeneidades espaciais como impurezas, deformações e misturas que introduzem flutuações espaciais nos parâmetros do sistema. Uma pergunta relevante seria se essas impurezas afetam o comportamento crítico desse sistema, e em caso positivo determinar a intensidade que essas flutuações têm que ter para que elas se tornem decisivas para a dinâmica do sistema.

\subsubsection{Desordem espacial e o critério de Harris-Luck}

Harris [28] formulou um critério para determinar se a presença de aleatoriedade espacial seria relevante para o comportamento crítico de uma certa classe de sistemas. Considerando transições de fase térmicas em sistemas ferromagnéticos ele chegou a uma condição sobre o expoente crítico $\alpha$, relacionado ao calor específico como função da temperatura nas vizinhanças do ponto crítico, $C \sim\left(t-t_{c}\right)^{\alpha}$.

O critério de Harris nos diz que se no caso "limpo" (sem flutuações espaciais) o expoente $\alpha$ for negativo, então flutuações fracas serão irrelevantes para o comportamento crítico do sistema. Já para sistemas com $\alpha>0$ teremos que as perturbações serão relevantes e irão afetar o comportamento crítico, levando a expoentes críticos diferentes dos encontrados no caso limpo. Usando a lei de escala $\alpha=2-d \nu_{\perp}$, onde $d$ é a dimensão do sistema e $\nu_{\perp}$ é o expoente relacionado ao comprimento de correlação $\xi \sim\left(t-t_{c}\right)^{-\nu_{\perp}}$, podemos ainda escrever o critério de Harris como

$$
d \nu_{\perp}<2
$$


Alguns anos após, Luck [29] iria estender o critério de Harris para sistemas com flutuações geométricas arbitrárias (caracterizadas por expoentes de flutuação $\omega$ ). Ele estabeleceu um critério para determinar a relevância dessa flutuações em termos do expoente de flutuação $\omega$. Iremos sucintamente derivar o critério de Harris-Luck no caso unidimensional, pois alguns dos argumentos utilizados nos serão úteis: se definirmos a distância global à criticalidade como $\epsilon=\left(t-t_{c}\right) / t_{c}$ em função de $t$ que assume o valor crítico $t_{c}$, temos que a escala de comprimento natural é o comprimento de correlação $\xi$. Flutuações locais nos parâmetros, caracterizadas pelo expoente $\omega$, podem provocar uma variação local $\Delta \epsilon$ na distância à criticalidade que se comporta como

$$
\Delta \epsilon \sim \frac{\xi^{\omega}}{\xi}=\xi^{\omega-1}
$$

mas como $\xi \sim \epsilon^{-\nu_{\perp}}$, teremos

$$
\Delta \epsilon \sim|\epsilon|^{(1-\omega) \nu_{\perp}}
$$

Para que as perturbações geométricas não afetem o comportamento crítico temos que à medida que nos aproximamos do ponto crítico (onde $\epsilon \rightarrow 0$ e $\xi \rightarrow \infty$ ) a condição $\Delta \epsilon \ll|\epsilon|$ seja satisfeita, o que nos leva diretamente ao chamado critério de Harris-Luck:

$$
\omega<1-\frac{1}{\nu_{\perp}},
$$

que nos diz que flutuações com $\omega$ maiores do que um valor crítico $\omega_{c}=1-1 /\left(\nu_{\perp}\right)$ irão ser relevantes para a transição de fase do sistema. É importante frisar que quando $\omega=\omega_{c}$ o critério de Harris-Luck nada diz sobre a estabilidade do ponto crítico.

Porém, todos os critérios que discutimos são para desordens de natureza espacial e se torna necessário discutir o que pode ser feito quanto a desordem temporal.

\subsubsection{Desordem temporal e a generalização do critério de Harris}

Além da contribuição de Luck houve várias outras generalizações do critério de Harris em diferentes direções. Kinzel [30] mostrou que desordens temporais (sem correlações) podem desestabilizar a criticalidade de um sistema se o expoente crítico relacionado ao tempo de correlação $\xi_{t} \sim \epsilon^{-\nu_{\|}}$violar a condição

$$
z \nu_{\perp}>2
$$

onde vale a relação $\nu_{\|}=z \nu_{\perp}$.

Estamos agora em posição de tentar estabelecer um análogo do critério de Harris-Luck para desordens temporais de natureza arbitrária, seguindo argumentos muito similares aos apresentados para deduzir o critério dado pela inequação (2.15). Nas redondezas do ponto crítico temos que o intervalo natural de tempo é o tempo de correlação $\xi_{t} \sim|\epsilon|^{-\nu_{\|}}$e que desordens temporais irão afetar o sistema por intervalos de tempo de duração $\xi_{t}^{\omega}$. Disso tiramos que a variação local da distância à criticalidade $\delta \epsilon$ pode ser escrita como:

$$
\delta \epsilon \sim \frac{\xi_{t}^{\omega}}{\xi_{t}} \sim|\epsilon|^{\nu_{\|}(1-\omega)} .
$$


Para que as flutuações temporais se tornem irrelevantes à medida que nos aproximamos do ponto crítico, teremos que satisfazer $\delta \epsilon \ll|\epsilon|$, que nos leva imediatamente à condição

$$
\omega<1-\frac{1}{\nu_{\|}}
$$

que servirá de critério para determinarmos se aperiodicidades temporais terão efeito sobre o comportamento crítico de um determinado modelo.

Para estender nossa discussão para englobar tanto perturbações espaciais como temporais podemos lançar mão do critério estabelecido por Vojta e Dickman [31], que apresentaram uma generalização do critério de Harris para sistemas que apresentam tanto desordem temporal quanto espacial. Não iremos efetivamente utilizar esse resultado, porém ele fornece uma visão ampla sobre o assunto e pode ser derivado como se segue. Dessa vez iremos definir a distância local à criticalidade $\epsilon$ em termos da distância global à criticalidade $\epsilon_{0} \mathrm{e}$ de flutuações locais $\eta(x, t)$, dadas por uma função aleatória que depende tanto do tempo como da posição:

$$
\epsilon \rightarrow \epsilon_{0}+\eta(x, t)
$$

Como se trata de flutuações podemos considerar sem perda de generalidade que o ruido $\eta(x, t)$ tem média (sobre a desordem) nula

$$
\langle\eta(x, t)\rangle=0,
$$

e caso se ela não fosse nula poderíamos absorver essa média em $\epsilon_{0}$. Também iremos adotar que a função de correlação

$$
G\left(x-x^{\prime}, t-t^{\prime}\right) \equiv\left\langle\eta(x, t) \eta\left(x^{\prime}, t^{\prime}\right)\right\rangle
$$

é invariante por translação.

A ideia para determinar se as flutuações são relevantes é comparar se localmente $\epsilon \ll \epsilon_{0}$. Perto do pronto crítico a variação média da distância à criticalidade local se toma em um volume $V_{\xi}$ de tamanho $\xi^{d}$ e por um tempo $\xi_{t}$. Com isso a média das flutuações será dada por:

$$
\langle\eta(x, t)\rangle=\frac{1}{\xi^{d} \xi_{t}} \int_{V_{\xi}} \mathrm{d}^{d} x \mathrm{~d} t \eta(x, t) .
$$

Com isso podemos escrever a variância de $\eta$ como

$$
\sigma_{\eta}^{2}\left(\xi, \xi_{t}\right) \equiv\left\langle\eta(x, t)^{2}\right\rangle=\left(\frac{1}{\xi^{d} \xi_{t}}\right)^{2} \int_{V_{\xi}} \mathrm{d}^{d} x \mathrm{~d}^{d} x^{\prime} \mathrm{d} t \mathrm{~d} t^{\prime} G\left(x-x^{\prime}, t-t^{\prime}\right) .
$$

Usando a invariância translacional da função de correlação temos que $\sigma_{\eta}^{2}$ pode ser aproximada como:

$$
\sigma_{\eta}^{2}\left(\xi, \xi_{t}\right) \approx \frac{1}{\xi^{d} \xi_{t}} \int_{-\xi / 2}^{\xi / 2} \mathrm{~d}^{d} x \int_{\xi_{t} / 2}^{\xi_{t} / 2} G(x, t) \mathrm{d} t
$$

Agora comparamos $\sigma_{\eta}$ com a distância global à criticalidade $\epsilon_{0} \sim \xi^{-1 / \nu_{\perp}}$. Se à medida que nos aproximarmos do ponto crítico (i.e. $\epsilon_{0} \rightarrow 0$ ) tivermos que $\sigma_{\eta} / \epsilon_{0} \rightarrow 0$ então a desordem se torna irrelevante. 
Em contraste, se $\epsilon_{0} \rightarrow 0$ mas ainda assim $\sigma_{\eta} / \epsilon_{0} \rightarrow \infty$, a desordem irá governar o comportamento crítico. Temos então que o critério para a estabilidade do ponto crítico frente a desordem será dada por (usando $\left.\left(\sigma_{\eta} / \epsilon_{0}\right)^{2} \rightarrow 0\right)$

$$
\xi^{2 / \nu_{\perp}-d} \xi_{t}^{-1} \int_{V_{\xi}} \mathrm{d}^{d} x \mathrm{~d} t G(x, t) \rightarrow 0,
$$

quando $\epsilon_{0} \rightarrow 0$ (ou $\xi, \xi_{t} \rightarrow \infty$ ). Alguns resultados importantes seguem. Se a desordem for somente espacial e for descorrelacionada (i.e. $G \sim \delta(x)$ ) teremos que o critério dado pela equação $(2.22)$ se torna, à medida que $\xi \rightarrow \infty$ :

$$
\xi^{2 / \nu_{\perp}-d} \rightarrow 0
$$

logo a desordem sera irrelevante se $d \nu_{\perp}>2$, recuperando o critério de Harris! Se a desordem for temporal e descorrelacionada, teremos que $\sigma^{2} \sim \xi_{t}^{-1} \sim \xi^{-z}$. A condição em (2.22) nos diz que a criticalidade será estável se:

$$
z \nu_{\perp}>2
$$

recuperando o critério de Kinzel.

Critérios como esses nos permitem fazer previsões acerca da relevância de perturbações feitas sobre um sistema, e serão relevantes para discutirmos as diferenças entre os tipos de desordem que iremos estudar nos próximos capítulos. 


\section{Capítulo 3}

\section{Modelos}

Pretendemos estudar o efeito da aperiodicidade determinística em diferentes modelos que iremos introduzir nessa seção. Também discutiremos alguns tipos de desordens, tanto aleatórias como determinísticas, e suas consequências sobre o comportamento crítico dos modelos aqui tratados.

\subsection{O processo de contato}

Proposto por T. E. Harris [32] (não confundir com A. B. Harris, que formulou o critério de Harris) o processo de contato (CP - Contact Process) é talvez o modelo mais simples que até mesmo em uma dimensão apresenta uma transição de fase contínua ${ }^{1}$. Ele é definido em uma rede de partículas interagentes, onde cada sítio pode estar ocupado ou vazio. A dinâmica envolve apenas duas possibilidades: Um sítio ocupado pode criar uma nova ocupação em seus sítios vizinhos, o que acontece a uma taxa $\lambda$, ou pode ficar desocupado espontâneamente, que ocorre com uma taxa $\mu$. Esse processo pode ser visto também como um modelo para a propagação de epidemias, onde um indivíduo (sítio) pode estar saudável (desocupado), porém susceptível a doença, ou infectado (ocupado) podendo transmitir a doença para seus vizinhos imediatos ou se curar (porém não se tornando imune a uma reinfecção).

Permitindo que o sistema evolua, ele pode atingir um estado onde não há mais indivíduos infectados, e a epidemia cessa. Esse estado é dito absorvente ou inativo. Outra possibilidade é o sistema evoluir para um estado onde o número (médio) de infectados permanece constante, a doença não se extingue e o estado é dito ativo. Entre a fase ativa e a fase absorvente (que só tem um estado) há uma transição em um certo ponto crítico. Uma imagem representando o regime típico do sistema partindo de uma rede com uma densidade inicial de infectados $\rho_{0}$ acima, abaixo e em cima do ponto crítico está representada na figura (3.1).

Com as regras estabelecidas, podemos construir um algoritmo para estudar o comportamento do sistema. Iremos apresentar um algoritmo simples e eficiente, porém outros métodos também são viáveis [33]. Partindo de uma rede de coordenação $z$ com $N$ sítios e uma distribuição inicial de indivíduos infectados, iteramos:

\footnotetext{
${ }^{1}$ Uma transição é dita contínua quando o parâmetro de ordem não apresenta descontinuidades.
} 

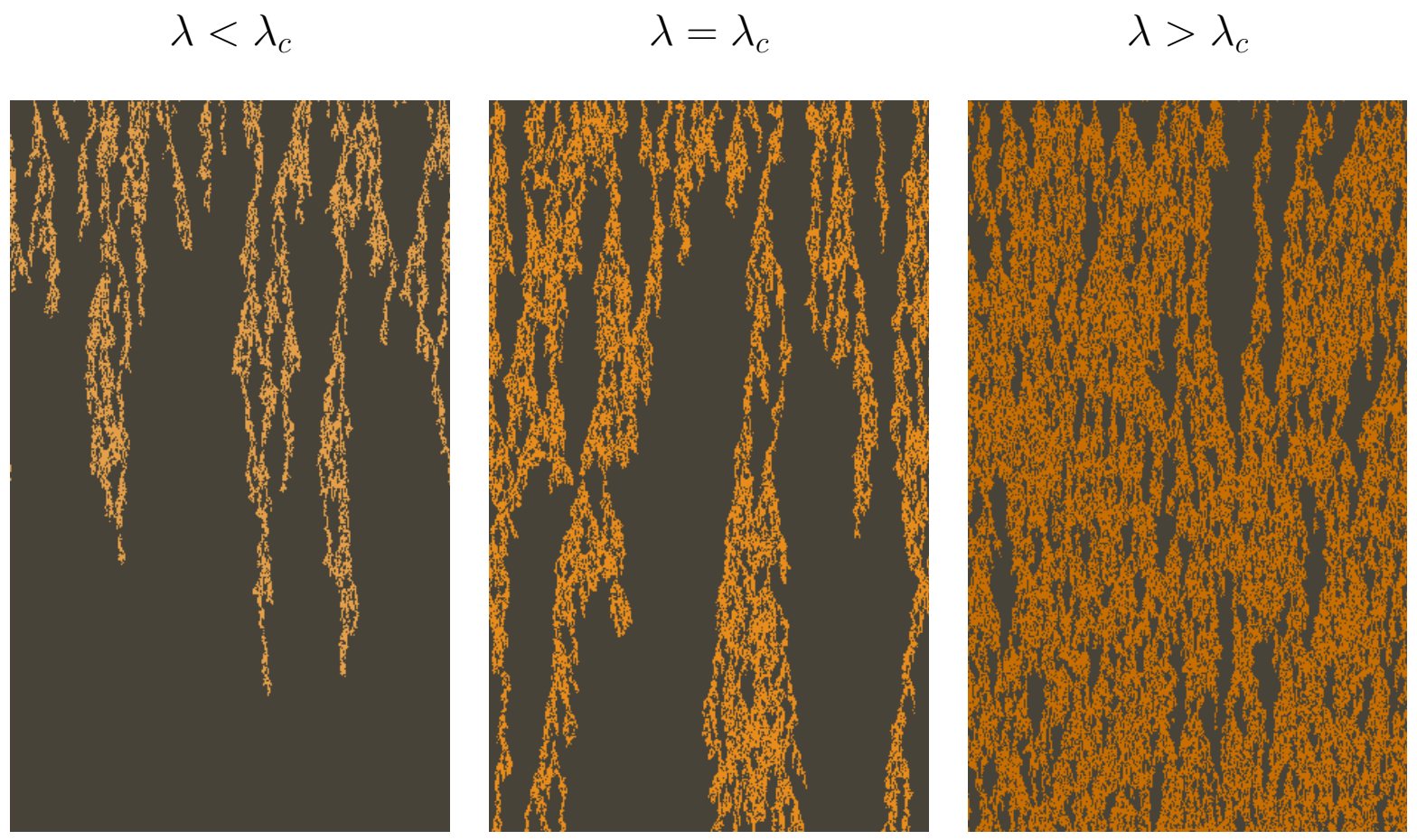

Figura 3.1: Evolução temporal de uma rede sob um processo de contato onde ocupações são representadas em laranja. Cada linha representa um instante de tempo, que evolui de cima para baixo. Em todos os casos o sistema parte de uma rede com uma densidade inicial de infectados $\rho_{0}=0.1$.

1. Selecionamos de forma aleatória um sítio infectado da rede.

2. Sorteamos um evento entre:

- Infecção de um dos vizinhos, cada um com probabilidade $(\lambda / z) /(\mu+\lambda)$, se ele não estiver infectado. Observe que indivíduos com mais vizinhos infectados têm mais probabilidade de se infectar (se há mais vizinhos infectados, há mais chance de sortear pelo menos um deles).

- Cura com probabilidade $\mu /(\mu+\lambda)$.

3. Incrementamos o tempo em $1 / N_{i}$, onde $N_{i}$ é o numero de indivíduos infectados na rede. Isso captura o comportamento de que quando há muitos indivíduos ativos na rede, vários eventos estariam acontecendo ao mesmo tempo e, então, um único evento tem efeito menor no passar do tempo.

4. Voltar para o passo 1, se ainda houver sítios ativos. 


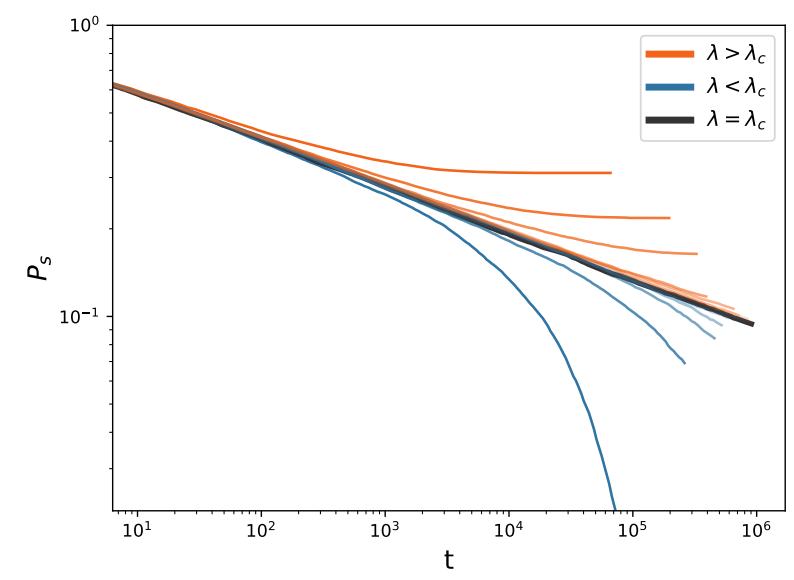

(a)

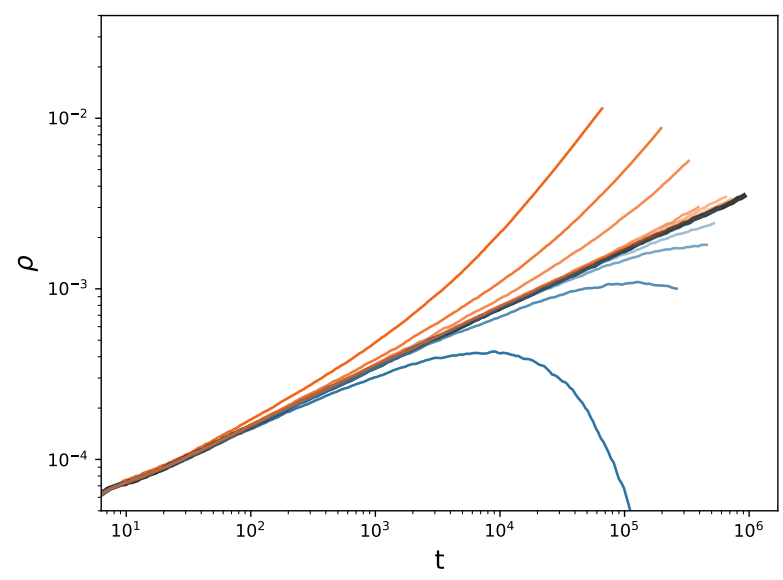

(b)

Figura 3.2: (3.2a) Evolução temporal da probabilidade de sobrevivência $P_{s}$ da rede ativa para o processo de contato limpo em uma dede unidimensional, parindo de um único sítio ativo. Cada curva representa a média sobre $10^{6}$ simulações com $10^{5}$ sítios. Curvas em laranja têm $\lambda>\lambda_{c} \approx 3.29$ e em azul têm $\lambda<\lambda_{c}$. $\mathrm{O}$ parâmetro $\lambda$ varia não linearmente de 3.4 na curva superior até 3.2 na curva inferior, passando pelo valor crítico (curva em preto). (3.2b) Evolução da densidade de sítios ativos $\rho$.

Com isso podemos simular, em tamanho finito ${ }^{2}$, o processo de contato e estudar seu comportamento. Reproduzimos alguns resultados característicos como a evolução temporal da probabilidade de sobrevivência da doença na população (probabilidade do sistema não evoluir para o estado absorvente) e a densidade de sítios ativos (representadas, respectivamente, nas figuras (3.2a) e (3.2b)). Podemos extrair também os expoentes críticos $\delta\left(\rho \sim t^{-\delta}\right), \nu_{\perp}\left(\xi \sim \epsilon^{-\nu_{\perp}}\right)$ e $\beta\left(\rho_{\text {est }} \sim \epsilon^{\beta}\right)$. Esses expoentes são os mesmos da classe da percolação direcionada, já que o CP pertence a essa classe de universalidade.

Por mais que o CP pareça ser um sistema simples, não há uma solução exata para ele. Para explicar esse fato precisamos antes discutir alguns aspectos teóricos do CP. Como qualquer processo Markoviano, o processo de contato é governado por uma equação mestra. Escrevemos a configuração do sistema como:

$$
\eta=\left(\eta_{1}, \eta_{2}, \eta_{3}, \ldots, \eta_{n}\right),
$$

onde a variável (estocástica) $\eta_{j}=0,1$ denota se um sítio está ocupado ou não. Definimos ainda a taxa de transição entre dois estados $\eta$ e $\eta^{\prime}$ que se diferem apenas pela ocupação de um único sítio como sendo:

$$
W\left(\eta, \eta^{\prime}\right)=\sum_{i} \delta\left(\eta_{1}^{\prime}, \eta_{1}\right) \delta\left(\eta_{2}^{\prime}, \eta_{2}\right) \ldots \delta\left(\eta_{i}^{\prime}, 1-\eta_{i}\right) \ldots \delta\left(\eta_{N}^{\prime}, \eta_{N}\right) \omega_{i}(\eta)
$$

onde o fator $w_{i}(\eta)$ pode ser interpretado como a taxa com que o $i$-ésimo sítio muda de ocupação. Introduzindo a notação $\eta^{i}$ para uma configuração que se obtém mudando a ocupação do $i$-ésimo sítio de uma configuração

\footnotetext{
${ }^{2} \mathrm{O}$ efeito do tamanho finito pode ser estudado utilizando o método de finite size scaling para extrapolar a análise para tamanhos arbitrários.
} 
$\eta$, podemos escrever a equação mestra desse sistema como:

$$
\frac{\mathrm{d}}{\mathrm{d} t} P(\eta, t)=\sum_{i}\left[w_{i}\left(\eta^{i}\right) P\left(\eta^{i}, t\right)-w_{i}(\eta) P(\eta, t)\right] .
$$

A evolução da média de uma função de estado $f(\eta)$, definida como

$$
\langle f(\eta)\rangle=\sum_{\eta} f(\eta) P(\eta, t)
$$

pode ser encontrada multiplicando os membros da equação (3.1) por $f(\eta)$ e somando sobre os estados $\eta$, o que resulta em:

$$
\frac{\mathrm{d}}{\mathrm{d} t}\langle f(\eta)\rangle=\sum_{\eta}\left\langle\left[f\left(\eta^{i}\right)-f(\eta)\right] \omega_{i}(\eta)\right\rangle
$$

Com isso podemos encontrar a evolução para a média da variável $\left\langle\eta_{i}\right\rangle$ assumindo $f(\eta)=\eta_{i}$ e $f\left(\eta^{i}\right)=1-\eta_{i}$ na equação acima. Isso nos dá imediatamente

$$
\frac{\mathrm{d}}{\mathrm{d} t}\left\langle\eta_{i}\right\rangle=\sum_{i}^{n}\left\langle\left(\left[\left(1-\eta_{i}\right)-\eta_{i}\right] w_{i}(\eta)\right\rangle=\left\langle\left(1-2 \eta_{i}\right) w_{i}(\eta)\right\rangle\right.
$$

Considerando as regras descritas anteriormente, temos que a taxa de transição $w_{i}(\eta)$ de mudança do estado do sítio $i$, de $\eta_{i}$ para $1-\eta_{i}$ pode ser escrita como [34]:

$$
w_{i}(\eta)=\frac{\lambda}{z}\left(1-\eta_{i}\right) \sum_{\delta} \eta_{i+\delta}+\mu \eta_{i}
$$

onde a soma se estende sobre os $z$ primeiros vizinhos do sítio $i$. O primeiro termo dessa soma diz respeito à infecção e o segundo ao processo de cura. Juntando as equações (3.3) e (3.4) à equação mestra (3.2) temos

$$
\frac{\mathrm{d}}{\mathrm{d} t}\left\langle\eta_{i}\right\rangle=\frac{\lambda}{z} \sum_{\delta}\left\langle\left(1-\eta_{i}\right) \eta_{i+\delta}\right\rangle-\mu\left\langle\eta_{i}\right\rangle,
$$

que é um resultado importante pois nos diz que $\left\langle\eta_{i}\right\rangle$ depende do sítio $i$ mas também da correlação entre dois vizinhos, assim como a correlação entre dois vizinhos vai depender da correlação de três vizinhos e assim em diante, nos dando uma hierarquia de equações que torna a análise teórica exata inviável por meios convencionais. Métodos aproximativos podem ser usados para truncar a soma, como feito pelas referências [35] e [36], e então estudar o comportamento crítico do sistema.

\subsubsection{Aproximação de campo médio e a equação logística}

Supondo uma solução homogênea e isotrópica podemos escrever que $\left\langle\eta_{i}\right\rangle=\rho$ (i.e. densidade homogênea de infectados) e $\left\langle\eta_{i} \eta_{i+\delta}\right\rangle=\phi$, que independente da posição $i$ e dos sítios vizinhos. Aliando essa discussão à equação (3.5) teremos que a evolução temporal de $\rho$ será dada por:

$$
\frac{\mathrm{d}}{\mathrm{d} t} \rho=\lambda(\rho-\phi)-\mu \rho
$$


A aproximação de campo médio simples consiste em argumentar que um sítio é descorrelacionado de seus vizinhos,

$$
\phi=\left\langle\eta_{i} \eta_{i+\delta}\right\rangle=\left\langle\eta_{i}\right\rangle\left\langle\eta_{i+\delta}\right\rangle=\rho^{2} .
$$

Com isso a equação (3.6) toma a forma

$$
\frac{\mathrm{d}}{\mathrm{d} t} \rho=(\lambda-\mu) \rho-\lambda \rho^{2}
$$

que é conhecida como a equação logística. A solução de (3.7) é dada através de

$$
\rho^{-1}=\rho_{0}^{-1} e^{(\mu-\lambda) t}+\frac{\lambda}{\mu-\lambda}\left(e^{(\mu-\lambda) t}-1\right)
$$

onde $\rho_{0}$ é a densidade de indivíduos no tempo $t=0$. Vemos que se $\lambda<\mu$ a densidade $\rho$ decai exponencialmente a 0 , logo estamos na fase absorvente. Por outro lado, se $\lambda>\mu$ teremos que à medida que $t \rightarrow \infty$ a densidade $\rho$ alcança um valor estacionário $\lambda /(\lambda-\mu)$, logo escala como $\rho_{\text {est }} \sim(\lambda-\mu)^{-1}$ na fase ativa, com expoente $\beta=1$. Temos também que o ponto $\lambda_{c}=\mu$ separa as fases ativa e absorvente, sendo então o ponto crítico. Nesse caso observamos que a equação logística toma a forma

$$
\frac{\mathrm{d}}{\mathrm{d} t} \rho=-\lambda_{c} \rho^{2}
$$

cuja solução é $\rho=(\lambda t+c)^{-1} \sim t^{-1}$, logo a densidade decai como uma lei de potência com expoente $\delta=1$. A figura (3.3) representa a evolução temporal de $\rho$ nesses três casos.

Os valores dos expoentes críticos são condizentes com os valores de campo médio da classe da percolação direcionada, o que não é surpreendente pois a equação logística é a resolução de campo médio do processo de contato, que pertence à classe DP.

A motivação para estudar a equação logística em física surge da aproximação de campo médio do CP, mas ela também aparece em outros contextos, como na descrição de populações biológicas, infraestrutura (distribuição de ferrovias se difundem logisticamente [37]) e economia [38], e servirá de ponto de partida para o estudo do efeito de aperiodicidades determinísticas temporais.

\subsection{Desordem}

Podemos agora analisar os efeitos da desordem no comportamento crítico dos modelos discutidos até aqui. Essa desordem pode ser de natureza tanto espacial como temporal e feita de maneira puramente aleatória ou somente aperiódica, porém deterministicamente. Iremos tratar brevemente de cada caso e discutir um pouco mais a fundo a aperiodicidade determinística espacial pois ela servirá de base para o estudo de aperiodicidade determinística temporal. Para um discussão mais aprofundada e rica sobre esse assunto recomendamos a referência [22]. 


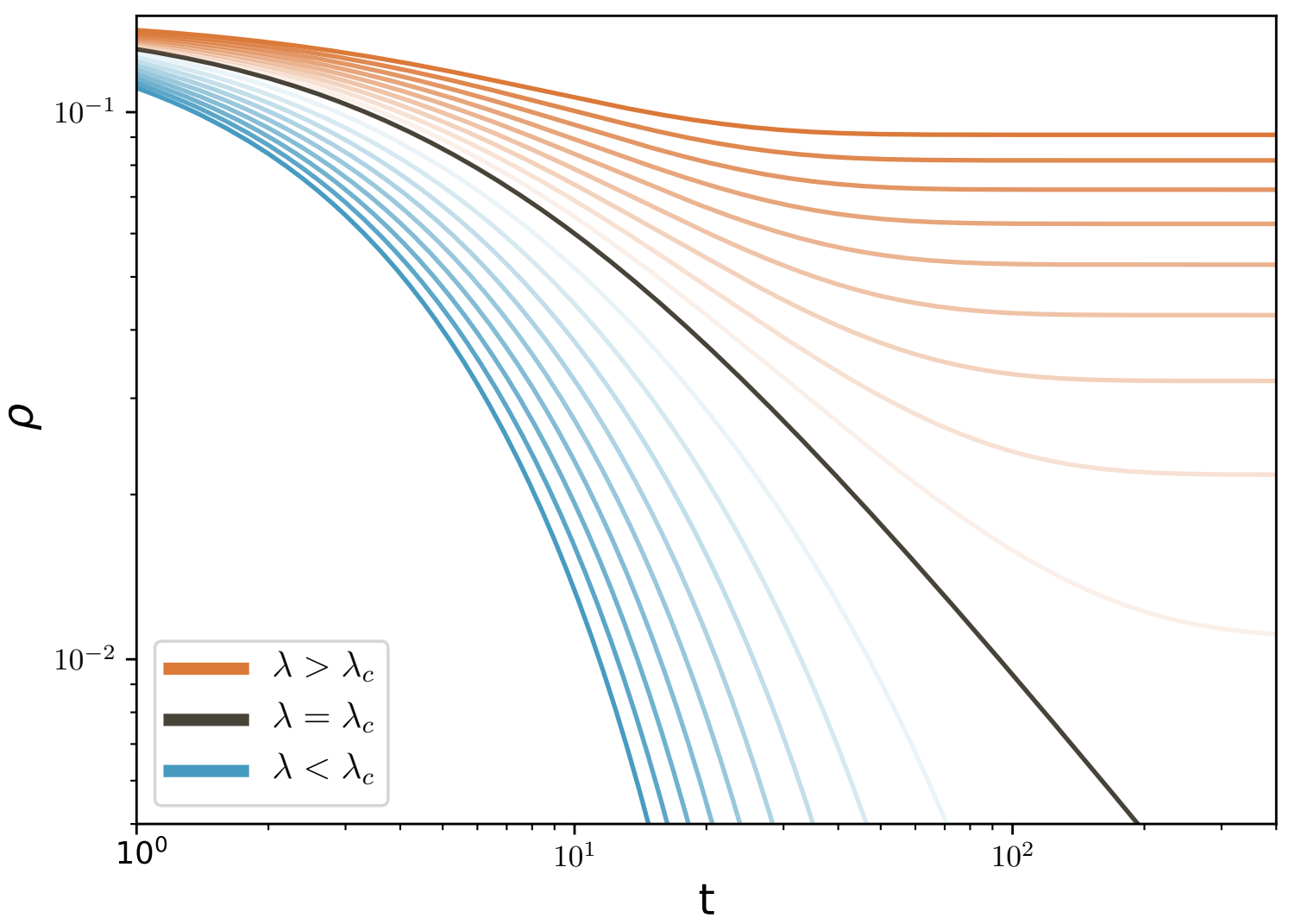

Figura 3.3: Evolução temporal da densidade $\rho$ partindo de uma densidade inicial $\rho_{0}=1$. Curvas acima do ponto crítico estão em laranja, curvas abaixo em azul e em preto está a curva crítica, onde $\lambda=\mu$.

\subsubsection{Desordem Espacial}

A motivação para estudar heterogeneidades espaciais surge do fato de que elas são comuns em sistemas físicos reais, podendo aparecer como impurezas ou rachaduras, e têm sido extensivamente estudadas [39]. Para modelos que exibem transições de fase com estado absorvente na classe DP o critério de Harris,

$$
d \nu_{\perp}>2
$$

prevê que desordens aleatórias espaciais fracas destroem a universalidade da DP para as dimensões "físicas" $d=1,2$ e 3 já que para todos esses casos o critério é violado. De fato, simulações numéricas feitas para modelos pertencentes à classe DP por Noest [40] e Moreira e Dickman [41] indicam que a introdução de desordem quenched (termo "emprestado" da metalurgia para desordem fixada na rede) leva a expoentes críticos não universais mesmo se a desordem for fraca. 


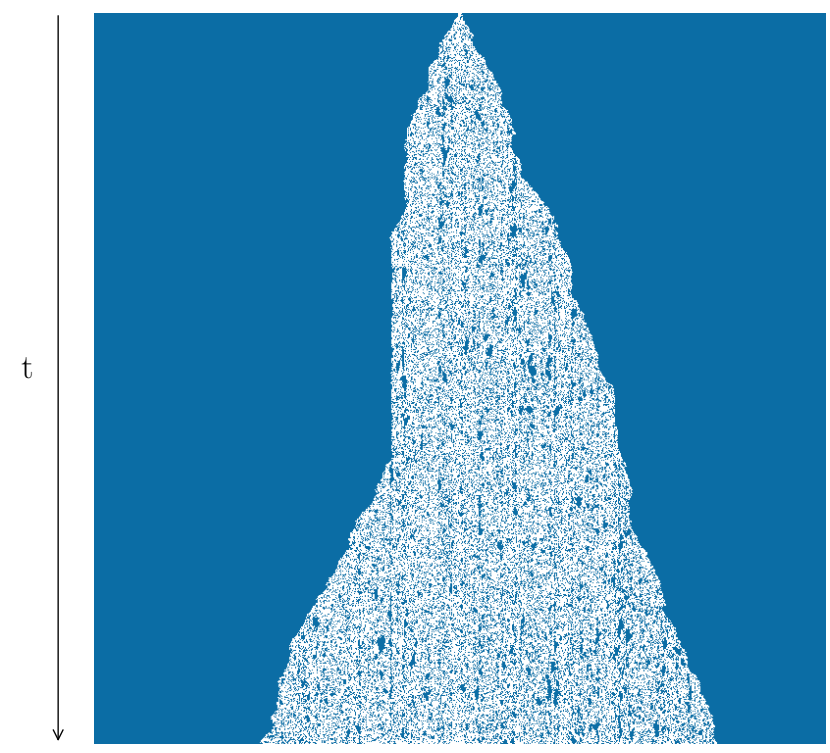

Figura 3.4: Evolução temporal do $\mathrm{CP}$ com desordem quenched na fase supercrítica (sítios ativos estão representados em branco), onde o processo de infecção têm que superar sítios que dificilmente ficam ativos, causando "avalanches" de infecção.

de escala $[43,44]$.

Vojta et al [13] estudaram, por sua vez, o efeito de desordem espacial aperiódica determinística no CP. Nesse caso consideramos um CP em uma rede unidimensional onde as taxas de infecção $\lambda$ dependem do sítio da rede, e alternam de acordo com a sequência generalizada de Fibonacci definida pela regra de inflação $A \rightarrow A B^{k}$ e $B \rightarrow A$, discutida na seção (2.1). Uma representação do modelo está exibida na figura (3.5). Como as perturbações possuem um limite em seu tamanho não devemos observar a formação de uma fase de Griffiths nesse caso.

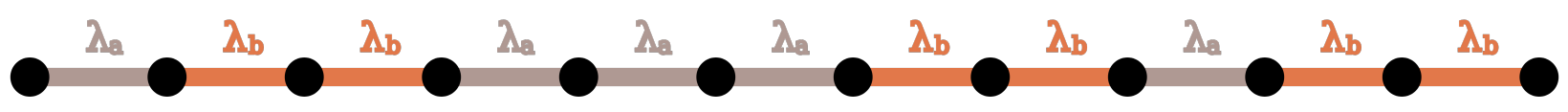

Figura 3.5: Representação da rede unidimensional com taxas de infecção aperiódicas. As taxas de infecção entre os sítios seguem a sequência generalizada de Fibonacci onde uma ligação " $A$ " representa que entre os sítios há uma taxa de infecção $\lambda_{a} / z$ (onde $z$ é a coordenação da rede e, para esse caso, temos $z=2$ ), e analogamente para ligações do tipo " $B$ ". No caso da figura a rede representa a quarta iteração da sequência generalizada de Fibonacci com $k=2$ e o fator $1 / 2$ foi omitido em todas as taxas para não poluir a imagem. 
Pode-se então estudar os efeitos das flutuações geométricas (caracterizadas pelo expoente de flutuação $\omega$ ) frente ao critério de Harris-Luck,

$$
\omega<\omega_{c}=1-\frac{1}{d \nu_{\perp}}
$$

que para o $\mathrm{CP}$ unidimensional assume o valor crítico $\omega_{c} \approx 0.0884$.

Para $k=1$ temos que $\omega_{1}=-1$, logo a desordem aperiódica é irrelevante para o comportamento crítico e a universalidade. Gráficos para a evolução do número de sítios ativos $N_{s}$ e da probabilidade de sobrevivência da rede ativa $P_{s}$ estão representados na figura (3.6a). Esse resultado contrasta com a desordem aleatória quenched, pois neste último caso até desordens fracas alteram a criticalidade, já para desordem determinística com $k=1$ podemos até mesmo considerar modulações fortes sem alterar o comportamento crítico.

O caso $k=2$ representa um cenário limite onde $\omega_{2} \lesssim \omega_{c}$, mas ainda assim as heterogeneidades se mostram irrelevantes para o comportamento crítico, o que pode ser verificado através de simulações de Monte Carlo. Há, porém, um transiente oscilatório extremamente lento para modulações fortes, que ainda não foi completamente eliminado em simulações numéricas. Já no caso $k=3$ temos que $\omega_{3}>\omega_{c}$ e as modulações aperiódicas das taxas de infecção levam a um comportamento crítico não usual, onde as grandezas do sistema não seguem mais as leis de potência usuais mas sim exponenciais esticadas, e surgem oscilações exóticas no comportamento da densidade de infectados e da probabilidade de sobrevivência, que apresentam "degraus" acentuados, como exibido na figura (3.6b). Isso de deve ao fato da formação de "ilhas" de sítios fortemente correlacionados extremamente susceptíveis à infecção, que, quando extintas, levam a quedas súbitas na densidade $\rho$. Esse efeito pode ser facilmente observado na figura 3.7. Um tratamento de grupo de renormalização pode ser feito para esse modelo e está explicado em detalhes na referência [13].

\subsubsection{Desordem Temporal}

Para a desordem temporal há resultados igualmente interessantes. Jensen [45] mostrou através de simulações de Monte Carlo que desordem temporal aplicada a um modelo da DP leva a uma mudança contínua nos expoentes críticos para qualquer valor de desordem, o que violaria o critério de Kinzel $\nu_{\|}>2$ já que essa condição é satisfeita nesse caso porém a criticalidade é afetada. O autor fornece algumas alternativas para justificar essa violação:

1. O critério de Kinzel não se aplica ao modelo estudado,

2. A relação de escala utilizada para encontrar $\nu_{\|}$não é válida,

3. Os expoentes foram extraídos realizando simulações partindo de uma rede com um único sítio ativo (esse expoentes são as vezes chamados de "expoentes dinâmicos"). É possível que os expoentes de "steady-state", obtidos partindo de uma rede inteiramente ativa, sejam diferentes.

Já para o CP e para a equação logística [46] temos que desordem temporal leva a um comportamento raro de dinâmicas lentas e transições de "ruído infinito" (infinite noise criticality), já que o ruído, caracterizado 


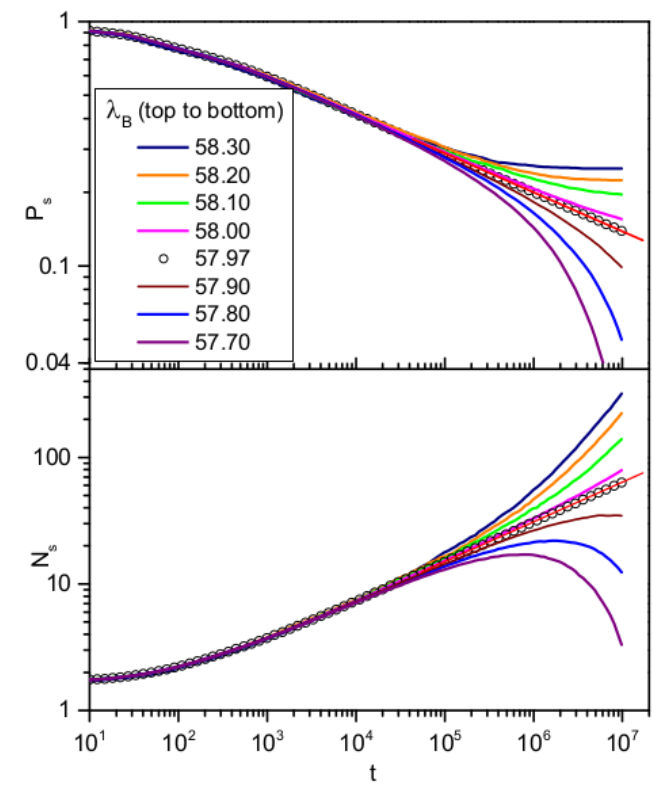

(a)

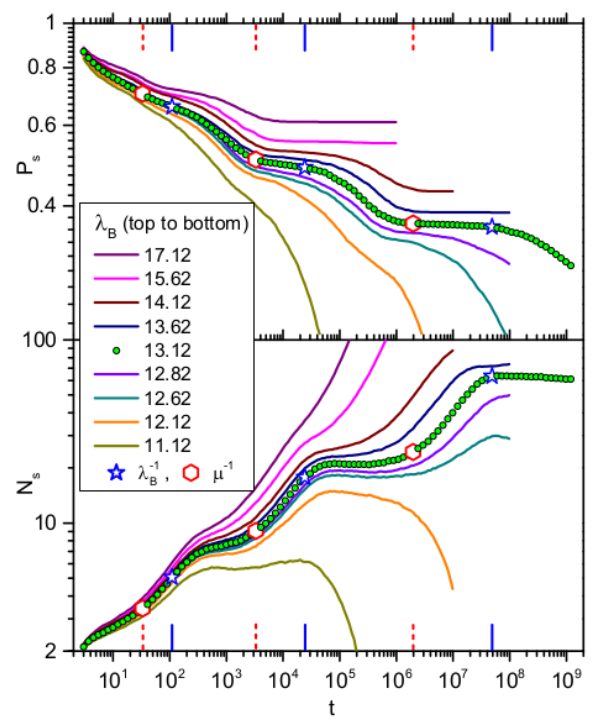

(b)

Figura 3.6: (3.6a) (Acima) Evolução temporal da probabilidade de sobrevivência da rede ativa para o caso $k=1$ nas proximidades do ponto crítico. (Abaixo) Evolução temporal do número de sítios ativos. (3.6b) Evolução temporal da probabilidade de sobrevivência da rede ativa (acima) e do número de sítios ativos (abaixo) para o caso $k=3$, onde modulações bem expressivas podem ser observadas na evolução de ambas as grandezas. Esse comportamento incomum leva a expoentes críticos não universais. Ambas figuras foram extraídas da referência [13]. 


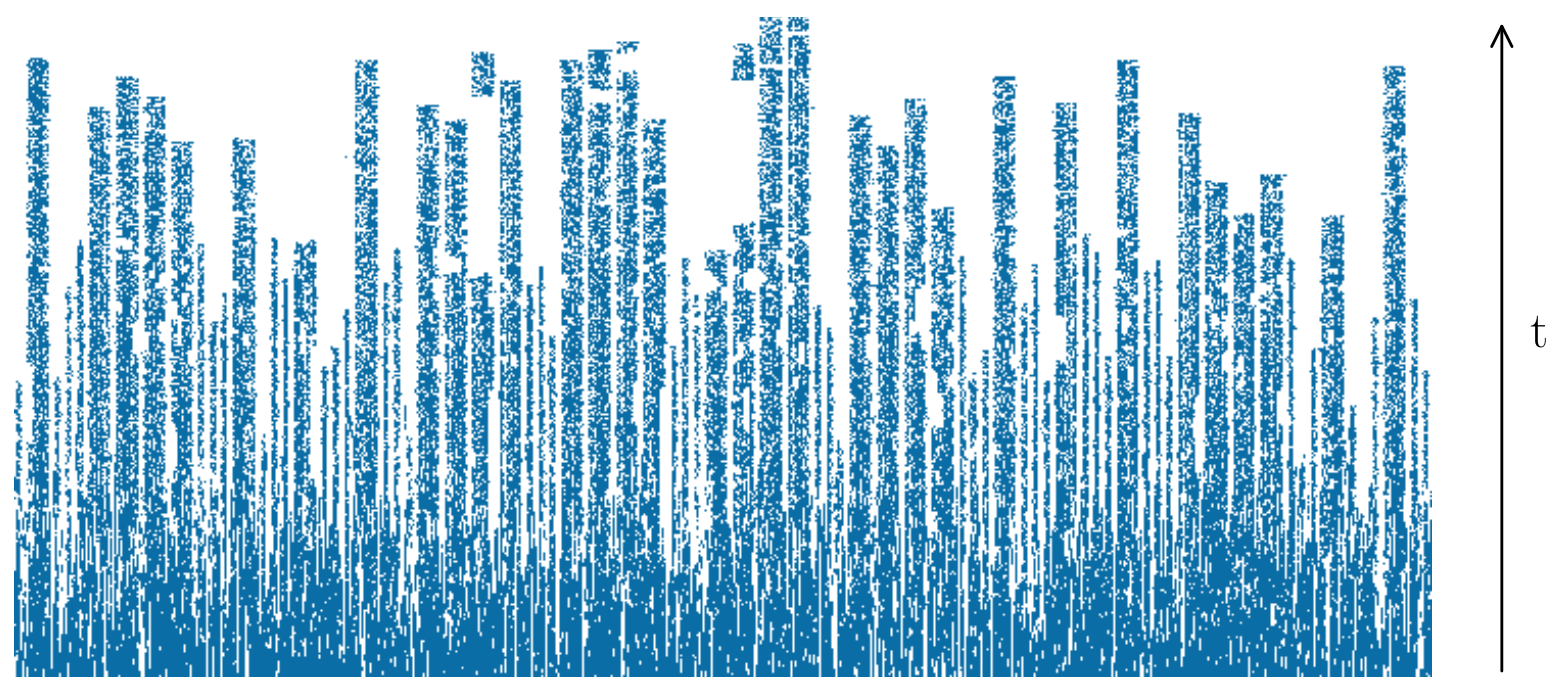

Figura 3.7: Evolução temporal de uma rede que inicialmente estava completamente ativa (sítios ativos estão representados em azul) para o caso $k=3$ onde observamos a formação de "ilhas" de sítios fortemente correlacionados onde a infecção de espalha facilmente. Quando uma dessas ilhas fica inativa temos quedas abruptas tanto na evolução da densidade $\rho$ como da probabilidade de sobrevivência $P_{s}$.

pela razão entre a densidade de infectados e seu desvio padrão, diverge quando $t \rightarrow \infty$. Esse comportamento se deve ao fato das flutuações temporais poderem afastar o sistema do comportamento limpo por uma duração indeterminada.

A análise da desordem aperiódica determinística temporal é a peça que falta nesse cenário e será o tópico dos próximos capítulos. 


\section{Capítulo 4}

\section{Equação Logística com Aperiodicidade Temporal}

Nessa seção começaremos a estudar o efeito que a introdução de aperiodicidade determinística temporal tem sobre a transição de fase de diferentes modelos. Começamos nossa discussão considerando um sistema regido pela equação logística:

$$
\frac{\mathrm{d}}{\mathrm{d} t} \rho=(\lambda-\mu) \rho-\lambda \rho^{2}
$$

onde $\mu$ é a taxa de cura, $\lambda$ a taxa de infecção e $\rho$ a densidade de indivíduos infectados. Vimos no capítulo 3 que a desordem temporal aleatória afeta o comportamento crítico desse sistema e leva a transições de fase de "ruído infinito". Vamos investigar agora se a desordem aperiódica determinística possui um efeito diferente sobre a criticalidade ou não.

Para introduzir a desordem aperiódica determinística no sistema começamos consideramos que os parâmetros do sistema se mantêm constantes em intervalos de tempo de duração $\Delta t_{j}$, porém alteram entre um conjunto " $A$ " de parâmetros $\left(\mu_{a}, \lambda_{a}, \Delta t_{a}\right)$ e um conjunto " $B$ " $\left(\mu_{b}, \lambda_{b}, \Delta t_{b}\right)$ seguindo a sequência generalizada de Fibonacci discutida na seção (2.1), que consiste em iterar a regra de substituição $A \rightarrow A B^{k}$ e $B \rightarrow A$ onde $B^{k}$ representa uma sequência de $k$ letras " $B$ ". Um esquema dessa situação está representado na figura (4.1a). Podemos escrever sem perda de generalidade que $\Delta t_{a}=\Delta t_{b} \equiv \Delta t$ (as diferenças podem ser absorvidas nas respectivas taxas $\lambda$ e $\mu$ ). Temos ainda que em cada intervalo $\Delta t$ a resolução da equação logística (4.1) ainda é válida:

$$
\rho_{n}^{-1}=a_{n} \rho_{n-1}^{-1}+c_{n}
$$

onde $a_{n}=\exp \left[\left(\mu_{n}-\lambda_{n}\right) \Delta t_{n}\right]$ e $c_{n}=\left(a_{n}-1\right) \lambda_{n} /\left(\mu_{n}-\lambda_{n}\right)$. Podemos iterar a expressão (4.2) para deixar a dependência com a densidade inicial $\rho_{0}$ explicita: 


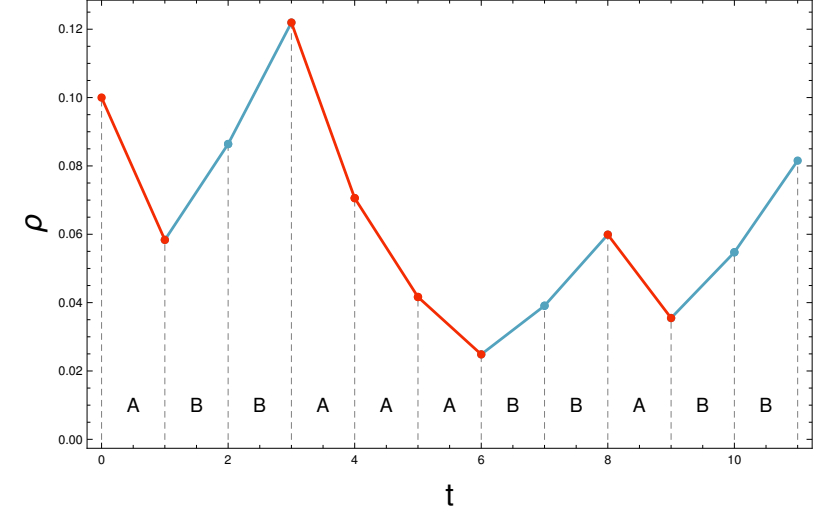

(a)

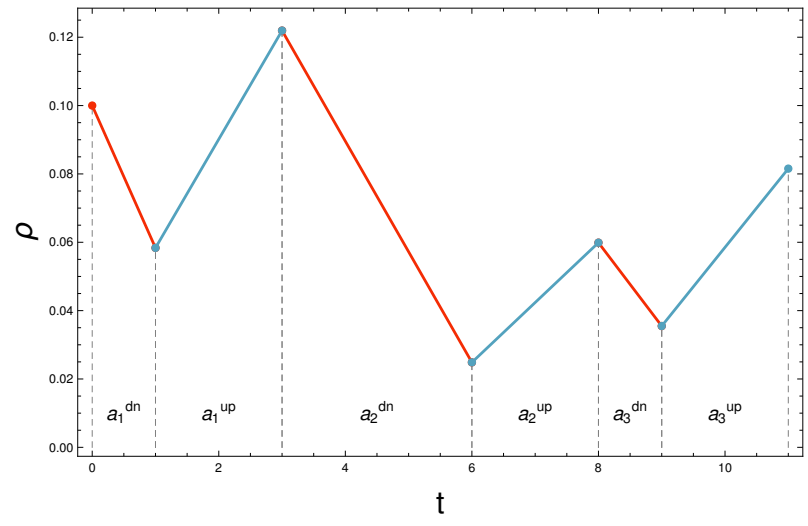

(b)

Figura 4.1: (4.1a) Evolução temporal da densidade de infectados $\rho$ (4.1b) Representação da primeira etapa do GR, onde os intervalos de tempo consecutivos de subida e descida são agrupados, criando um padrão em "zig-zag". Os novos intervalos de subida e descida possuem, respectivamente, as taxas $a^{\text {up }}<1$ e $a^{\mathrm{dn}}>1$.

$$
\begin{aligned}
\rho_{n}^{-1} & =a_{n} \rho_{n-1}^{-1}+c_{n} \\
& =a_{n}\left(a_{n-1} \rho_{n-2}+c_{n-1}\right)+c_{n} \\
& =a_{n}\left(a_{n-1}\left(a_{n-2} \rho_{n-3}+c_{n-2}\right)+c_{n-1}\right)+c_{n} \\
& =\left(a_{n} a_{n-1} a_{n-2}\right) \rho_{n-3}^{-1}+\left(a_{n} a_{n-1} c_{n-2}+a_{n} c_{n-1}+c_{n}\right)
\end{aligned}
$$

Iterando até o primeiro intervalo chegamos à expressão

$$
\rho_{n}^{-1}=\underbrace{\left(\prod_{i=1}^{n} a_{i}\right)}_{\mathbb{A}_{n}} \rho_{0}^{-1}+\underbrace{\sum_{i=1}^{n} c_{i}\left(\prod_{j=i+1}^{n} a_{j}\right)}_{\mathbb{C}_{n}},
$$

que pode ser reescrita no formato da equação (4.2):

$$
\rho_{n}^{-1}=\mathbb{A}_{n} \rho_{0}^{-1}+\mathbb{C}_{n}
$$

Podemos analisar o contribuição de $\mathbb{A}_{n}$ e $\mathbb{C}_{n}$ na evolução temporal de $\rho$. Temos que o termo $\mathbb{C}_{n}$ atua só impedindo que a densidade seja maior do que 1 , já o termo $\mathbb{A}_{n}$ é dado por:

$$
\mathbb{A}_{n}=\prod_{i=1}^{n} a_{i}=\prod_{i=1}^{n} e^{\left(\mu_{i}-\lambda_{i}\right) \Delta t}=e^{\sum_{i=1}^{n}\left(\mu_{i}-\lambda_{i}\right) \Delta t} .
$$

Introduzindo os valores médios $\langle\lambda\rangle=\left(\lambda_{1}+\cdots+\lambda_{n}\right) / n$ obtemos:

$$
\mathbb{A}_{n}=e^{n\left(\langle\mu\rangle_{n}-\langle\lambda\rangle_{n}\right) \Delta t}
$$

onde podemos ter os seguintes regimes: 
- $\langle\mu\rangle_{n}>\langle\lambda\rangle_{n}: \lim _{n \rightarrow \infty} e^{n\left(\langle\mu\rangle_{n}-\langle\lambda\rangle_{n}\right) \Delta t} \rightarrow \infty$,

- $\langle\mu\rangle_{n}<\langle\lambda\rangle_{n}: \lim _{n \rightarrow \infty} e^{n\left(\langle\mu\rangle_{n}-\langle\lambda\rangle_{n}\right) \Delta t} \rightarrow 0$.

Separando esses comportamentos temos a condição crítica:

$$
\lim _{n \rightarrow \infty}\langle\mu\rangle_{n}=\lim _{n \rightarrow \infty}\langle\lambda\rangle_{n} .
$$

Como $a_{n}$ só depende da diferença entre $\lambda$ e $\mu$ podemos escolher sem perda de generalidade que a desordem temporal se deve somente à taxa $\lambda$, o que nos permite escrever $\mu_{a}=\mu_{b}=\mu$ (a diferença entre $\mu_{a}$ e $\mu_{b}$ poderia ser absorvida nas taxas de infeção $\lambda$ ). Com isso podemos encontrar o valor esperado de $\lambda$ explicitamente:

$$
\langle\lambda\rangle_{N}=\frac{\lambda_{1}+\cdots+\lambda_{N}}{N}=\frac{N_{a}}{N} \lambda_{a}+\frac{N_{b}}{N} \lambda_{b},
$$

onde $N$ é o tamanho da cadeia de Fibonacci e $N_{a, b}$ são o número de letras " $A$ " e " $B$ " na cadeia. No limite $N \rightarrow \infty$ temos que (ver seção 2.1):

$$
\lim _{N \rightarrow \infty} \frac{N_{a}}{N} \equiv x_{a}=\left(\frac{1+\sqrt{1+4 k}}{2}\right)^{-1}=\zeta_{+}^{-1} .
$$

onde $\zeta_{+}$é o maior autovalor da matriz de substituição que gera a sequência de Fibonacci e $x_{b}=1-x_{a}$ é a fração complementar. Com isso podemos reescrever a equação (4.4) como:

$$
x_{a} \lambda_{a}+x_{b} \lambda_{b}=\mu,
$$

e fixando um valor de $\lambda_{a}$ na equação acima podemos encontrar o valor crítico $\lambda_{b}^{*}$

$$
\lambda_{b}^{*}=\frac{\mu \zeta_{+}-\lambda_{a}}{\zeta_{+}-1}
$$

A evolução do termo $\mathbb{A}_{n}$ sob iterações $n$ acima e abaixo do ponto crítico está representada na figura (4.2).

Outro fator importante a ser estudado é o ruído do sistema, caracterizado pela a razão

$$
\frac{\sigma_{\rho}}{\rho}
$$

entre a densidade de infectados $\rho$ e seu desvio padrão $\sigma_{\rho}$. Podemos observar como essa razão se comporta para decidir se a transição de fase terá um comportamento de "ruído infinto" ou se o ruído é assintóticamente irrelevante para a transição.

\subsection{Grupo de renormalização}

Para estudar o comportamento crítico do sistema iremos construir um grupo de renormalização (GR) que é fortemente inspirado pelo GR para desordens espaciais fortes [47]. O primeiro passo do GR consiste em agrupar todos os intervalos de tempo consecutivos que tenham $\mu_{n}>\lambda_{n}$ em um único intervalo com 


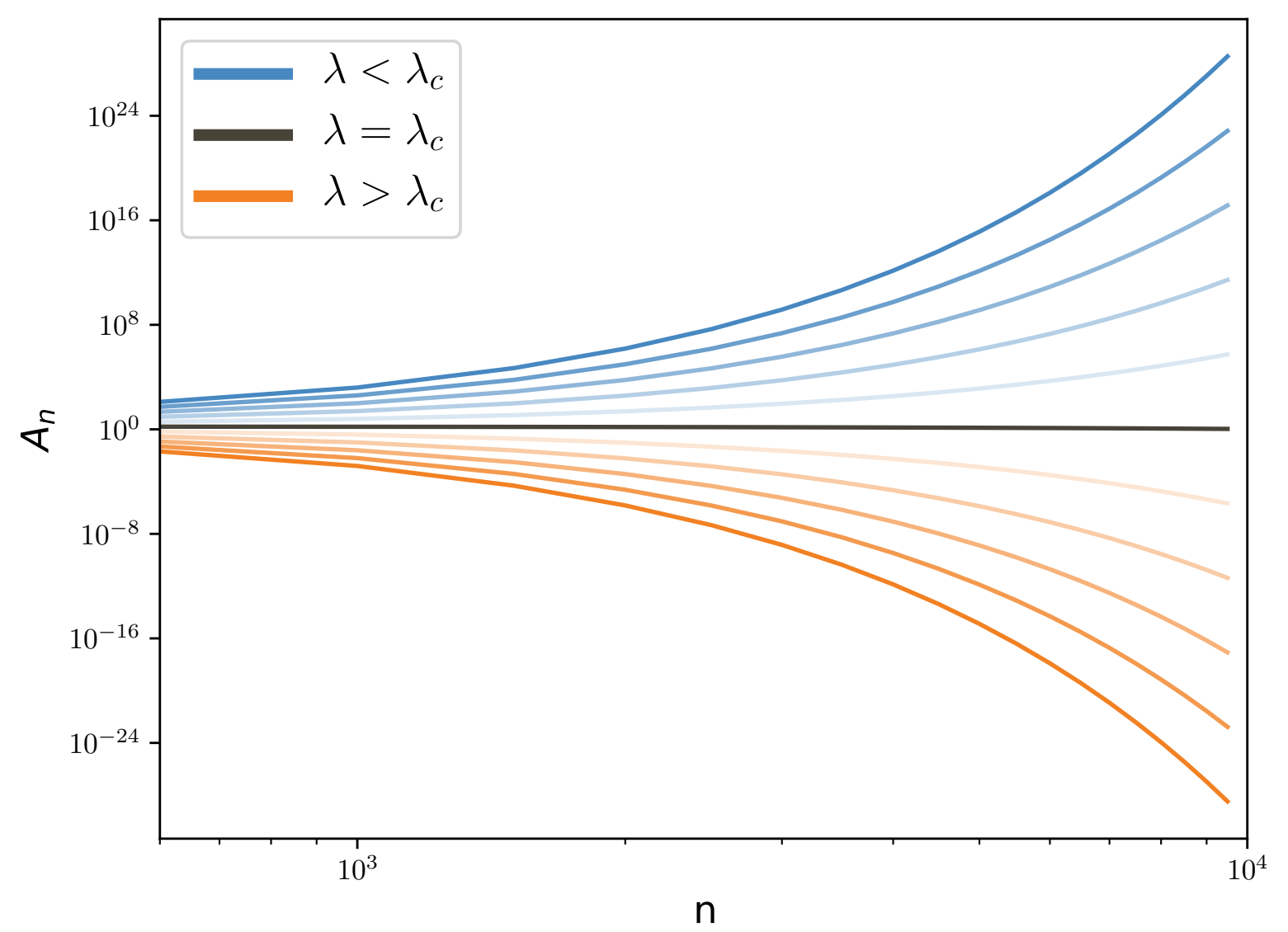

Figura 4.2: Evolução temporal do termo $\mathbb{A}_{n}$ para valores de $\lambda_{b}$ próximos de $\lambda_{b}^{*}$ no caso $k=1$ onde $\lambda_{b}^{*} \sim$ 1.80902. Curvas laranjas estão na fase ativa onde $\lambda_{b}>\lambda_{b}^{*}$ e curvas azuis estão na fase absorvente com $\lambda_{b}<\lambda_{b}^{*}$. A curva preta representa o caso crítico $\lambda_{b}=\lambda_{b}^{*}$

$a_{i} \equiv a_{i}^{u p}<1$ de tamanho $\Delta t^{u p}$ e os intervalos com $\mu_{n}<\lambda_{n}$ em um intervalo com $a_{i} \equiv a_{i}^{d n}>1$ de tamanho $\Delta t^{d n}$. Isso cria uma curva em "zig-zag" com intervalos alternantes de subida e descida, como representado na figura (4.1b).

Como na sequência generalizada de Fibonacci temos apenas 3 tipos de blocos de letras possíveis,

- $(k+1)$ letras $A$,

- $k$ letras $B$,

- 1 letra $A$,

teremos apenas 3 tipos de intervalos após essa primeira etapa do GR: supondo $\lambda_{b}>\mu>\lambda_{a}$ temos que, após essa primeira etapa, haverá apenas um tipo de segmento $a^{u p}$ (do agrupamento das sequências de $k$ letras $B$ ) e dois tipos de segmentos $a^{d n}$ : um da sequência de $(k+1)$ letras $A$ e outro do intervalo com 1 letra $A$, como 
ilustrado na figura (4.3). Esquematicamente:

$$
\begin{aligned}
\left(a_{B}\right)^{k} & \rightarrow a^{u p} \equiv a^{++}, \\
\left(a_{A}\right)^{1} & \rightarrow a^{d n^{\prime}} \equiv a^{-}, \\
\left(a_{A}\right)^{k+1} & \rightarrow a^{d n} \equiv a^{--},
\end{aligned}
$$

onde

$$
a^{++}<1<a^{-}<a^{--}
$$

Um esquema dessa etapa do GR está representado na figura 4.3, onde os intervalos com os parâmetros $a^{++}, a^{-}$e $a^{--}$estão representados pelas letras " $B$ ", " $A$ " e " $C$ ", respectivamente.

Seguindo a ideia geral do grupo de renormalização para desordem forte pretendemos eliminar a cada passo os segmentos com o parâmetro $a_{i}$ mais próximo de 1 , pois eles são os que menos afetam o comportamento da densidade (se $a_{n} \approx 1$ então $\rho_{n+1} \approx \rho_{n}$ ). Ao eliminar esses segmentos corrigimos os intervalos de tempo e então iteramos esse procedimento.

Uma etapa de renormalização consiste, então, em agrupar os segmentos com os parâmetros $a_{i}$ mais próximos de 1 com seus vizinhos imediatos. Com isso os novos intervalos renormalizados terão:

$$
\begin{aligned}
\tilde{a} & =a_{i-1} a_{i} a_{i+1}, \\
\tilde{\Delta t} & =\Delta t_{i-1}+\Delta t_{i}+\Delta t_{i+1} .
\end{aligned}
$$

Podemos então definir a escala do grupo de renormalização:

$$
\Omega \equiv \min \left(a_{i}^{\mathrm{dn}}, 1 / a_{i}^{\mathrm{up}}\right)
$$

que nos permite escrever (ver figura (4.1b)):

$$
a= \begin{cases}\tilde{a}^{d n}=a_{i+1}^{d n} a_{i}^{d n} / \Omega, & \text { se } \Omega=a_{i}^{u p-1} \\ \left(1 / \tilde{a}^{u p}\right)=\left(1 / a_{i-1}^{u p}\right)\left(1 / a_{i}^{u p}\right) / \Omega, & \text { se } \Omega=a_{i}^{d n}\end{cases}
$$

e os intervalos de tempo como:

$$
\begin{aligned}
\tilde{\Delta t}^{u p} & =\Delta t_{i+1}^{u p}+\Delta t_{i}^{d n}+\Delta t_{i}^{u p}, \\
\tilde{\Delta t}^{d n} & =\Delta t_{i-1}^{d n}+\Delta t_{i}^{u p}+\Delta t_{i}^{d n} .
\end{aligned}
$$

Agora precisamos verificar se a estrutura geral da sequência de Fibonacci é preservada a cada etapa. Seguindo uma argumentação muito próxima da referência [48] começamos supondo que $a_{0}^{-}$é a taxa intermediária e que vale inicialmente a desigualdade

$$
a_{0}^{++}<1<a_{0}^{-}<a_{0}^{--}
$$

Iremos então agrupar no primeiro passo os intervalos com as taxas intermediarias e os intervalos vizinhos. Na sequência generalizada de Fibonacci isso representa juntar $k$ grupos de letras " $A$ " que estão "ilhadas" entre 
$k+1$ grupos de letras $B^{k}$ (ver figura (4.4)), onde o agrupamento dessa etapa resulta nos intervalos " $E$ "). A taxa resultante será a nova menor taxa do sistema $\left(\right.$ se $\left.\left(a_{0}^{-} a_{0}^{++}\right)^{k}<1\right)$ :

$$
a_{1}^{++}=\left(a_{0}^{-}\right)^{k}\left(a_{0}^{++}\right)^{k+1} .
$$

Para voltar a relação inicial dada pela equação (4.11) precisamos de mais uma renormalização, pois temos agora duas taxas de subida e apenas uma de descida que seguem $a_{1}^{++}<a_{0}^{++}<1<a_{0}^{--}$(representados, respectivamente, pelas letras " $E$ ", " $B$ " e " $C$ " da figura (4.4)). A nova taxa intermediária é $a_{0}^{++}$. Os $k$ clusters com $a_{0}^{++}$estão entre $k+1$ clusters com $a_{0}^{--}$, e após agrupar esses intervalos (dando origem aos intervalos " $F "$ da figura) a nova maior taxa do sistema será (se $\left.\left(a_{0}^{++} a_{0}^{--}\right)^{k}>1\right)$ :

$$
a_{1}^{--}=\left(a_{0}^{++}\right)^{k}\left(a_{0}^{--}\right)^{k+1}
$$

nos dando a relação $a_{1}^{++}<1<a_{0}^{--}<a_{1}^{--}$, que segue a estrutura da relação inicial entre as taxas do sistema. Renomeando as taxas, temos o segundo passo do GR:

$$
\begin{aligned}
a_{1}^{++} & =\left(a_{0}^{++}\right)^{k+1}\left(a_{0}^{-}\right)^{k}, \\
a_{1}^{-} & =a_{0}^{--}, \\
a_{1}^{--} & =\left(a_{0}^{++}\right)^{k}\left(a_{0}^{--}\right)^{k+1} .
\end{aligned}
$$

Tirando o logaritmo e estendendo o argumento para um passo genérico $n$ teremos a regra geral:

$$
\begin{aligned}
& \ln \left(a_{n+1}^{++}\right)=(k+1) \ln \left(a_{n}^{++}\right)+k \ln \left(a_{n}^{-}\right) \\
& \ln \left(a_{n+1}^{-}\right)=\ln \left(a_{n}^{--}\right) \\
& \ln \left(a_{n+1}^{--}\right)=k \ln \left(a_{n}^{++}\right)+(k+1) \ln \left(a_{n}^{--}\right)
\end{aligned}
$$

ou matricialmente:

$$
\left(\begin{array}{c}
\ln \left(a_{n}^{++}\right) \\
\ln \left(a_{n}^{-}\right) \\
\ln \left(a_{n}^{--}\right)
\end{array}\right)=\left(\begin{array}{ccc}
(k+1) & k & 0 \\
0 & 0 & 1 \\
k & 0 & (k+1)
\end{array}\right)^{n}\left(\begin{array}{c}
\ln \left(a_{0}^{++}\right) \\
\ln \left(a_{0}^{-}\right) \\
\ln \left(a_{0}^{--}\right)
\end{array}\right)
$$

e similarmente para os intervalos de tempo:

$$
\left(\begin{array}{c}
\Delta t_{n}^{++} \\
\Delta t_{n}^{-} \\
\Delta t_{n}^{--}
\end{array}\right)=\left(\begin{array}{ccc}
(k+1) & k & 0 \\
0 & 0 & 1 \\
k & 0 & (k+1)
\end{array}\right)^{n}\left(\begin{array}{c}
\Delta t_{0}^{++} \\
\Delta t_{0}^{-} \\
\Delta t_{0}^{--}
\end{array}\right) .
$$

Vale realçar que para esse método funcionar temos que tanto $\left(a_{n}^{-} a_{n}^{++}\right)^{k}<1$ como $\left(a_{n}^{++} a_{n}^{--}\right)^{k}>1$ devem valer para um passo $n$ qualquer ${ }^{1}$. Discutiremos a validade dessas condições e o que acontece se elas forem desrespeitadas posteriormente. Verificamos se a estrutura de Fibonacci é preservada numericamente para todas as sequências de tamanho inferior a $10^{10}$ (porém ainda falta uma prova matemática rigorosa). $\mathrm{O}$ próximo passo é analisar o fluxo do grupo de renormalização e estudar o comportamento crítico do sistema.

\footnotetext{
${ }^{1}$ A quebra dessas condições não implica necessariamente que a transformação não pode ser mais iterada, mas ela começa a divergir do comportamento crítico e eventualmente irá falhar pois iremos renormalizar uma taxa que não é intermediária
} 


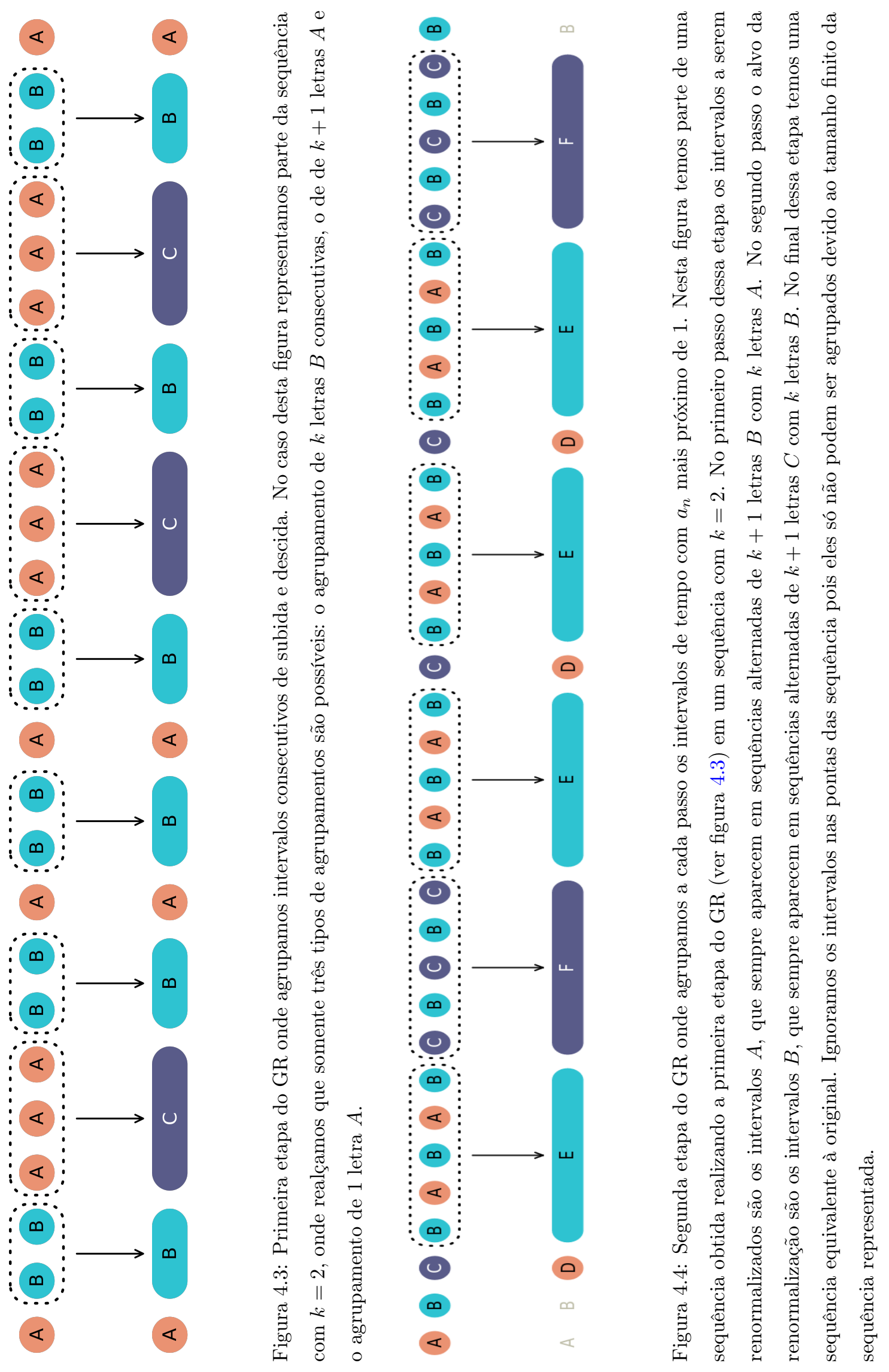




\subsection{Previsões do GR}

Podemos reescrever a equação (4.12) da seguinte forma:

$$
\vec{a}_{n}=M \vec{a}_{n-1}=M^{n} \vec{a}_{0}
$$

onde:

$$
\vec{a}_{n} \equiv\left(\begin{array}{c}
\ln \left(a_{n}^{++}\right) \\
\ln \left(a_{n}^{-}\right) \\
\ln \left(a_{n}^{--}\right)
\end{array}\right)=\left(\begin{array}{c}
\left(\mu_{n}-\lambda_{b, n}\right) \Delta t_{n}^{++} \\
\left(\mu_{n}-\lambda_{a, n}\right) \Delta t_{n}^{-} \\
\left(\mu_{n}-\lambda_{a, n}\right) \Delta t_{n}^{--}
\end{array}\right), \quad \boldsymbol{M} \equiv\left(\begin{array}{ccc}
(k+1) & k & 0 \\
0 & 0 & 1 \\
k & 0 & (k+1)
\end{array}\right)
$$

A matriz $M$ tem como autovalores 1 e $\Xi_{ \pm}=\zeta_{ \pm}+k$, onde $\zeta_{ \pm}=\frac{1}{2}(1 \pm \sqrt{1+4 k})$, e pode ser decomposta como:

$$
M=V \Lambda V^{-1}
$$

onde $\boldsymbol{\Lambda}$ é uma matriz diagonal composta pelos autovalores de $\boldsymbol{M}: \boldsymbol{\Lambda}=\operatorname{diag}\left\{1, \Xi_{-}, \Xi_{+}\right\}$e $\boldsymbol{V}=\left(\left|v_{1}\right\rangle,\left|v_{2}\right\rangle,\left|v_{3}\right\rangle\right)$ onde $v_{i}$ são os autovetores de $\boldsymbol{M}$. Com isso temos:

$$
\vec{a}_{n}=\boldsymbol{V} \boldsymbol{\Lambda}^{n} \boldsymbol{V}^{-1} \vec{a}_{0}
$$

Vamos agrupar todas as constantes em variáveis auxiliares $\eta$ e $\tau$ por simplicidade. As formas explicitas dessas variáveis estão no apêndice A (os termos $\eta$ são dadas pelas equações A.4 até A.12). Temos em notação reduzida:

$$
\left(\begin{array}{c}
\ln a_{n}^{++} \\
\ln a_{n}^{-} \\
\ln a_{n}^{--}
\end{array}\right)=\left(\begin{array}{c}
\eta_{0}+\eta_{0}^{-} \Xi_{-}^{n}+\eta_{0}^{+} \Xi_{+}^{n} \\
\eta_{1}+\eta_{1}^{-} \Xi_{-}^{n}+\eta_{1}^{+} \Xi_{+}^{n} \\
\eta_{2}+\eta_{2}^{-} \Xi_{-}^{n}+\eta_{2}^{+} \Xi_{+}^{n}
\end{array}\right) .
$$

De forma similar os intervalos de tempo serão dados através de

$$
\left(\begin{array}{c}
\Delta t_{n}^{++} \\
\Delta t_{n}^{-} \\
\Delta t_{n}^{--}
\end{array}\right)=\left(\begin{array}{c}
\tau_{0}+\tau_{0}^{-} \Xi_{-}^{n}+\tau_{0}^{+} \Xi_{+}^{n} \\
\tau_{1}+\tau_{1}^{-} \Xi_{-}^{n}+\tau_{1}^{+} \Xi_{+}^{n} \\
\tau_{2}+\tau_{2}^{-} \Xi_{-}^{n}+\tau_{2}^{+} \Xi_{+}^{n}
\end{array}\right),
$$

onde os termos $\tau$ são dados pelas equações A.13 até A.21. Todos os termos $\eta$ e $\tau$ possuem um fator $(k-2)^{-1}$, o que torna essa análise inviável para o caso $k=2$ (um efeito similar acontece no caso de desordem aperiódica espacial [13]), logo uma análise mais detalhada se torna necessária para esse caso particular. Tal análise está desenvolvida no apêndice B.

Temos que os termos que acompanham o maior autovalor $\Xi_{+}$irão dominar o comportamento do sistema à medida que $n \rightarrow \infty$. Se os prefatores $\eta_{i}^{+}, i \in\{0,1,2\}$ não forem nulos, teremos que todos os parâmetros " $a_{n}$ " irão divergir. Com isso deduzimos que o ponto critico será dado pela condição $\eta_{i}^{+}=0$. Para todos $\eta_{i}^{+}$ chegamos à mesma condição (ver apêndice A): 


$$
\lambda_{b, 0}^{*}=\frac{\mu \zeta_{+}-\lambda_{a, 0}}{\zeta_{+}-1}
$$

que coincide com o resultado que obtivemos anteriormente somente analisando o termo $a_{n}$ da equação logística. Além disso, se $\lambda_{b} \lessgtr \lambda_{b}^{*}$ teremos que $\eta_{i}^{+} \lessgtr 0$, o que nos permite usar $\eta_{i}^{+}$como uma medida de distância à criticalidade. Muitos resultados importantes seguem.

\subsection{Fluxo do Grupo de Renormalização}

Temos que o GR pode ser iterado indefinidamente no ponto crítico, porém falha eventualmente nas proximidades dele, em um certo passo que denotaremos de $n^{*}$, onde o sistema muda do comportamento crítico para o comportamento ou da fase ativa ou da fase inativa. Na fase ativa o fluxo do GR deixa de ter um caráter condizente com o comportamento crítico e passa a ter o caráter da fase ativa quando $\ln \left(a_{n^{*}}^{--}\right)$ alcança 0. Impor essa condição nos leva a uma equação transcendental:

$$
\ln a_{n}^{--}=-\eta_{0}+\eta_{2}^{-} \Xi_{-}^{n^{*}}+\eta_{2}^{+} \Xi_{+}^{n^{*}}=0 .
$$

Para o caso $k=1$ temos que $\Xi_{-}<1 \operatorname{logo} \lim _{j \rightarrow \infty} \Xi_{-}^{j}=0$. Isso nos dá o passo de crossover:

$$
n^{*}=\frac{\ln \left(\eta_{0} / \eta_{2}^{+}\right)}{\ln \left(\Xi_{+}\right)},
$$

onde somente soluções inteiras positivas fazem sentido físico. Na fase ativa podemos estimar a escala de tempo como $\left\langle\Delta t_{n^{*}}\right\rangle$, logo o tempo de correlação segue

$$
\xi_{t} \sim\left\langle\Delta t_{n^{*}}\right\rangle \sim \Xi_{+}^{n^{*}}
$$

Como $\eta_{2}^{+}$pode ser usado como distância à criticalidade, podemos ainda afirmar que

$$
\xi_{t} \sim\left(\eta_{2}^{+}\right)^{-\nu_{\|}}
$$

e das equações (4.18) e (4.19) tiramos que o expoente crítico $\nu_{\|}$é dado através de:

$$
\nu_{\|}=\frac{\ln \left(\Xi_{+}\right)}{\ln \left(\Xi_{+}\right)}=1
$$

$\log \nu_{\|}=1$, que é o mesmo valor do expoente limpo.

O caso $k=2$ é especialmente delicado pois ele requer uma análise separada, que está desenvolvida no apêndice B. Dessa análise temos que o passo de crossover pode ser encontrado resolvendo uma equação transcendental, que se resolvida também leva a $\nu_{\|} \approx 1.0$.

Já para o caso $k=3$ temos que o termo $\eta_{0}$ pode ser ignorado pois $\Xi_{-}>1$ e $\Xi_{+}>1$. Isso nos dá o passo de crossover (válido somente para o caso $k=3$ )

$$
n^{*}=\frac{\ln \left(\eta_{2}^{+} / \eta_{2}^{-}\right)}{\ln \left(\Xi_{-} / \Xi_{+}\right)},
$$


onde somente soluções inteiras positivas fazem sentido físico. Prosseguindo da mesma maneira como fizemos para o caso $k=1$ tiramos que o expoente crítico $\nu_{\|}$é dado através de:

$$
\nu_{\|}=\frac{\ln \left(\Xi_{+}\right)}{\ln \left(\Xi_{+}\right)-\ln \left(\Xi_{-}\right)},
$$

que para $k=3$ vale $\nu_{\|} \approx 1.46434$, que é diferente do valor limpo $\nu_{\|}^{\text {cl }}=1.0$ ! Se lembrarmos ainda que $\omega=\ln \left|\zeta_{-}\right| / \ln \zeta_{+}$e $\Xi_{ \pm}=\zeta_{ \pm}+k$ temos que:

$$
\nu_{\|}=\frac{1}{1-\omega},
$$

que satura exatamente o critério de estabilidade.

Para encontrar o expoente $\beta\left(\rho_{\text {est }} \sim \epsilon^{\beta}\right)$ precisamos primeiramente relacionar a densidade $\rho$ com os parâmetros do sistema. A densidade estacionária pode ser encontrada realizando uma média sobre diversas configurações iniciais, porém, como discutido no apêndice A, essa não é uma tarefa trivial uma vez que a equação logística não possui uma noção de espaço nem de dimensionalidade. Contudo, evidências numéricas (figuras 4.6 a 4.13) indicam fortemente que a densidade estacionária pode ser estimada considerando uma evolução com taxas constantes e iguais aos seus valores médios caso realizássemos a média sobre configurações (uma discussão mais profunda sobre a equivalência entre essa médias está no apêndice A). Para a equação logística com taxas constantes a densidade estacionária pode ser estimada diretamente usando que no estado estacionário podemos escrever $\dot{\rho}=0$. Usando esse resultado diretamente na equação logística 4.1 temos

$$
\rho_{\mathrm{est}}=\frac{\lambda-\mu}{\lambda} \sim \lambda^{-1}
$$

$\log o \beta=1$. Como as evidências numéricas indicam que esse resultado independe do valor de $k$, temos que $\beta=1$ para todos os valores de $k$. O expoente $\delta$, relacionado à evolução da densidade de infectados no ponto crítico, pode ser encontrado através da lei de escala:

$$
\delta=\frac{\beta}{\nu_{\perp}} .
$$

\subsection{Previsões explícitas do Grupo de Renormalização}

Para a equação logística "limpa" temos que $\nu_{\|}=1$, logo o critério de estabilidade nos diz que perturbações serão relevantes se o expoente de flutuação $\omega$ for maior do que o valor crítico $\omega_{c}=0$. Com isso podemos estudar cada caso individualmente.

\subsection{1 $\mathrm{k}=1$}

Para $k=1$ temos que os autovalores da matriz $\boldsymbol{M}$ valem $\Xi_{-}=\zeta_{-}+k=0.3820$ e $\Xi_{+}=\zeta_{+}+k=2.618$. Como $\omega_{1}=-1$ não viola o critério de estabilidade para desordens temporais,

$$
\omega<1-\frac{1}{\nu_{\|}},
$$


temos que as flutuações temporais aperiódicas devem ser irrelevantes para o comportamento do sistema. Temos que o GR prevê os expoentes críticos

$$
\delta=1.0, \quad \nu_{\|}=1.0, \quad \beta=1.0
$$

que são iguais aos expoentes "limpos".

\subsection{2 $\mathrm{k}=2$}

Para $k=2$ temos que os autovalores da matriz $\boldsymbol{M}$ valem $\Xi_{-}=1$ e $\Xi_{+}=3$. Nesse caso $\omega_{2}=0$ satura exatamente o critério de estabilidade, e o sistema está exatamente no ponto que separa se o GR funciona ou não. Como a solução geral não se aplica para o caso $k=2$, já que o autovalor 1 se torna degenerado, temos que adaptar o GR para sanar esse problema. Realizando as mudanças necessárias (como feito no apêndice B) temos que o GR prevê o expoente crítico $\nu_{\|}=1.04(2)$. Dada a discussão até esse ponto temos ainda que $\beta=1.0, \operatorname{logo} \delta=1.0$ também. Todos os valores são condizentes com os expoentes limpos.

\subsection{3 $\mathrm{k}=3$}

Nesse caso os autovalores da matriz $\boldsymbol{M}$ valem $\Xi_{-}=2.303$ e $\Xi_{+}=5.303$. Como $\Xi_{1}>1$ temos que o GR é assintoticamente correto. $\omega_{3} \approx 0.3171$ viola o critério de estabilidade, e as flutuações temporais devem afetar o comportamento crítico do sistema. O GR prevê expoentes universais (que não dependem da modulação) cujos valores se situam entre os valores do caso limpo e os do caso puramente aleatório $\delta^{\text {rnd }}=1 / 2, \nu_{\|}^{\text {rnd }}=2, \beta^{\text {rnd }}=1$ :

$$
\delta \approx 0.685, \quad \nu_{\|} \approx 1.46, \quad \beta=1.0
$$

\subsection{4 $\mathrm{k}>3$}

Como $\Xi_{-}$cresce à medida que aumentamos $k$, o método do GR é valido para todos os valores $k \geq 4$. Como $\omega_{k}>0$ para todos os casos, em todos a desordem deve afetar o comportamento crítico. Os expoentes críticos podem ser extraídos de maneira completamente análoga à feita para o caso $k=3$.

\subsection{Resultados Numéricos}

Para testar as previsões do critério de estabilidade (4.24) e do GR realizamos iterações numéricas da equação logística com aperiodicidade temporal determinística para os casos $k=\{1,2,3\}$. Também podemos investigar a evolução do ruído tanto da densidade de infectados $\rho$ como de seu logaritmo para todos os casos e estudar se as transições podem ser caracterizadas como sendo de "ruído infinito" ou não. 


\subsection{1 $\mathrm{k}=1$}

De acordo com o critério de estabilidade a desordem temporal com $k=1$ é irrelevante para o comportamento crítico do sistema. À medida que iteramos o GR temos que tanto $\ln a_{n}^{++} \operatorname{como} \ln a_{n}^{--}$tendem a constantes (ver apêndice A), logo o ruído do sistema deve ficar constante. O GR também prevê que os expoentes críticos $\nu_{\|}, \beta$ e consequentemente $\delta$ são iguais a 1 , logo iguais aos expoentes do caso limpo. O comportamento do sistema nas proximidades do ponto crítico está exibido na figura (4.7a).

Para amenizar o efeito dos ruídos e facilitar a análise numérica (especialmente para os casos com $k \geq 2$ ), mas ainda preservando a estrutura da sequência de Fibonacci, podemos realizar médias sobre varias simulações (de mesmo tamanho) que começam em pontos aleatórios da sequência generalizada de Fibonacci.

O tempos de correlação $\xi_{t}$ podem ser estimados observando o ponto onde o sistema diverge do seu comportamento crítico, como exibido na figura (4.6). Usando $\xi_{t} \sim \epsilon^{-\nu_{\|}}$extraímos $\nu_{\|}=1.00(5)$ e de $\rho(t) \sim t^{-\delta}$, no ponto crítico, temos $\delta=1.00$. Já o expoente $\beta$ pode ser extraído observando a evolução da densidade estacionária, na fase ativa, para diferentes distâncias à criticalidade, onde $\rho_{\text {est }} \sim \epsilon^{\beta}$. Tanto o ajuste como as previsões do GR para $\rho_{\text {est }}$ (iterado o GR até o passo de crossover e então iterando a equação logística com os parâmetros encontrados) estão exibidos na figura (4.7b), de onde tiramos $\beta=1.00$. Outra maneira de estimar os expoentes é introduzindo a reescala $\rho \rightarrow \rho / \epsilon^{\beta}$ e $t \rightarrow t / \epsilon^{-\nu_{\|}}$. Realizando essa escala com os valores $\beta=1$ e $\nu_{\|}=1$ obtemos um colapso praticamente perfeito, como exibido na figura (4.5).

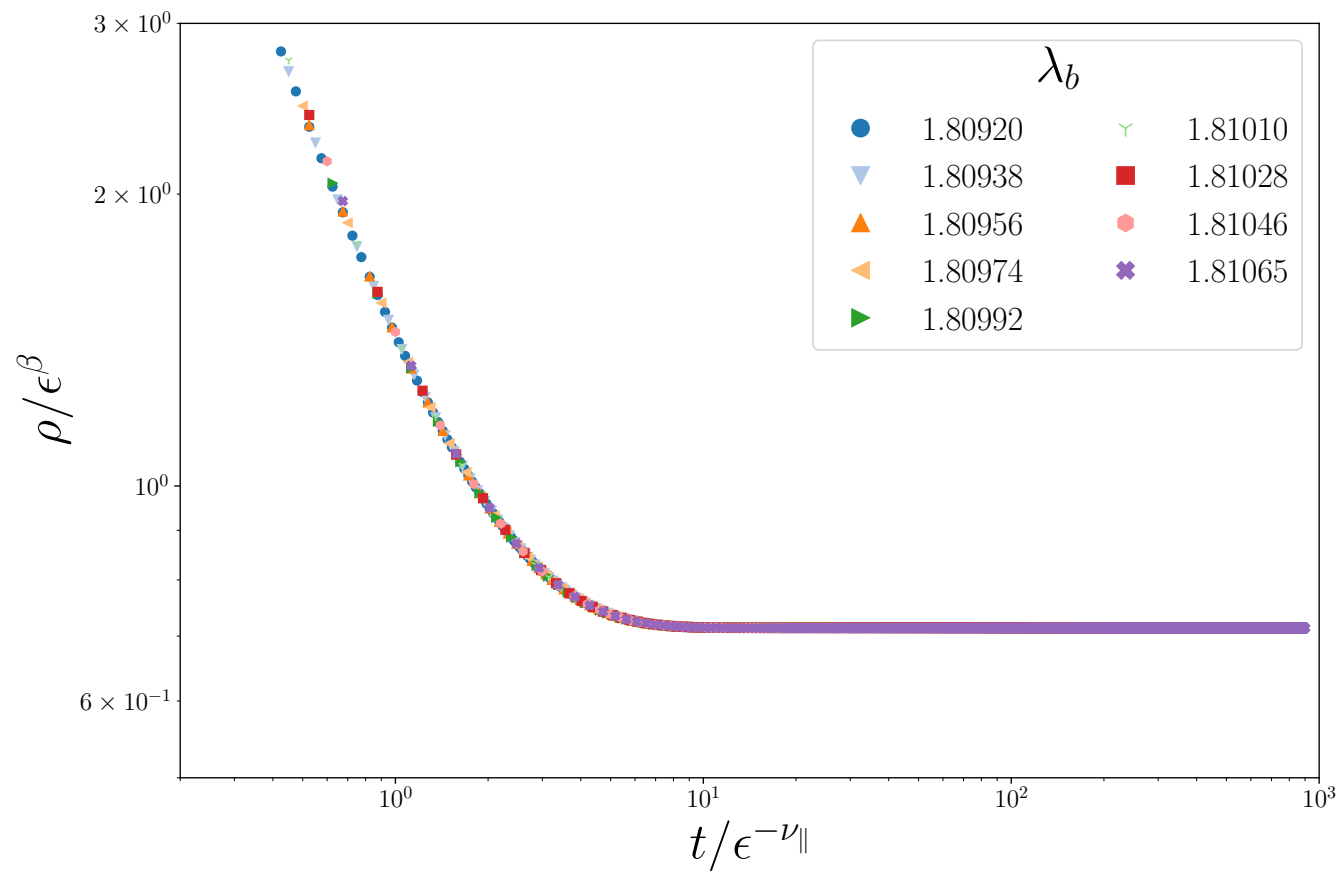

Figura 4.5: Colapso da evolução temporal da densidade $\rho$ para diferentes valores de $\lambda_{b}$ utilizando as reescalas $\rho \rightarrow \rho / \epsilon^{\beta}$ e $t \rightarrow t / \epsilon^{-\nu_{\|}} \operatorname{com} \beta=1.0$ e $\nu_{\|}=1.00$. Nesse caso temos que $k=1$. 


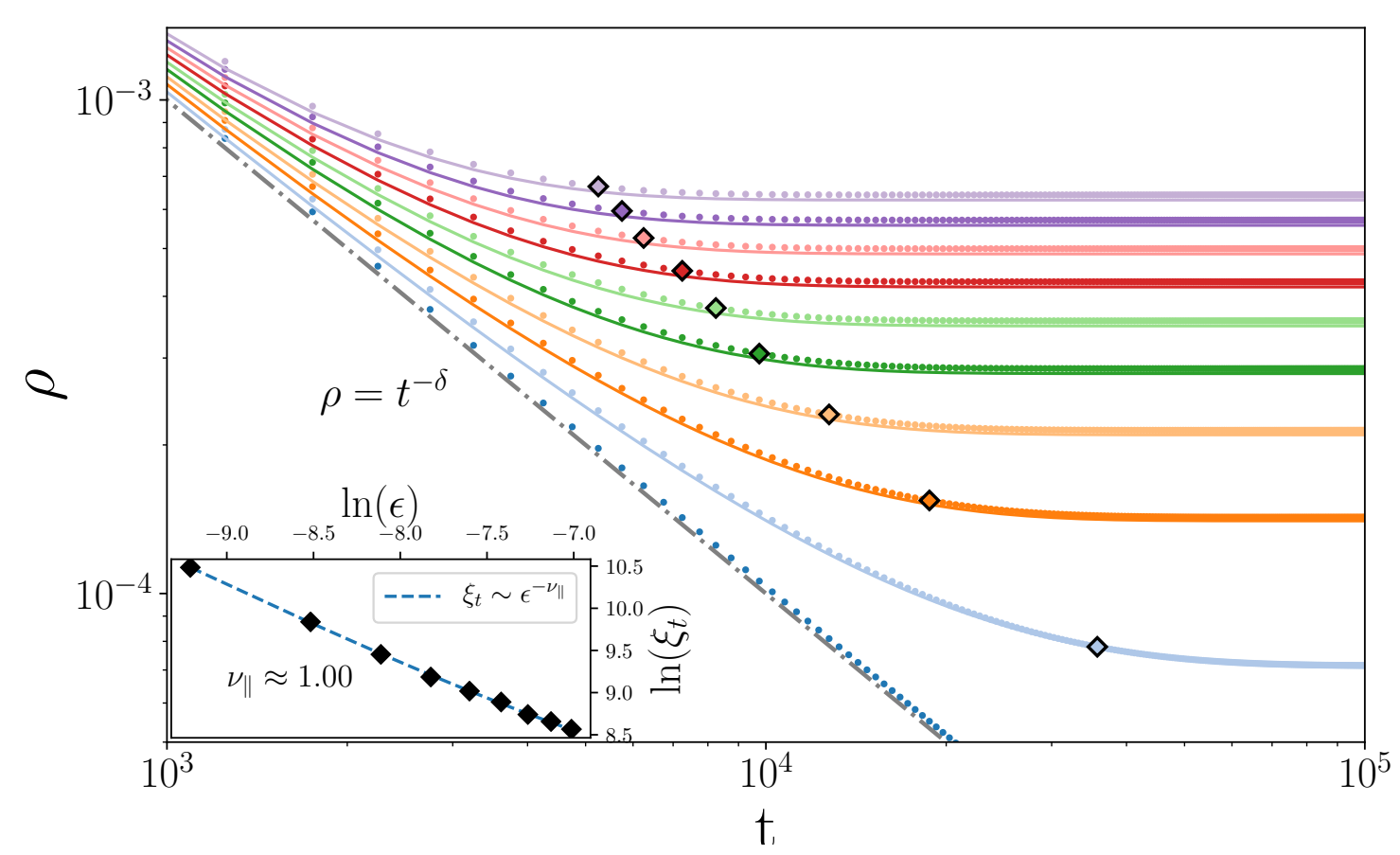

Figura 4.6: Evolução temporal da densidade média $\langle\rho\rangle$ na fase ativa com $k=1$, onde $\lambda>\lambda_{c}\left(\lambda_{a}=0.5\right.$, $\lambda_{b}=(1+\epsilon) \lambda_{b}^{*}$ e $\epsilon$ vale, de baixo para cima, $\left.0.0000,0.0001, \ldots, 0.0009\right)$. Pontos foram obtidos tirando a média sobre $10^{5}$ condições iniciais (cada simulação partiu de um ponto diferente da sequência de Fibonacci). A linha ponto-tracejada representa o comportamento crítico do sistema "limpo" onde $\rho=t^{-1}$. Os losangos contornados em preto representam a estimativa do tempo de correlação $\xi_{t}$. No inset estão plotados os tempos de correlação contra a distância ao ponto critico, de onde extraímos $\nu_{\|}=1.00$. As linhas cheias representam a evolução de $\rho$ caso as taxas do sistema fossem constantes e iguais aos seus valores nas médias configuracionais.

Em resumo tiramos da análise numérica os expoentes

$$
\delta=1.00, \quad \nu_{\|}=1.00, \quad \beta=1.00
$$

que são condizentes com os expoentes "limpos" $\delta^{\mathrm{cl}}=1, \nu_{\perp}^{\mathrm{cl}}=1, \beta^{\mathrm{cl}}=1$, como previsto. Também obtivemos resultados numéricos para o ruído de $\rho$ e de $\ln \rho$, que estão representados na figura (4.8). Vemos que o ruído da densidade de infectados tende a uma constante a medida que o ruido de $\ln \rho$ assintoticamente tende à 0 . Esses comportamentos não levam a uma transição de ruído infinto, o que é compatível com os resultados dos expoentes críticos já que a criticalidade do sistema não deveria ser afetada, tomando em conta toda discussão feita até esse ponto. 


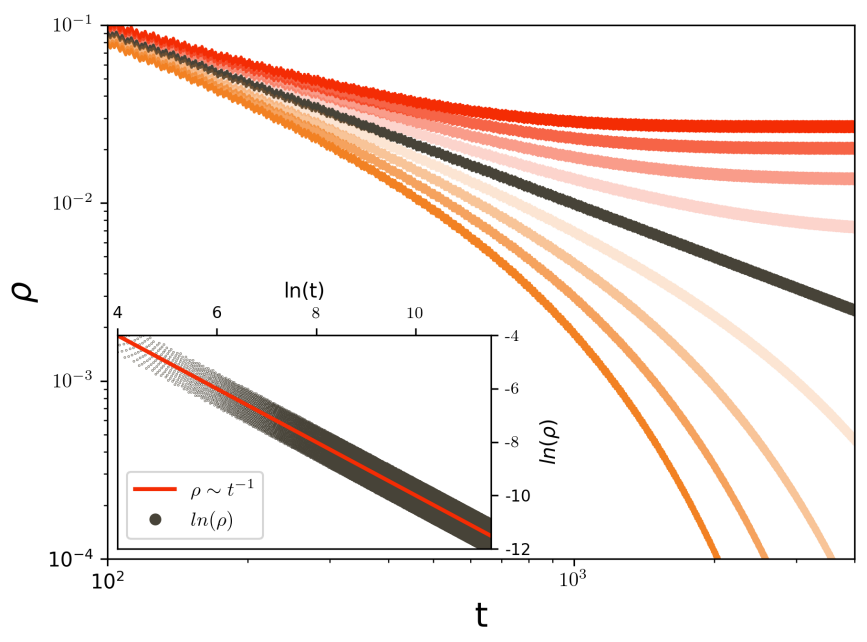

(a)

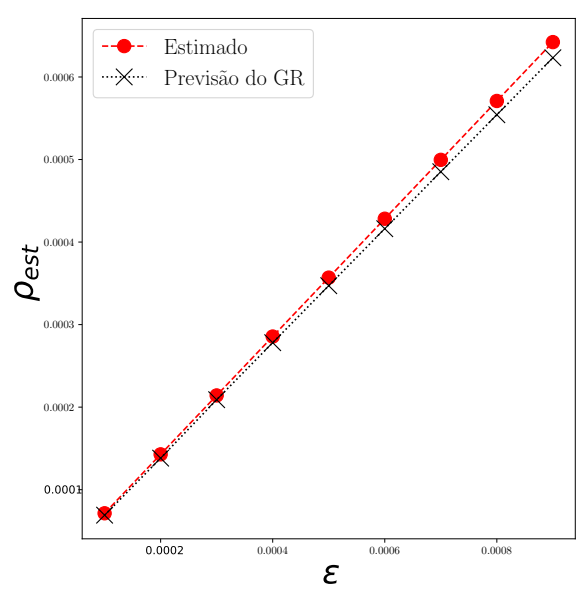

(b)

Figura 4.7: (4.7a) Evolução temporal da densidade de infectados $\rho$ abaixo (representada pelas curvas em laranja), acima (vermelho) e no ponto crítico (preto) com $k=1$. No inset está a curva crítica em maiores detalhes (somente os valores de $\rho$ pada cada tempo, representados por pontos pretos que ficam muito próximos dando a ilusão de uma linha cheia), para tempos maiores. A linha sólida representa o comportamento "limpo". (4.7b) Em círculos estão estimativas das densidades estacionárias $\rho_{e s t}$ para diferentes valores da distância à criticalidade $\epsilon$. Em $\times$ estão as previsões do GR para $\rho_{\text {est }}$ para cada $\epsilon$. Linhas tracejadas não possuem significado e servem para guiar o olho.

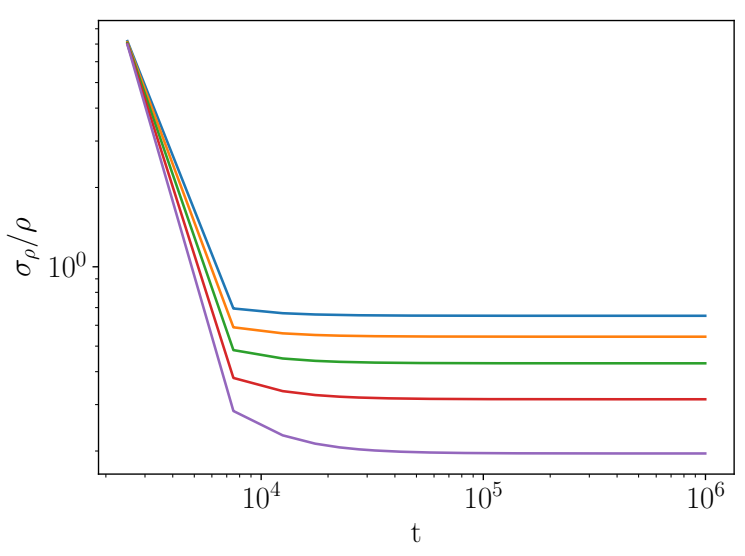

(a)

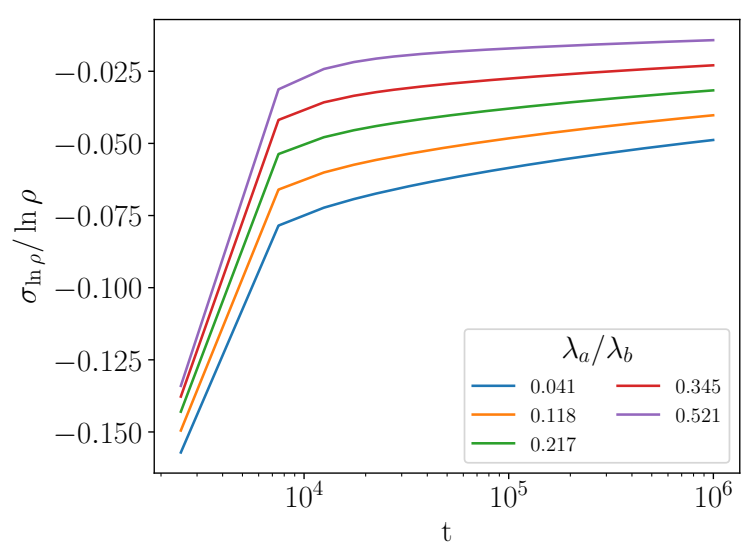

(b)

Figura 4.8: (4.8a) Evolução temporal do ruído da densidade de infectados para o caso $k=1$. O ruído tende a um valor constante para todos valores da modulação $\lambda_{a} / \lambda_{b}$. Todas as curvas representam médias sobre 60 mil condições iniciais aleatórias. (4.8b) Evolução temporal do ruído do logaritmo da densidade de infectados, que tende a um valor constante para todos os casos. 


\subsection{2 $\mathrm{k}=2$}

O caso $k=2$ é particularmente interessante pois ele satura exatamente o critério de estabilidade e para ele a teoria do GR precisa ser adaptado (o que também ocorre no caso de aperiodicidade determinística espacial [13]) devido a degenerescência do autovalor 1, logo uma análise mais detalhada é necessária e está apresentada no apêndice B.

Como $\omega_{2}=0$ é igual a $\omega_{c}=0$ temos que o sistema esta no meio fio entre ser ou não afetado pela desordem. Resultados interessantes saem da iteração numérica, onde observamos que a desordem cresce à medida que o tempo evolui, porém o sistema ainda se comporta de maneira condizente com o caso limpo. Tanto os resultados para o tempo de correlação, exibidos na figura (4.9), como os resultados para a densidade estacionária na fase ativa e a evolução temporal da densidade (figura 4.10b) no ponto crítico são condizentes com o comportamento limpo.

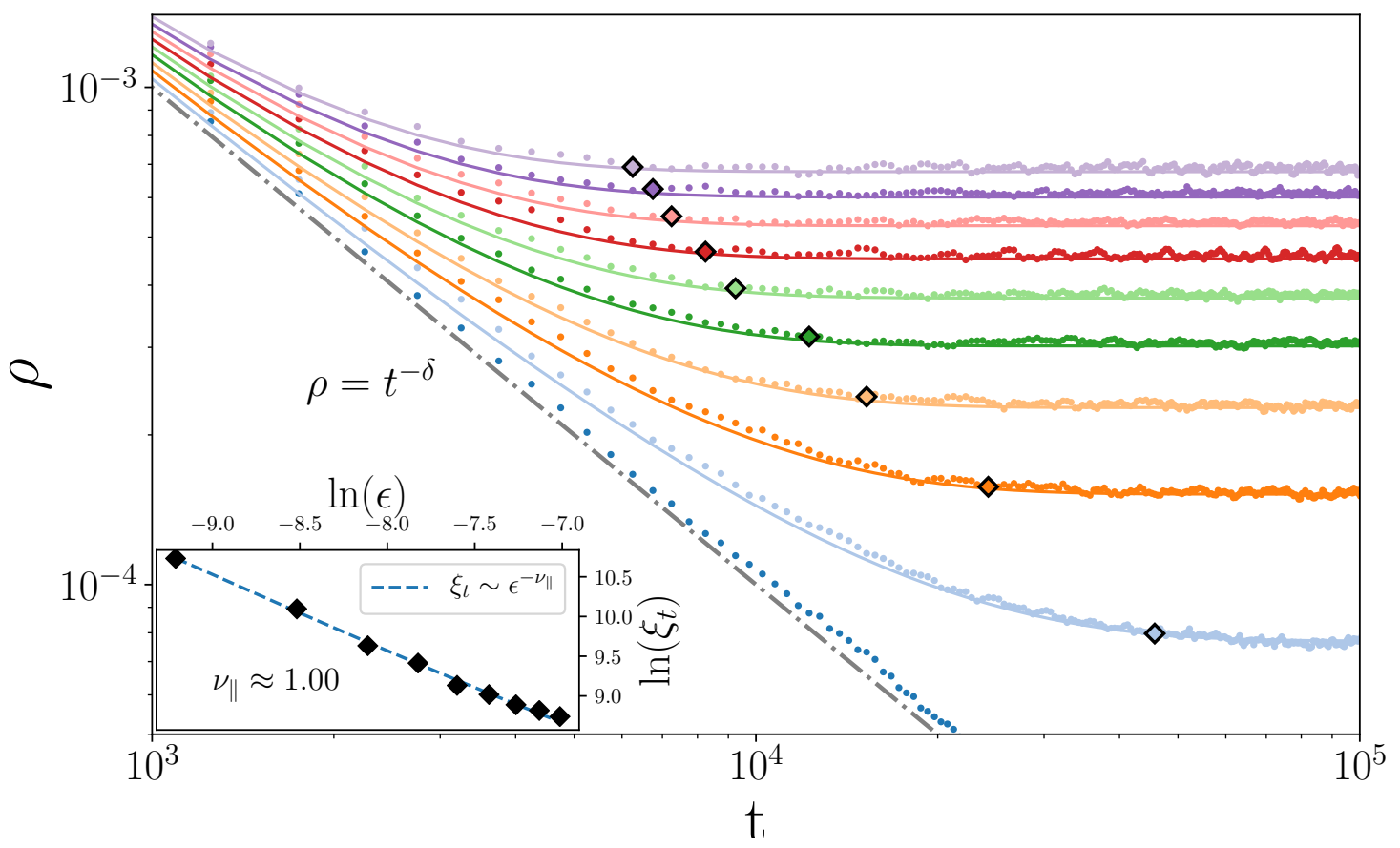

Figura 4.9: Evolução temporal da densidade média $\langle\rho\rangle$ na fase ativa com $k=2$, onde $\lambda_{b}=(1+\epsilon) \lambda_{b}^{*}$ e $\epsilon$ vale, de baixo para cima, 0.0000, 0.0001, ., 0.0009. A linha ponto-tracejada representa o comportamento crítico do sistema "limpo" onde $\rho=t^{-1}$. No inset estão plotados os tempos de correlação contra a distância ao ponto critico, de onde extraímos $\nu_{\|}=1.04(2)$. Linhas cheias são as evoluções com as taxas uniformes correspondentes.

Da análise numérica temos os expoentes

$$
\delta=1.00, \quad \nu_{\|}=1.04(2), \quad \beta=1.00
$$




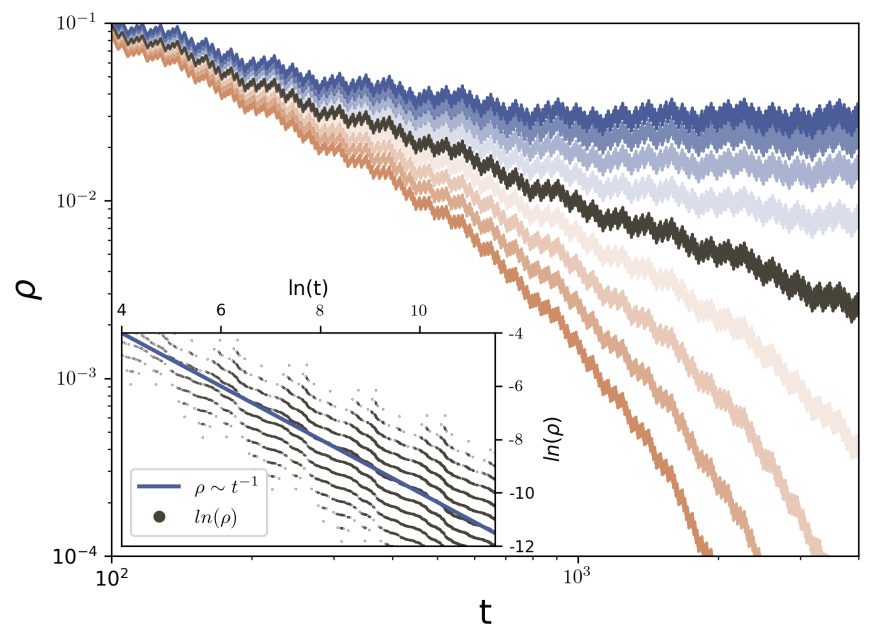

(a)

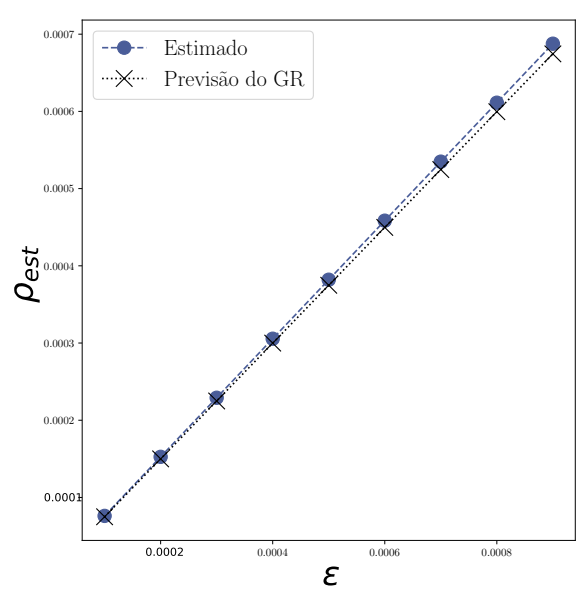

(b)

Figura 4.10: (4.10a) Evolução temporal da densidade de infectados $\rho$ abaixo (bege), acima (azul) e no ponto crítico (preto) para o caso $k=2$. No inset está a curva crítica em maiores detalhes (somente os valores de $\rho$ pada cada tempo, representados por pontos pretos que ficam muito próximos dando a ilusão de que há uma linha cheia em preto), onde observamos que por mais que o grupo se comporte de maneira condizente com o caso limpo, o ruído se torna cada vez mais relevante. (4.10b) Em círculos estão estimativas das densidades estacionárias $\rho_{\text {est }}$ para diferentes valores da distância à criticalidade $\epsilon$. Em $\times$ estão as previsões do GR para $\rho_{\text {est }}$ para cada $\epsilon$. 


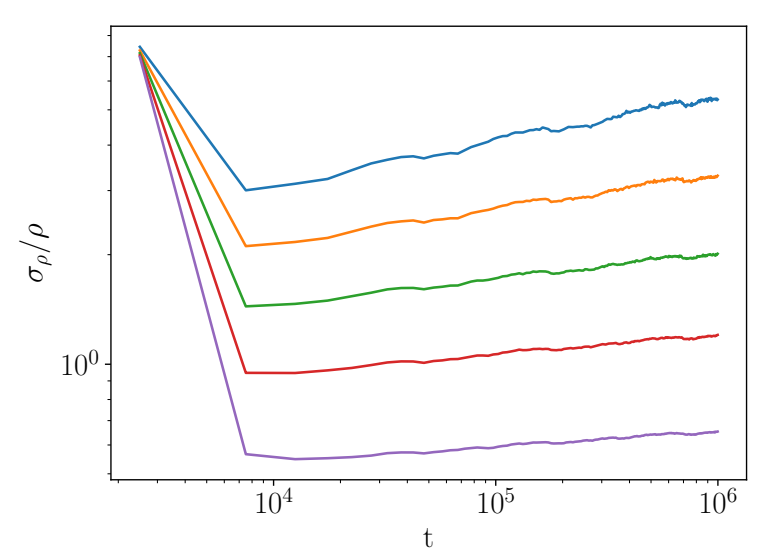

(a)

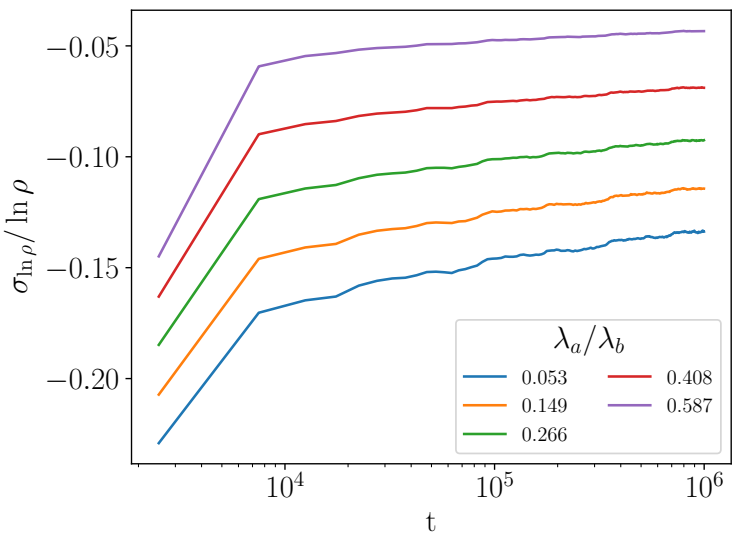

(b)

Figura 4.11: (4.11a) Evolução temporal do ruído da densidade de infectados para o caso $k=2$. Assim como no caso $k=1$ as curvas representam médias sobre 60 mil condições iniciais. Vemos que o ruído aumenta com o passar do tempo, o que caracteriza uma transição de ruído infinito, por mais que os expoentes críticos não tenham sido afetados pela desordem. (4.11b) Evolução temporal do ruído do logaritmo da densidade de infectados, que alcançam valores estacionários não nulos.

que também são condizentes com os expoentes "limpos". Já o ruído da densidade de infectados cresce a medida que o ruído do logaritmo da densidade tende a uma constante, como observado na figura (4.11). Nesse caso, porém, o ruído diverge de uma forma que não é compatível com o comportamento de desordem infinita observado no caso de desordem temporal aleatória descorrelacionada, o que é muito interessante pois por mais que os expoentes críticos não tenham sido afetados o sistema ainda apresenta flutuações que divergem a medida que $t \rightarrow \infty$, reforçando o caráter marginal do caso $k=2$.

\subsection{3 $\mathrm{k}=3$}

No caso $k=3$ o critério de estabilidade nos diz que a desordem é relevante e deve afetar o comportamento crítico. O GR prevê expoentes críticos diferentes do caso limpo e tanto $\ln a_{n}^{++} \operatorname{como} \ln a_{n}^{--} \operatorname{divergem~rapi-}$ damente. A presença intensa do ruído é facilmente observada na evolução temporal da densidade $\rho$, como exibido na figura (4.14a). O comportamento crítico é fortemente afetado por flutuações log-periódicas que fazem $\rho$ sempre voltar a um valor fixo, somente para cair violentamente em seguida. Tal efeito pode ser observado na figura (4.14a).

Os tempos de correlação podem ser estimados como nos casos anteriores, porém a presença do ruído torna sua estimativa mais difícil e aumenta a incerteza associada. Uma forma de amenizar esse ruido e estimar os expoentes críticos é colapsando as curvas, o que pode ser feito introduzindo a reescala $\rho \rightarrow \rho / \epsilon^{\beta}$ e $t \rightarrow t / \epsilon^{-\nu_{\|}}$. Utilizando os expoentes previstos $\left(\beta=1.0\right.$ e $\left.\nu_{\|}=1.46\right)$ observamos um colapso aceitável, como pode ser 
observado na figura (4.12)

Para efeito de comparação, se estimarmos o tempo de correlação diretamente da evolução temporal de $\rho^{2}$ obtemos $\nu_{\|} \approx 1.43(6), \delta \approx 0.68$, e $\beta=1.00$. Gráficos dos tempos de correlação com a curva crítica e da densidade estacionária estão exibidos, respectivamente, nas figuras (4.13) e (4.14b).

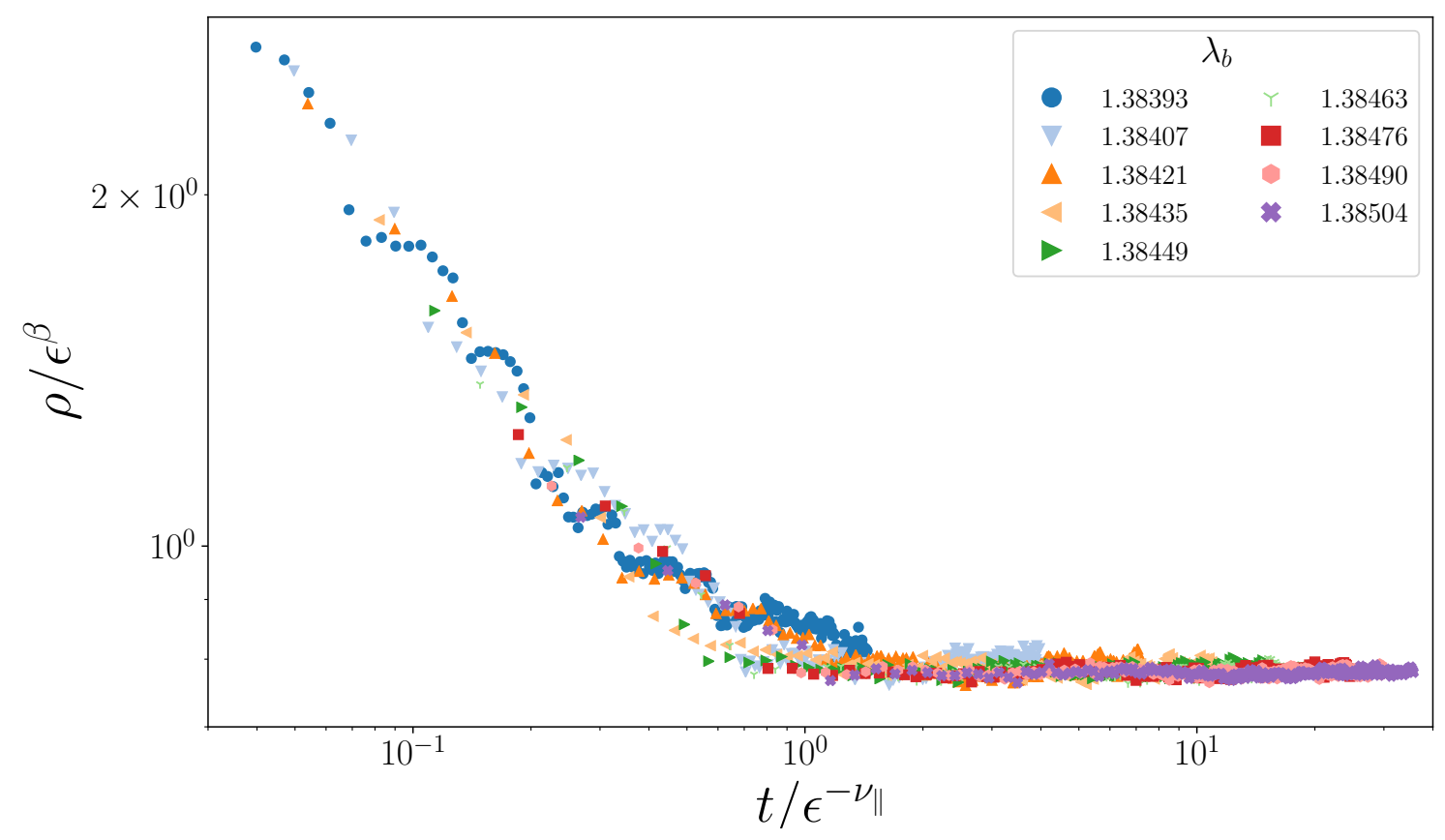

Figura 4.12: Colapso da evolução temporal da densidade $\rho$ para diferentes valores de $\lambda_{b}$ utilizando as reescalas $\rho \rightarrow \rho / \epsilon^{\beta}$ e $t \rightarrow t / \epsilon^{-\nu_{\|}} \operatorname{com} \beta=1.0$ e $\nu_{\|}=1.46$. Nesse caso temos que $k=3$.

Já o comportamento do ruído da densidade de infectados e de seu logaritmo podem ser observados na figura (4.15), onde notamos que o ruído de $\rho$ diverge e de $\ln \rho$ tende a ficar constante. Esses comportamentos sugerem uma transição de ruído infinito, o que também é observado no caso de desordem aleatória temporal como discutido no capítulo 3 .

Resumimos todos os expoentes críticos encontrados na seguinte tabela:

\footnotetext{
${ }^{2}$ Tais estimativas foram feitas pegando o primeiro ponto compatível dentro de três incertezas com a média dos últimos 500 pontos.
} 


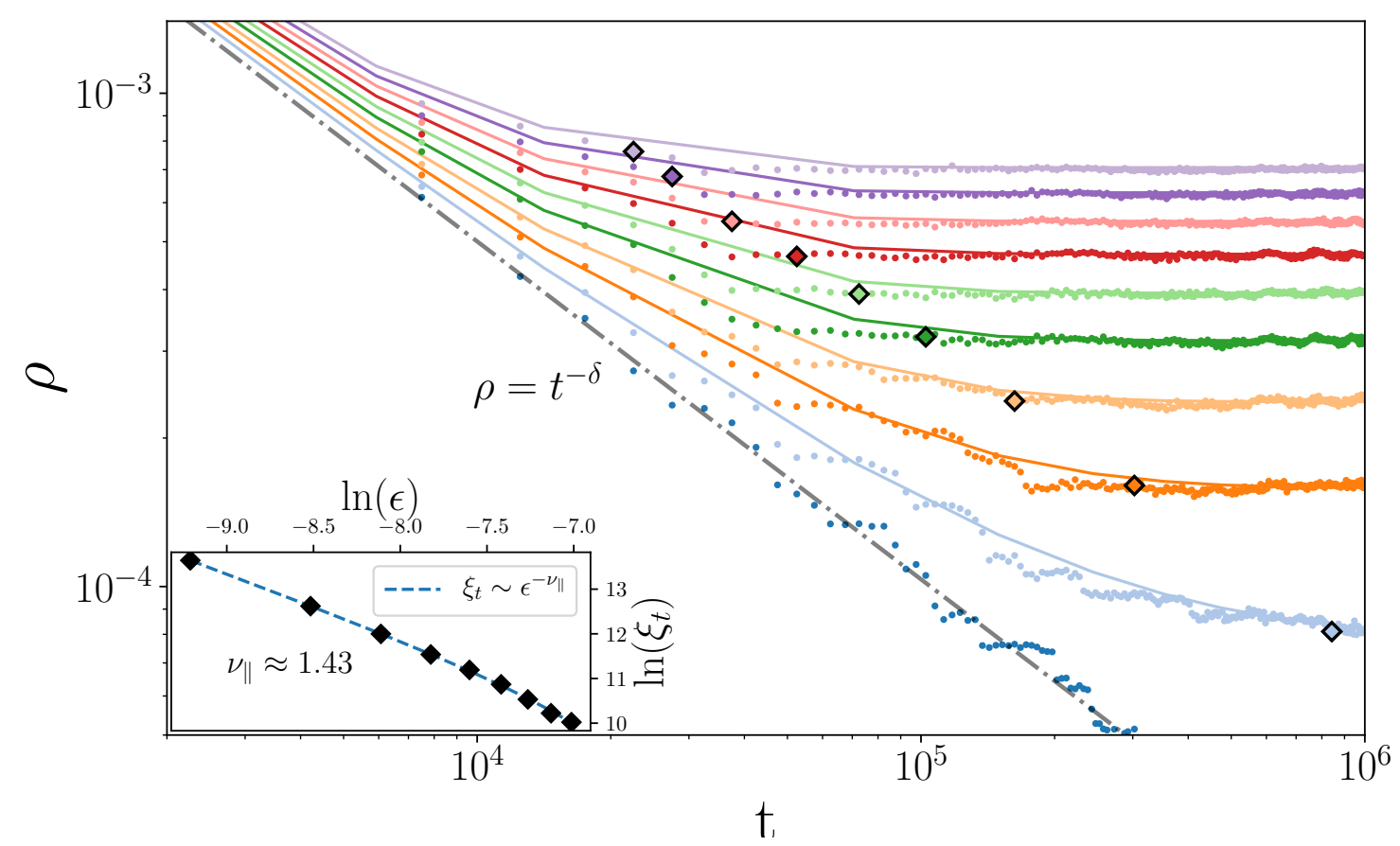

Figura 4.13: Evolução temporal da densidade média $\langle\rho\rangle$ na fase ativa para $k=3$. A linha ponto-tracejada representa um ajuste $\rho \sim t^{-\delta}$ de onde extraímos $\delta \approx 0.68$. Os losangos contornados em preto representam a estimativa do tempo de correlação $\xi_{t}$. No inset estão plotados os tempos de correlação contra a distância ao ponto critico, de onde extraímos $\nu_{\|} \approx 1.43(6)$. As linhas cheias são as evoluções de $\rho$ no caso uniforme porém com as taxas iguais aos seus valores na média configuracional correspondente.

\begin{tabular}{|c|c|c|c|c|c|c|c|}
\hline Expoente & \multicolumn{3}{|c|}{ GR } & \multicolumn{3}{c|}{ Numérico } & Limpo \\
\hline & $k=1$ & $k=2$ & $k=3$ & $k=1$ & $k=2$ & $k=3$ & \\
\hline$\beta$ & 1.00 & 1.00 & 1.00 & 1.00 & 1.00 & 1.00 & 1.00 \\
$\nu_{\|}$ & 1.00 & $1.04(2)$ & 1.46 & 1.00 & $1.04(2)$ & 1.46 & 1.00 \\
$\delta$ & 1.00 & $0.96(4)$ & 0.685 & 1.00 & $0.96(4)$ & 0.68 & 1.00 \\
\hline
\end{tabular}

Tabela 4.1: Expoentes críticos para a equação logística com desordem aperiódica determinística temporal estimados para diferentes valores de $k$. São exibidos, também, os valores do caso limpo para efeitos de comparação. 


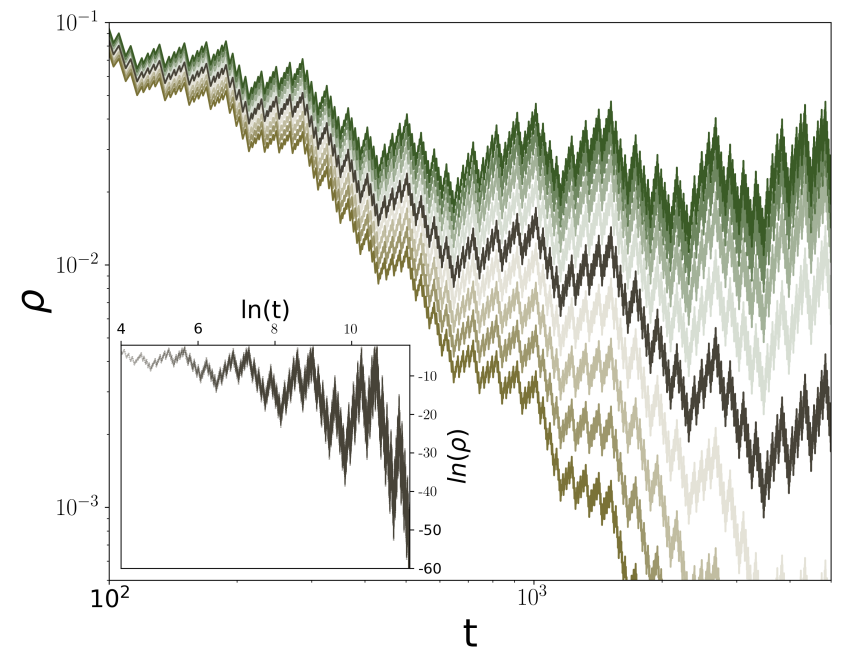

(a)

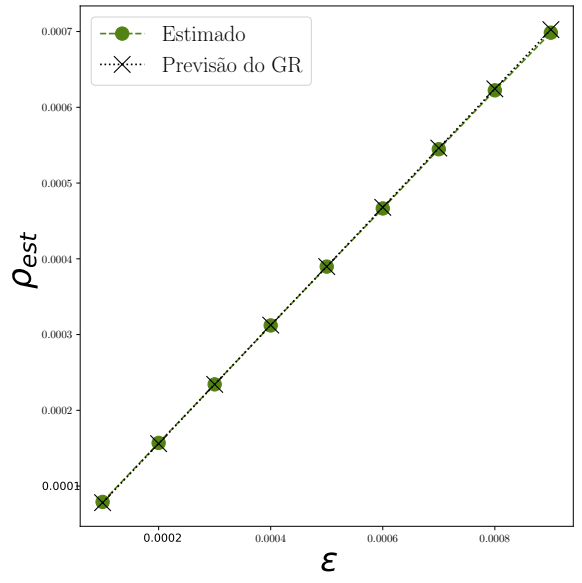

(b)

Figura 4.14: (4.14a) Evolução temporal da densidade de infectados $\rho$ (partindo de uma única condição inicial) abaixo (marrom), acima (verde) e no ponto crítico (preto) para o caso $k=3$. No inset está a curva crítica em maiores detalhes. Realçamos o forte ruído, que leva a densidade de infectados de valores em torno de $10^{-60}$ até $10^{-1}$ rapidamente. (4.14b) Em círculos estão estimativas das densidades estacionárias $\rho_{\text {est }}$ para diferentes valores da distância à criticalidade $\epsilon$. Em $\times$ estão as previsões do GR para $\rho_{\text {est }}$ para cada $\epsilon$.

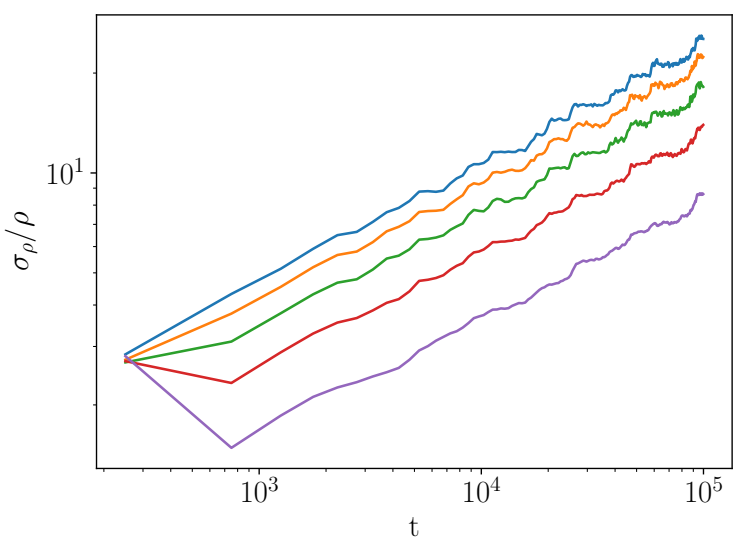

(a)

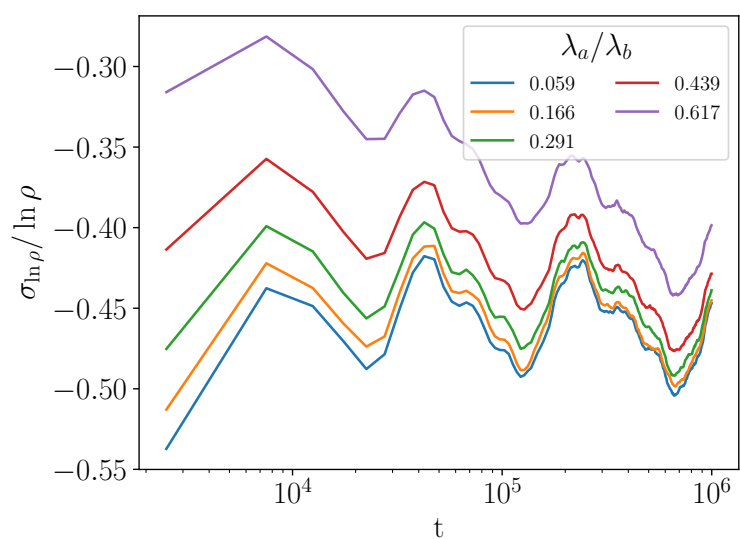

(b)

Figura 4.15: (4.15a) Evolução temporal do ruído da densidade de infectados para o caso $k=3$. Há, nesse caso, em aumento visível no ruído que caracteriza uma transição de ruído infinito. (4.15b) Evolução temporal do ruído do logaritmo da densidade de infectados, que oscilam fortemente. 


\section{Capítulo 5}

\section{Processo de Contato com Aperiodicidade Temporal}

Esse capítulo é dedicado ao processo de contato (discutido no capítulo 3.1) com desordem determinística temporal. Ao contrário do caso espacial, a desordem temporal não deve criar as "ilhas" de sítios fortemente correlacionados como observado na figura (3.7), porém ela deverá afetar todos os sítios ao mesmo tempo. Iremos investigar como essa diferença irá afetar o comportamento crítico do CP.

Diferentemente da equação logística, que não possui nenhuma noção de espaço e nem de dimensionalidade, o processo de contato é definido em uma rede espacial de dimensão $d$. Introduzimos a desordem temporal como fizemos antes, assumindo que, durante intervalos de tempo de duração $\Delta t$, as taxas $(\mu, \lambda)$ alternam entre os valores $\left(\mu_{a}, \lambda_{a}\right)$ e $\left(\mu_{b}, \lambda_{b}\right)$ de acordo com a sequência generalizada de Fibonacci. Assumindo sem perda de generalidade que $\lambda_{b}>\lambda_{a}$ teremos que o sistema irá oscilar entre intervalos onde a dinâmica de infecção prevalece e intervalos onde a cura é predominante, como pode ser facilmente observado na figura (5.1).

Para o caso limpo do CP temos que os expoentes críticos são [34]:

$$
\beta=0.276, \quad \nu_{\|}=1.734, \quad \delta=0.1594, \quad \theta=0.3137 .
$$

Podemos então aplicar o critério de estabilidade do ponto crítico discutido na seção 2.3.2:

$$
\omega_{c}=1-\frac{1}{\nu_{\|}},
$$

que numericamente, para o CP, têm o valor $\omega_{c} \approx 0.42329$. Para os diferentes casos de $k$ temos que o expoente $\omega_{k}$ assume os valores $\omega_{1}=-1, \omega_{2}=0, \omega_{3} \approx 0.3171$ e $\omega_{4} \approx 0.4738$. Isso nos leva à conclusão que para o CP a desordem temporal só será relevante para $k \geq 4$, o que é diferente de todos os modelos com desordem aperiódica determinística que discutimos até esse ponto, pois para eles o caso $k=3$ já viola o critério de estabilidade. Para desordem aleatória temos que $\omega=0.5$, logo o critério determina que desordem puramente aleatória também deve ser relevante, o que já foi verificado anteriormente [46]. 


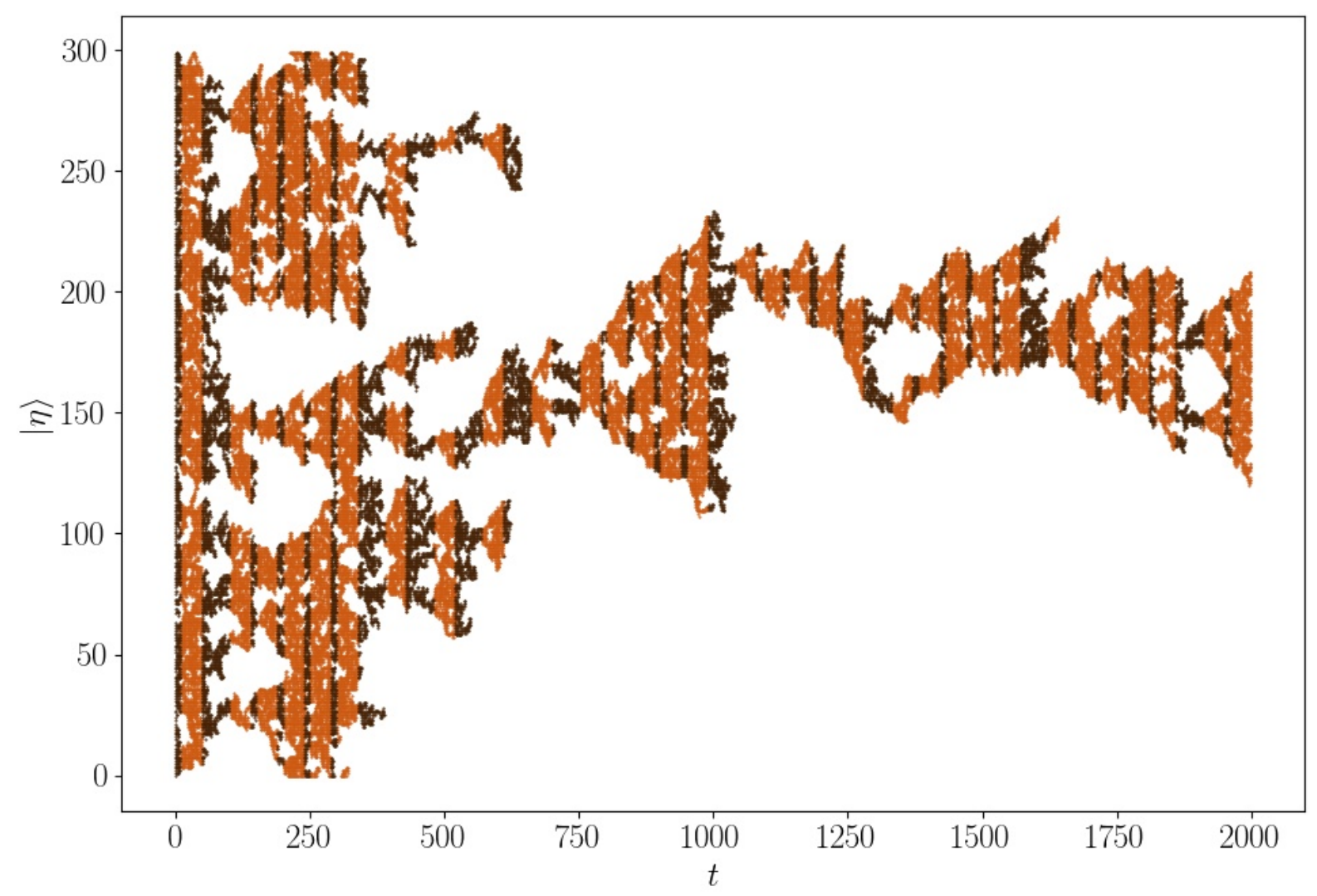

Figura 5.1: Evolução temporal da configuração $|\eta\rangle$ dos sítios de uma rede onde se toma um processo de contato com desordem temporal determinística com $k=4$. Pontos em laranja representam intervalos onde $\lambda=\lambda_{b}>\lambda_{a}$ e o processo de infecção é mais acentuado e pontos em marrom o caso $\lambda=\lambda_{a}$ onde o processo de cura predomina. Partimos de uma rede inteiramente ativa com $\Delta t=5$ e $\lambda_{a}=1.8$ e $\lambda_{b}=18.0$.

O caso $k=4$ está acima de $\omega_{c}$ crítico mas somente por um pouco, então esperamos ver alterações menos pronunciadas do que nos outros casos. Partimos então para adaptar nossa teoria ao CP e estudar o comportamento crítico do sistema.

\subsection{Grupo de Renormalização}

Como o processo de cura não depende das vizinhanças de um sítio nem da dimensão $d$, podemos considerar que durante trechos onde $\lambda<\mu$ o decaimento da densidade $\rho$ ainda será exponencial, assim como na equação logística. Já para o processo de infecção a dimensionalidade têm efeito. Nesse caso temos que $\lambda>\mu$ e a densidade irá crescer de forma não trivial e no máximo balisticamente quando $\lambda \gg \mu$, onde $\rho(t)=\rho_{0}(1+b t)$ e $b$ é a constante balística. Isso nos força a modificar o grupo de renormalização para incluir esse comportamento.

Essa análise teórica permanece como uma questão em aberto. Iremos, nas próximas seções, apresentar a 
teoria desenvolvida até esse ponto, por mais que ela apresente limitações (que serão devidamente discutidas).

\subsubsection{Adaptação do GR}

Podemos tentar adaptar o GR nos inspirando no tratamento apresentado na referência [46], que formula um GR para o processo de contato com desordem temporal aleatória. Começamos fazendo a hipótese de que a desordem é forte, logo em trechos onde $\lambda \ll \mu$ a densidade irá decair exponencialmente assim como na equação logística

$$
\rho(t)^{-1}=a_{n} \rho_{0}^{-1}
$$

onde $a_{n} \equiv \exp \left[\left(\mu-\lambda_{n}\right) \Delta t\right]$ e a relação de renormalização para trechos de descida da densidade $\rho$ não precisa ser modificada:

$$
\tilde{a}^{d n}=\frac{a_{i}^{d n} a_{i+1}^{d n}}{\Omega}
$$

Já os trechos de subida da densidade precisam ser modificados.

Como a desordem é forte podemos aproximar:

$$
\rho(t)=\rho_{0}(1+b t)
$$

logo:

$$
1 / \tilde{a}^{u p}=\left(1+\tilde{b} \tilde{\Delta} t^{u p}\right) \approx\left(\tilde{b} \tilde{\Delta t}{ }^{u p}\right)=\left(b_{i} \Delta t_{i}^{u p}+b_{i-1} \Delta t_{i-1}^{u p}\right)=\frac{1}{a_{i}^{u p}}+\frac{1}{a_{i-1}^{u p}} .
$$

Disso tiramos a nova relação de recursão:

$$
\left(1 / \tilde{a}^{u p}\right)=\left(1 / a_{i}^{u p}\right)+\left(1 / a_{i-1}^{u p}\right)-\Omega,
$$

onde o último termo foi adicionado à mão para preservar o comportamento correto no caso onde $a_{i}^{u p}=a_{i-1}^{u p}=$ $1 / \Omega$.

Prosseguindo como fizemos com a equação logística, agrupamos todos os intervalos consecutivos onde $a_{n}<1$ e $a_{n}>1$ em intervalos $a^{++}, a^{-}$e $a^{--}$. A diferença será que os intervalos balísticos serão combinados de maneira aditiva:

$$
\rho_{0}(1+\tilde{b} \tilde{\Delta} t)=\rho_{0}[1+b(k \Delta t)] \Rightarrow a_{0}^{++}=(k b \Delta t)^{-1} .
$$

Buscamos então eliminar os intervalos com $a_{n}$ mais próximo de 1, assim como fizemos para a equação logística. Teremos novamente que somente um agrupamento é possível a cada passo e precisamos realizar dois passos para preservar a estrutura da rede. De maneira completamente análoga chegamos às relações:

$$
\begin{aligned}
\left(a_{n+1}^{++}\right)^{-1} & =(k+1)\left(a_{n}^{++}\right)^{-1}-k a_{n}^{-} \\
a_{n+1}^{-} & =a_{n}^{--} \\
a_{n+1}^{--} & =\left(a^{++}\right)^{k}\left(a^{--}\right)^{k+1}
\end{aligned}
$$




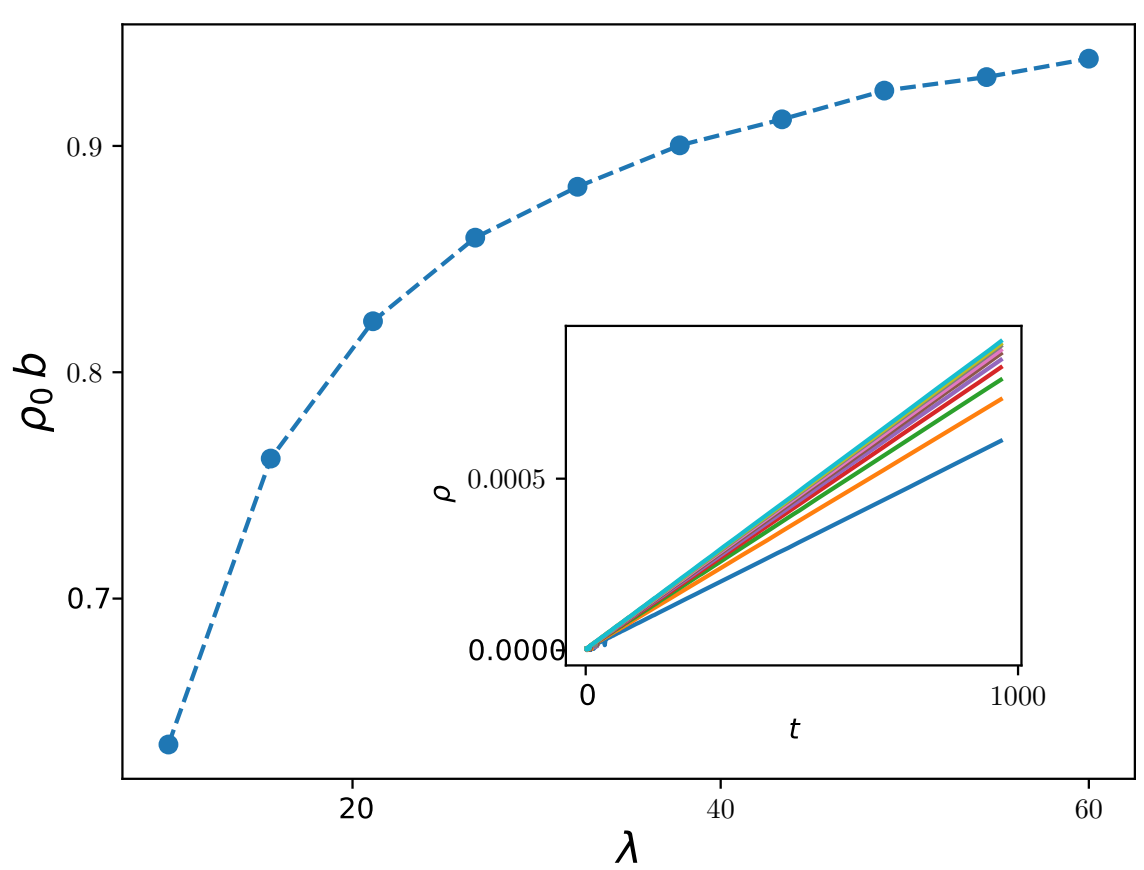

Figura 5.2: Parâmetros $\rho_{0} b$ para diferentes valores de $\lambda \gg \lambda_{c}$, onde $\lambda_{c} \approx 3.3$. Valores representam médias sobre 1000 simulações de sistemas de tamanho $10^{6}$, partindo de um único sítio infectado. No inset estão as evoluções temporais das densidades $\rho$ para cada valor de $\lambda$, apenas para visualizar se a aproximação de espalhamento balístico é razoável.

onde $a_{0}^{++}=(k b \Delta t)^{-1}, a_{0}^{-}=\exp \left[\left(\mu-\lambda_{a}\right) \Delta t\right]$ e $a_{0}^{--}=\exp \left[(k+1)\left(\mu-\lambda_{a}\right) \Delta t\right]$ são as condições iniciais dos parâmetros.

A constante balística $b$ pode ser encontrada numericamente simulando um CP limpo e realizando um ajuste $\rho=\rho_{0}(1+b t)$ para tempos pequenos (antes que efeitos de tamanho finito tomem ação). O resultado dessa análise está na figura (5.2). Se fixarmos $\lambda_{a}=1.3$ e $\mu=1$ temos que as simulações de Monte Carlo indicam o valor crítico $\lambda_{b} \approx 51$ para $k=4$, logo o valor crítico esperado da constante balística deve ser da ordem de $\sim 0.92$.

Iterando numericamente o sistema de equações 5.2 a 5.4 para as condições iniciais citadas anteriormente observamos uma mudança de comportamento para as taxas $a^{-}$e $a^{--}$, porém para valores de $b$ bem distantes do esperado: $b_{c} \approx 0.19$. Tal iteração numérica está exibida na figura (5.3).

Temos então que a adaptação do GR consegue prever uma transição de fase, porém dua forma analítica é de difícil solução e sua implementação numérica se provou extremamente sensível aos parâmetros iniciais. Estes fatores tornam essa abordagem um desafio que ainda precisa ser resolvido.

Em sua forma atual, a nossa análise se resume à iteração numérica das relações de recursão. Uma possível explicação para a discrepância na precisão dos parâmetros críticos é o fato de talvez termos que 

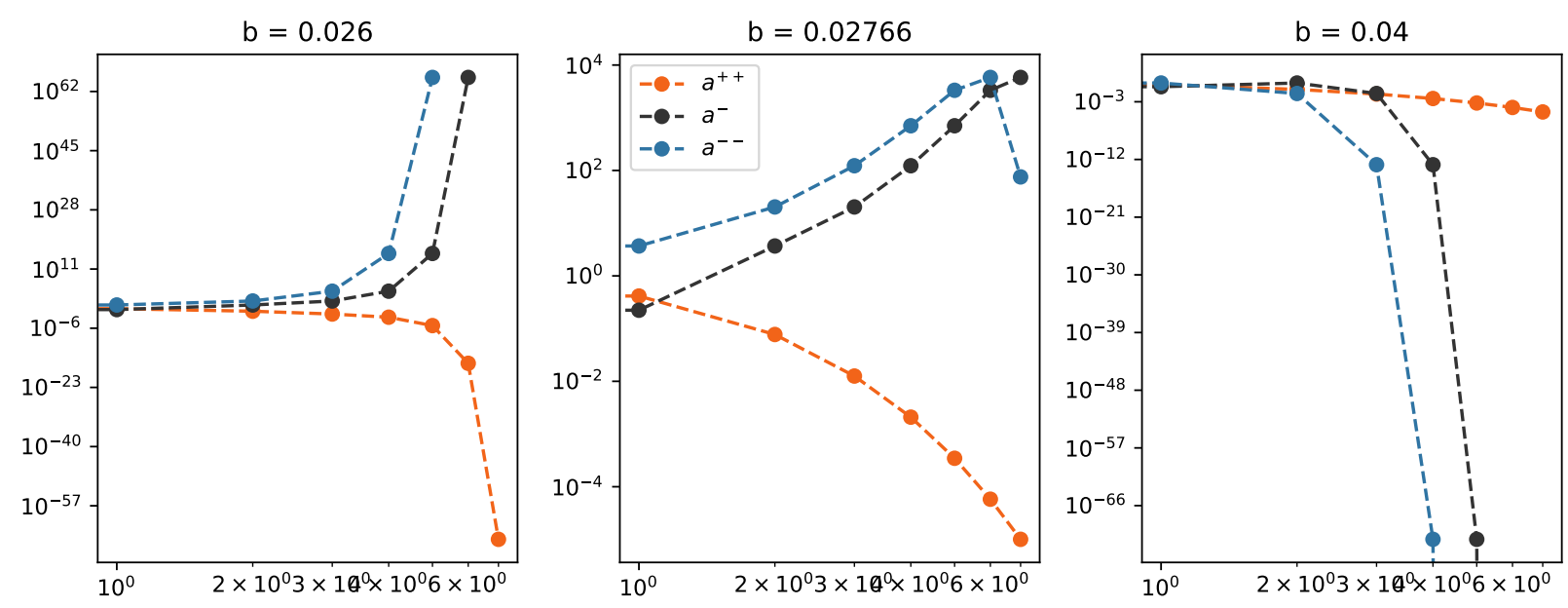

Figura 5.3: Iteração numérica do grupo de renormalização para diferentes valores de $\rho_{0} b$ com $\lambda_{a}=1.3$. Observamos uma mudança de comportamento nos arredores do valor $b=0.027$, que está bem longe dos valores típicos encontrados para $b$ simulando o caso limpo.

usar desordens ainda mais fortes para que as hipóteses de espalhamento balístico nos trechos de subida e decaimento exponencial igual ao da equação logística nos trechos de descida sejam válidas.

\subsubsection{Abordagem Alternativa}

Outra possível abordagem para o problema é através do formalismo de operadores. Se considerarmos um espaço vetorial onde os vetores da base são dados por $|\eta\rangle=\left|\eta_{1} \eta_{2} \ldots \eta_{N}\right\rangle$ temos que a evolução do vetor probabilidade $|\Psi(t)\rangle$ pode ser escrita como:

$$
\frac{\mathrm{d}}{\mathrm{d} t}|\Psi(t)\rangle=S|\Psi(t)\rangle
$$

onde o operador de evolução $S$ é dado por [34]:

$$
S=\frac{\lambda}{z}\left(\mathcal{A}_{i}+\mathcal{A}_{i}^{\dagger}-\mathbb{1}\right)\left(\mathbb{1}-\mathcal{N}_{i}\right) \sum_{\delta} \mathcal{N}_{i+\delta}+\sum_{i} \mathcal{N}_{i}
$$

onde $z$ é a coordenação da rede, $\mathcal{A}$ e $\mathcal{A}^{\dagger}$ são os operadores de aniquilação e criação e $\mathcal{N}$ é o operador número. As somas em $\delta$ significam somas entre todos os primeiros vizinhos. Como há desordem temporal o operador $S$ depende do tempo, logo não é possível simplesmente usar um ansatz exponencial para continuar as contas. Temos ainda que os operadores $S_{a}$ e $S_{b}(S$ em intervalos do tipo " $A$ " e " $B$ ", respectivamente) também não comutam. Para continuar com a abordagem com operadores se torna necessário encontrar uma expressão para

$$
S_{n}=\prod_{i=0}^{n} S_{i}
$$

onde as taxas do sistema oscilam de acordo com a sequência de Fibonacci. Com esse resultado seria possível realizar um tratamento perturbativo para estudar o comportamento crítico do sistema sem mesmo utilizar a 
abordagem por grupo de renormalização.

Ambos tratamentos teóricos elencados possuem sérias dificuldades analíticas que ainda não foram resolvidas e representam questões que ainda podem ser exploradas em estudos subsequentes.

\subsection{Simulações de Monte Carlo}

\subsubsection{Algoritimos e Metodologia}

Para estimar o efeito da aperiodicidade determinística e testar as previsões do critério de estabilidade realizamos simulações de Monte Carlo do CP com desordem temporal determinística. Nosso sistema pode ser caracterizado pela taxa de cura $\mu$ uniforme na rede, fixada em 1 por simplicidade, e pela taxa de infecção $\lambda(t)$ que oscila entre os valores $\lambda_{b}>\lambda_{a}$ em intervalos de tempos de tamanho $\Delta t$ (também fixada em 1), seguindo a sequência generalizada de Fibonacci. O algoritmo para simular esse sistema consiste nas seguintes etapas:

1. Com $t=0$ sortear uma distribuição inicial de sítios ativos;

2. Verificar se o tempo $t$ pertence a um intervalo do tipo " $A$ " ou " $B$ " e ajustar a taxa $\lambda$ de acordo;

3. Escolher aleatoriamente um sítio ativo e sortear entre os eventos:

- Cura com probabilidade $\mu /(\lambda+\mu)$,

- Infecção à esquerda com probabilidade $(\lambda / 2) /(\mu+\lambda)$,

- Infecção à direita com probabilidade $(\lambda / 2) /(\mu+\lambda)$.

4. Incrementar o tempo em $1 / N_{a}$, onde $N_{a}$ é o número de sítios ativos na rede;

5. Se o tempo não alcançou seu limite voltar ao passo (2), caso contrário terminar.

Usando esse algoritmo podemos estudar os casos $k=1,2,3,4$ e 5 e testar as previsões do critério de estabilidade. Para encontrar o ponto crítico utilizamos um segundo algoritmo de "bissecção", que consiste em:

1. Fixar $\lambda_{a}$ em um valor condizente com a fase absorvente (i.e. $\lambda_{a}<3.298$ [34]) e estabelecer um limite superior e inferior para $\lambda_{b}$, um que certamente está na fase ativa $\left(\lambda_{\text {inf }}\right)$ e um que está certamente na fase ativa $\left(\lambda_{\text {sup }}\right)$.

2. Realizar simulações do CP com $\lambda_{b}=\left(\lambda_{\text {inf }}+\lambda_{\text {sup }}\right) / 2$ até um certo tempo $t_{\max }$. Começar cada simulação em partes diferentes da sequência de Fibonacci para amenizar as flutuações geométricas (assim como fizemos para a equação logística) mas mantendo as propriedades gerais da sequência.

3. Determinar se com esse valor de $\lambda_{b}$ o sistema se encontra na fase ativa ou absorvente: 
- Se a simulação nem chegou à $t_{\max }$ então ela é inativa. Caso contrário:

- Verificar se a inclinação final da probabilidade de sobrevivência é menor ou maior, em módulo, do que a inclinação inicial dentro de uma tolerância $\epsilon$. Se a inclinação final for maior do que a inicial então caracterizamos a simulação como inativa (está caindo mais do que no começo) e se menor, ativa. Se estiver dentro da tolerância verificamos as inclinações de $m$ conjuntos de $n$ pontos no final da simulação e verificamos se as inclinações só crescem ou só diminuem. Se as inclinações forem compatíveis com 0 então nenhuma simulação "morreu" nesse intervalo e dizemos que estamos na fase ativa. Caso não haja um tendência clara na evolução da inclinação interpolamos uma parábola nos últimos $n$ pontos e analisamos o sinal da concavidade: Se o sinal for negativo então estamos na fase inativa e se for positivo estamos na fase ativa.

4. Se o sistema se encontra na fase ativa, atualizamos o limite superior $\lambda_{\text {sup }}=\lambda_{b}$ e se inativo atualizamos o limite inferior $\lambda_{\text {inf }}=\lambda_{b}$, incrementamos o tempo máximo de simulação e o número total de simulações e retornamos ao passo 2 .

Para cada caso realizamos em torno de $5 \times 10^{4}$ simulações por parâmetro com sistemas de tamanho $10^{6}$ até tempos da ordem de $10^{6}$.

\subsubsection{Resultados para $\mathrm{k}=1$ e $\mathrm{k}=2$}

De acordo com o critério de estabilidade temos que as flutuações temporais fracas irão ser irrelevantes para o comportamento crítico do sistema pois $\omega_{1}=-1$ e $\omega_{2}=0$ que estão abaixo do valor crítico $\omega_{c}=$ $1-1 / \nu_{\|} \approx 0.42329$. Com essas considerações esperamos que para ambos os casos o sistema permaneça na classe da DP.

Para testar essa previsão realizamos simulações com modulações da ordem de $\lambda_{a} / \lambda_{b} \approx 0.4$. Os resultados para a densidade de sítios ativos e a probabilidade de sobrevivência da rede ativa estão exibidos na figura (5.4a). Os expoentes críticos são extraídos realizando ajustes $P_{s} \sim t^{-\delta}$ e $\rho \sim t^{\Theta}$ nas curvas críticas e obtivemos os valores $\delta=0.151(9)$ e $\Theta=0.320(18)$, que são condizentes com os valores limpos $\delta_{\mathrm{DP}}=0.15946$ e $\Theta_{\mathrm{DP}}=0.31369$. Com isso podemos concluir que desordem fraca não afeta a criticalidade nos casos $k=1,2$ e o sistema permanece na classe da DP.

\subsubsection{Resultados para $\mathrm{k}=3$}

Para $k=3$ temos que o expoente de flutuação geométrica assume o valor $\omega_{3} \approx 0.317$, que está levemente abaixo do valor crítico $\omega_{c}$. Com isso podemos esperar que flutuações fracas não devam afetar o comportamento crítico porém que desordens fortes façam aparecer um transiente de oscilações muito lento, assim como o caso $k=2$ para desordens determinísticas espaciais (que nesse modelo é o caso que está levemente abaixo do valor crítico $\left.\omega_{c}\right)$. 
Realizando simulações para valores pequenos de desordem da ordem de $\lambda_{a} / \lambda_{b} \approx 0.5$, representadas na figura 5.4b, onde as modulações foram amenizadas pela média sobre realizações e podemos extrair os expoentes críticos $\delta=0.141(8)$ e $\Theta=0.353(18)$, também condizentes com os valores limpos $\delta_{\mathrm{DP}}=0.159$ e $\Theta_{\mathrm{DP}}=0.313$, porém no limite de três intervalos de confiança em ambos os casos. Para desordens fortes observamos a presença de oscilações, principalmente na fase inativa. Esse comportamento não usual nos faz ter que realizar mais simulações para amenizar o ruído extremamente pronunciado.

Para desordens suficientemente fortes começamos a observar expoentes que não são mais condizentes com os valores limpos. Isso se deve ao fato de que o critério de Harris-Luck (e portanto nossa "generalização temporal" dele) só vale para desordens fracas. Podemos então analisar se existe um valor de desordem a partir do qual o comportamento crítico deixe de ser compatível com o comportamento limpo. Para tal fim realizamos simulações para diferentes valores de desordem e observamos que a medida que a modulação fica mais forte os expoente se afastam dos respectivos valores limpos. Tais resultados estão exibidos na figura $(5.5)$.

\subsubsection{Resultados para $\mathrm{k}=4$ e $\mathrm{k}=5$}

O caso $k=4$ representa a primeira instância onde o critério de estabilidade é violado pois $\omega_{4} \approx 0.47>\omega_{c}$. Porém, ao contrário do caso de desordem determinística espacial onde o caso $k=3$ viola o critério de HarrisLuck, o valor do expoente de flutuação geométrica $\omega$ só excede o valor crítico levemente, o que significa que iremos precisar de desordens relativamente fortes para observar efeitos palpáveis na criticalidade.

Começamos a análise numérica com valores pequenos de desordem. Realizamos 15 passos de bissecção $\operatorname{com} \lambda_{a}=2.5$ e os resultados estão exibidos na figura (5.6a). Dos ajustes $\rho=t^{\Theta}$ e $P_{s}=t^{-\delta}$ temos os valores $\delta=0.141(5)$ e $\Theta=0.365(16)$, que são incompatíveis, dentro de três intervalos de confiança, com os valores limpos, porém marginalmente.

Como o valor do expoente $\omega$ para $k=4$ é apenas um pouco maior do que o valor crítico, esperamos que o impacto da desordem seja sutil, requerendo muitas simulações por tempos longos para ser realmente apreciada numericamente. Podemos então nos voltar para o caso $k=5$ onde decididamente o efeito da desordem deve ser observado. Realizando simulações com os mesmo conjunto de parâmetros iniciais mas com $k=5$ obtemos os expoentes $\delta=0.149(1)$ e $\Theta=0.26(1)$, que decididamente não são compatíveis com os valores limpos. O resultados estão exibidos na figura (5.6b). 

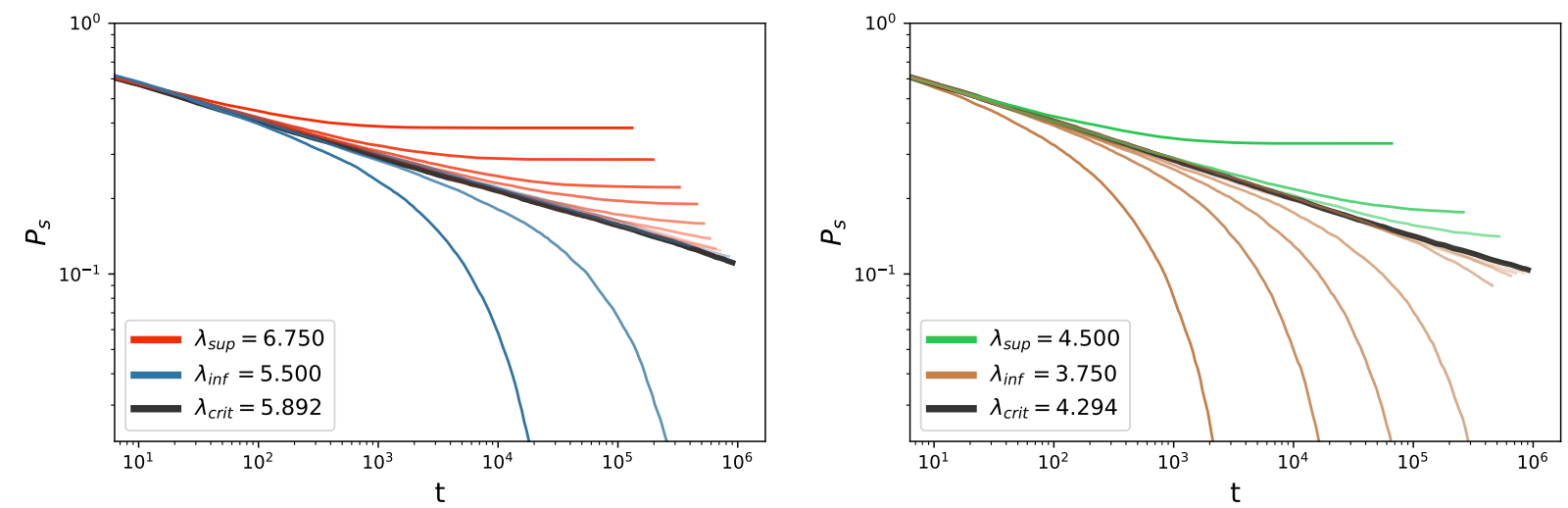

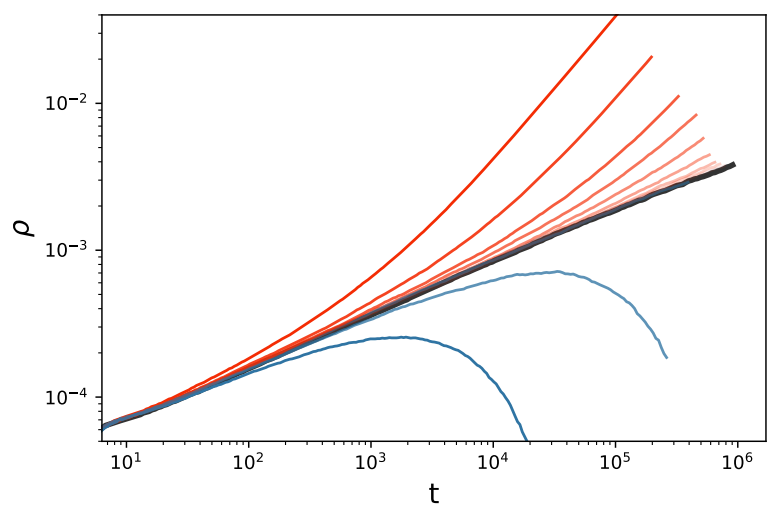

(a)

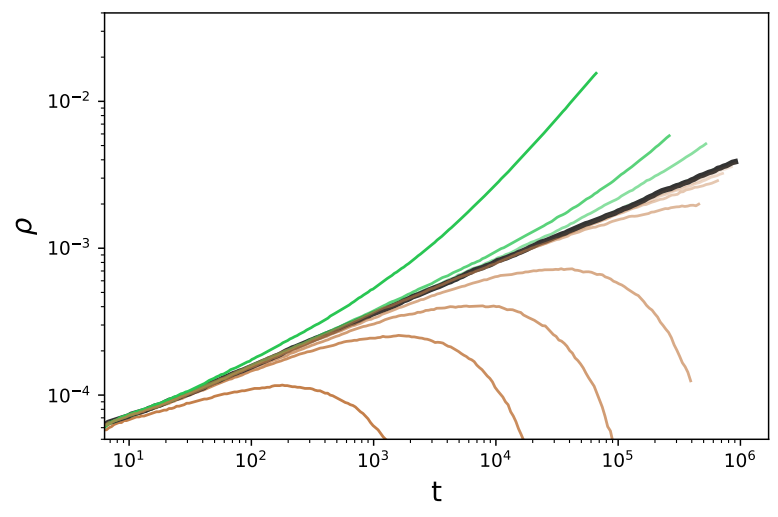

(b)

Figura 5.4: (5.4a) Evolução da densidade de infectados $\rho$ (painel superior) e da probabilidade de sobrevivência $P_{s}$ (painel inferior) da rede ativa para $k=1$. O parâmetro $\lambda_{b}$ crítico foi encontrado realizando 15 passos do algoritmo de bissecção explicado no corpo do texto com $\lambda_{a}=2.5$. Curvas em laranja foram determinadas como ativas pelo algoritmo enquanto curvas em azul foram taxadas de inativas. A curva em preta representa o valor final da bissecção, que é nossa estimativa do parâmetro crítico. (5.4b) Evolução de $\rho$ e $P_{s}$ para o caso $k=3$. Curvas em verde foram determinadas como ativas e curvas em marrom como inativas. 

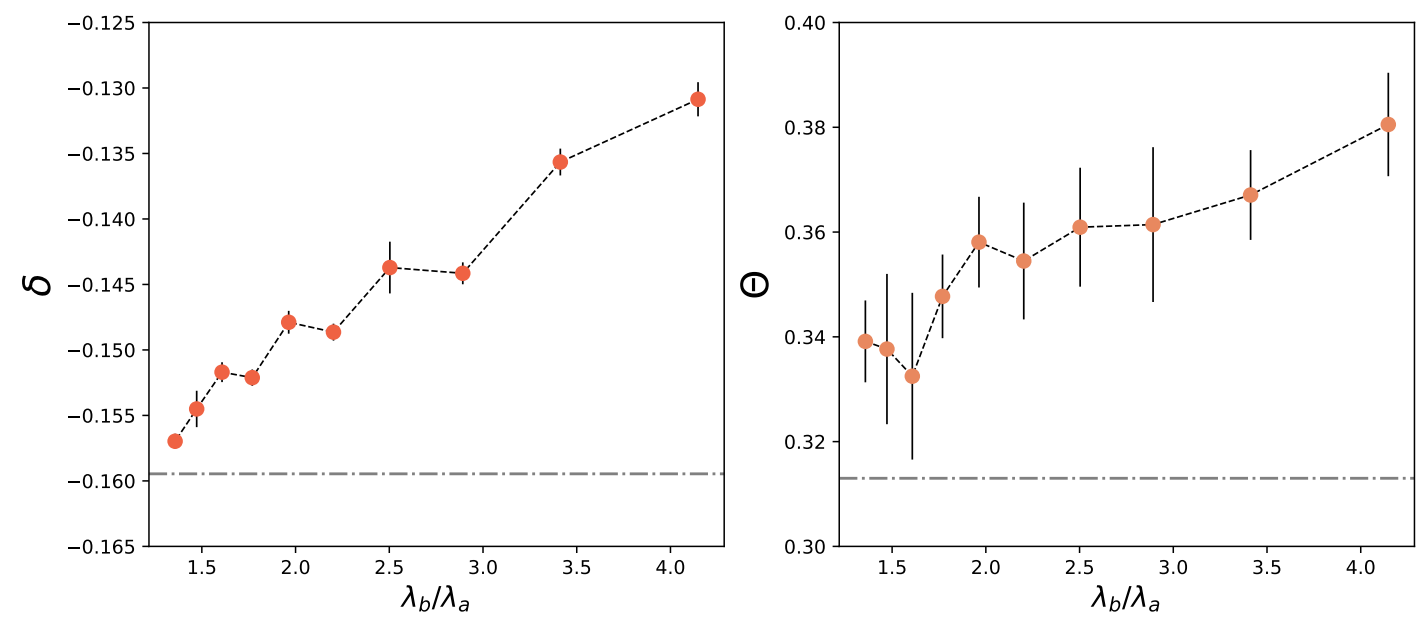

Figura 5.5: Dependência dos expoentes críticos $\delta$ e $\Theta$ com a força da modulação $\lambda_{b} / \lambda_{a}$ para $k=3$. Os valores limpos de cada expoente estão destacados pelas linhas horizontais pontilhadas. As linhas tracejadas não possuem significado e servem apenas para guiar os olhos. 

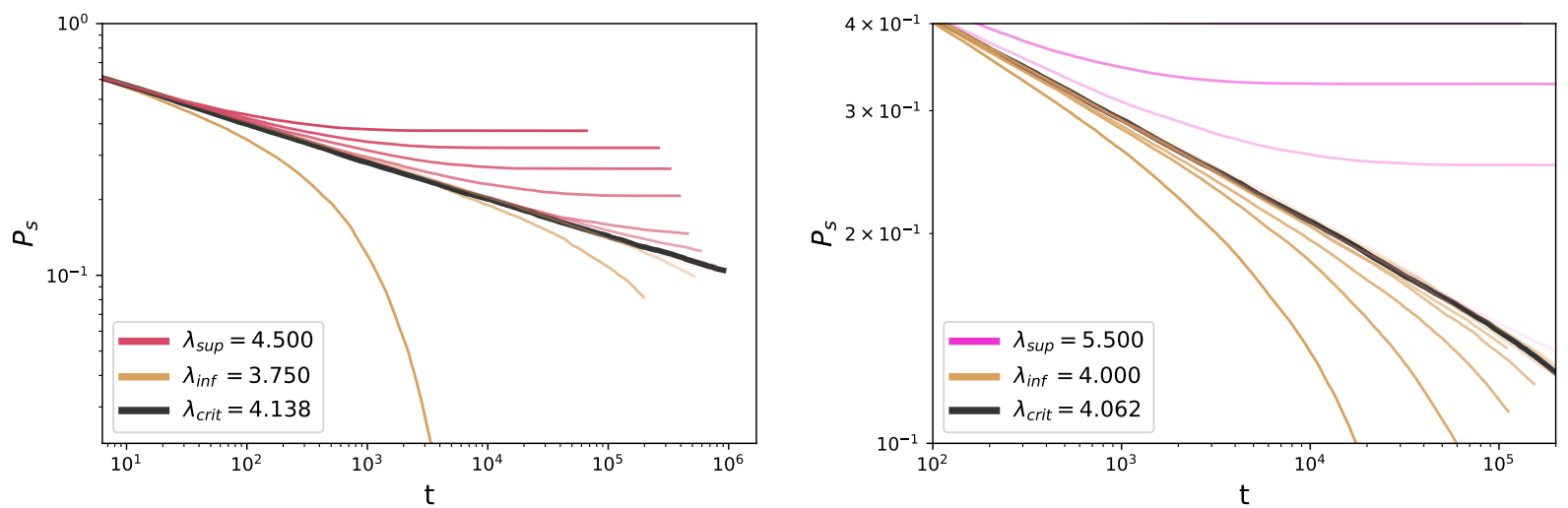

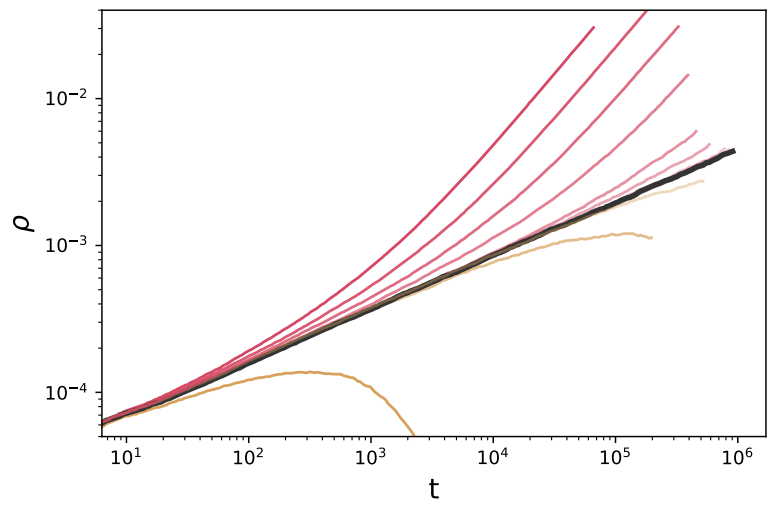

(a)

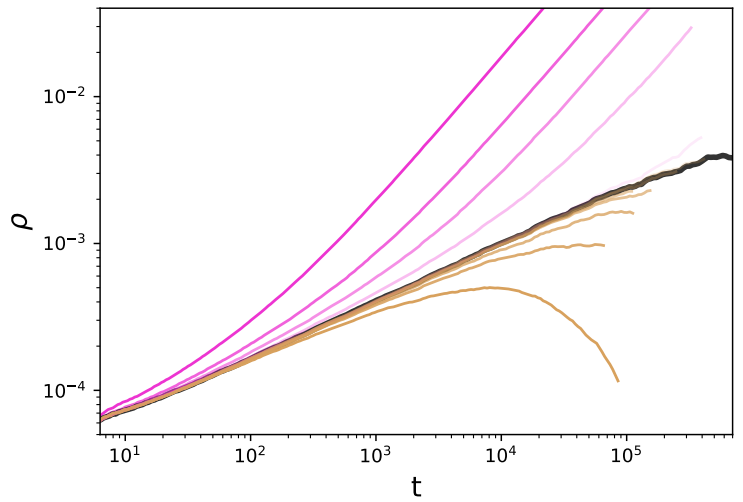

(b)

Figura 5.6: (5.6a) Evolução temporal da densidade $\rho$ e da probabilidade de sobrevivência $P_{s}$ para o caso $k=4$. Foram realizados 15 passos de bissecção entre os parâmetros $\lambda_{\text {sup }}=6$ e $\lambda_{\text {inf }}=3$ (5.6b) Evoluções temporais da densidade e da probabilidade de sobrevivência para o caso $k=5$. Para esse caso foram realizadas $10^{6}$ simulações, cerca de dez vezes mais do que foi feito para os outros casos de $k$. 



\section{Capítulo 6}

\section{Conclusão}

Neste trabalho exploramos os efeitos de desordem determinística aperiódica temporal no processo de contato e em sua solução de campo médio, a equação logística. Introduzimos a desordem fazendo com que os parâmetros do sistemas estudados oscilassem temporalmente de acordo com a sequência generalizada de Fibonacci, caracterizada por um parâmetro $k$ que afeta a intensidade das flutuações introduzidas pela sequência. Adaptamos o critério de Harris-Luck para desordens de natureza temporal e utilizamos teoria de grupo de renormalização, simulações de Monte Carlo e argumentos de escala para estudar o efeito da presença da aperiodicidade determinística temporal na criticalidade de ambos modelos, comparando nossos resultados com as previsões fornecidas pelo critério de estabilidade.

O primeiro modelo estudado foi a equação logística que frente à desordem aleatória tem sua criticalidade afetada até por desordens fracas, e apresenta transições de fase com ruídos pronunciados. Nesse caso o critério de estabilidade prevê que apenas modulações aperiódicas com $k \geq 3$ irão afetar o comportamento crítico do sistema, porém o caso $k=2$ é especialmente delicado pois ele satura exatamente o critério. Desenvolvemos um tratamento teórico de grupo de renormalização que nos forneceu previsões sobre o comportamento crítico do sistema e nos muniu com maneiras de extrair parte dos expoentes críticos relevantes, porém ainda faltam argumentos para extrair mais um expoente crítico que permitiria concluir esta análise (os expoentes que faltam são relacionados à grandezas de natureza espacial e são de difícil obtenção pois a equação logística não possui nenhuma informação espacial). Simulações de Monte Carlo extensas foram utilizadas para ratificar as previsões teóricas e verificamos que as previsões da generalização temporal do critério de estabilidade são compatíveis com os resultados obtidos, onde sistemas com $k=1$ não tiveram seu comportamento crítico afetado pela desordem. Já no caso de $k=2$ temos que os expoentes críticos não parecem ter sido afetados, porém as flutuações na densidade de infectados são intensas e só crescem com o passar do tempo, porém o ruído diverge de uma maneira não compatível com o comportamento de desordem infinita como observado no caso de desordem temporal descorrelacionada, reforçando o caráter marginal desse caso. Observamos, porém, que para os casos com $k \geq 3$ os expoentes críticos são afetados e as flutuações na densidade $\rho$ também divergem com a evolução do tempo no ponto crítico, caracterizando transições de ruído infinito. 
Em seguida estudamos o processo de contato, que, ao contrário da equação logística, possui efeitos de dimensionalidade. A teoria de grupo de renormalização precisou ser adaptada para incluir os efeitos da dimensionalidade na evolução do sistema. Esta análise ainda está sendo desenvolvida e apresentamos as abordagens desenvolvidas até a redação atual desta dissertação. Em seu estado atual o tratamento por grupo de renormalização prevê uma transição de fase se iterado numericamente, porém as relações de recorrência obtidas são complexas e não lineares, o que limita a análise teórica. Simulações de Monte Carlo detalhadas foram realizadas para testar as previsões do critério de estabilidade e estudar o comportamento do sistema frente a desordem temporal determinística. Nesse caso o critério prevê que somente a partir do caso $k=4$ a desordem começaria a afetar o comportamento crítico, o que contrasta com o cenário onde a desordem determinística é de natureza espacial pois sistemas com $k=3$ já teriam seu comportamento crítico alterado.

Observamos através de simulações um comportamento compatível com o previsto para todos os casos estudados. Porém o caso $k=4$, por saturar apenas marginalmente o critério de estabilidade, apresenta efeitos sutis que requerem simulações ainda mais extensas e finas para classificá-lo decisivamente como incompatível com o comportamento limpo, como é previsto pelo critério de estabilidade. Estudamos então o caso $k=5$ para obter resultados mais cristalinos, que certamente diferem do comportamento limpo.

Exploramos também o efeito da modulação sobre o comportamento crítico no caso $k=3$, onde observamos que o critério estabelecido funciona, como esperado, somente para desordens fracas; sendo que modulações fortes levam a expoentes não universais. Este caso é especialmente interessante pois desordem determinísticas espaciais chegam a alterar o comportamento do sistema nesse caso, porém observamos que desordens temporais fracas não afetam a criticalidade.

Esses resultados contrastam com o que é observado quando consideramos desordens espaciais aperiódicas determinísticas, onde sequências com $k \geq 3$ afetam a criticalidade do sistema, gerando modulações logperiódicas nas grandezas do sistema. Observamos que para o caso temporal são necessárias sequências com flutuações ainda mais intensas com $k \geq 4$.

Vimos nesse trabalho que, assim como a desordem temporal aleatória, a desordem determinística aperiódica leva a transições de fase com ruídos pronunciados, onde os expoentes críticos do sistema são afetados. Porém esse efeito não é observado em todos os casos, como esperado considerando a generalização temporal do critério de Harris-Luck. Um efeito similar é observado no caso espacial se comparamos o efeito de desordens aleatórias e determinísticas sobre a criticalidade. Para o caso temporal o critério de estabilidade prevê um expoente de flutuação $\omega_{c}$ crítico maior do que no caso espacial, o que significa que flutuações mais intensas são necessárias para afetar a criticalidade de um sistema, como verificamos numericamente para o processo de contato e para a equação logística. 
Apêndices 



\section{Apêndice A}

\section{Renormalização da equação logística para desordem determinística}

Seguindo o argumento do capítulo (4) iremos apresentar contas explicitas do GR proposto e explorar com mais profundidade alguns resultados interessantes. Temos que um passo $n$ do grupo de renormalização (GR) é dado através das equações

$$
\begin{aligned}
& \ln \left(a_{n+1}^{++}\right)=k \ln \left(a_{n}^{-}\right)+(k+1) \ln \left(a_{n}^{++}\right), \\
& \ln \left(a_{n+1}^{-}\right)=\ln \left(a_{n}^{--}\right), \\
& \ln \left(a_{n+1}^{--}\right)=k \ln \left(a_{n}^{++}\right)+(k+1) \ln \left(a_{n}^{--}\right),
\end{aligned}
$$

ou matricialmente:

$$
\left(\begin{array}{c}
\ln \left(a_{n}^{++}\right) \\
\ln \left(a_{n}^{-}\right) \\
\ln \left(a_{n}^{--}\right)
\end{array}\right)=\left(\begin{array}{ccc}
(k+1) & k & 0 \\
0 & 0 & 1 \\
k & 0 & (k+1)
\end{array}\right)^{n}\left(\begin{array}{c}
\ln \left(a_{0}^{++}\right) \\
\ln \left(a_{0}^{-}\right) \\
\ln \left(a_{0}^{--}\right)
\end{array}\right)
$$

e similarmente para os intervalos de tempo:

$$
\left(\begin{array}{c}
\Delta t_{n}^{++} \\
\Delta t_{n}^{-} \\
\Delta t_{n}^{--}
\end{array}\right)=\left(\begin{array}{ccc}
(k+1) & k & 0 \\
0 & 0 & 1 \\
k & 0 & (k+1)
\end{array}\right)\left(\begin{array}{c}
\Delta t_{0}^{++} \\
\Delta t_{0}^{-} \\
\Delta t_{0}^{--}
\end{array}\right) .
$$

Podemos reescrever a equação (A.1) da seguinte forma:

$$
\vec{a}_{n}=\boldsymbol{M} \vec{a}_{n-1}=\boldsymbol{M}^{n} \vec{a}_{0},
$$

onde:

$$
\vec{a}_{n} \equiv\left(\begin{array}{c}
\ln \left(a_{n, n}^{++}\right) \\
\ln \left(a_{n, n}^{-}\right) \\
\ln \left(a_{n, n}^{--}\right)
\end{array}\right)=\left(\begin{array}{c}
\left(\mu_{n}-\lambda_{b, n}\right) \Delta t_{n}^{++} \\
\left(\mu_{n}-\lambda_{a, n}\right) \Delta t_{n}^{-} \\
\left(\mu_{n}-\lambda_{a, n}\right) \Delta t_{n}^{--}
\end{array}\right), \quad \boldsymbol{M} \equiv\left(\begin{array}{ccc}
(k+1) & k & 0 \\
0 & 0 & 1 \\
k & 0 & (k+1)
\end{array}\right)
$$


A matriz $M$ têm como autovalores 1 e $\Xi_{ \pm}=\zeta_{ \pm}+k=\zeta_{ \pm}^{2}$, onde $\zeta_{ \pm}=\frac{1}{2}(1 \pm \sqrt{1+4 k})$, e autovetores

$$
v_{1}=\left(\begin{array}{c}
-1 \\
1 \\
1
\end{array}\right), v_{-}=\left(\begin{array}{c}
-\zeta_{+} / k \\
-\Xi_{+} / k^{2} \\
1
\end{array}\right), v_{+}=\left(\begin{array}{c}
-\zeta_{-} / k \\
-\Xi_{-} / k^{2} \\
1
\end{array}\right) \text {. }
$$

Temos que $\boldsymbol{M}$ pode ser decomposta como:

$$
\boldsymbol{M}=\boldsymbol{V} \boldsymbol{\Lambda} \boldsymbol{V}^{-1}
$$

onde $\boldsymbol{\Lambda}$ é uma matriz diagonal composta pelos autovalores de $\boldsymbol{M}: \boldsymbol{\Lambda}=\operatorname{diag}\left\{1, \Xi_{-}, \Xi_{+}\right\}$e $\boldsymbol{V}=\left(v_{1}, v_{-}, v_{+}\right)$ têm suas colunas dadas pelos autovetores de $\boldsymbol{M}$. Com isso temos:

$$
\vec{a}_{n}=\boldsymbol{V} \boldsymbol{\Lambda}^{n} \boldsymbol{V}^{-1} \vec{a}_{0}
$$

Usando $\vec{a}_{0}=\left(\left(\mu-\lambda_{b}\right) k,\left(\mu-\lambda_{a}\right),(k+1)\left(\mu-\lambda_{a}\right)\right)$ como condição inicial, temos, usando variáveis auxiliares $\eta_{i} \operatorname{com} i=\{0,1,2\}$ :

$$
\left(\begin{array}{c}
\ln a_{n}^{++} \\
\ln a_{n}^{-} \\
\ln a_{n}^{--}
\end{array}\right)=\left(\begin{array}{c}
\eta_{0}+\eta_{0}^{-} \Xi_{-}^{n}+\eta_{0}^{+} \Xi_{+}^{n} \\
\eta_{1}+\eta_{1}^{-} \Xi_{-}^{n}+\eta_{1}^{+} \Xi_{+}^{n} \\
\eta_{2}+\eta_{2}^{-} \Xi_{-}^{n}+\eta_{2}^{+} \Xi_{+}^{n}
\end{array}\right)
$$

que explicitamente têm a forma (introduzindo a notação $D \equiv[2(k-2) \sqrt{1+4 k}]^{-1}$ ):

$$
\begin{aligned}
\eta_{0} & =D\left[\left(\mu-\lambda_{a}\right)-k\left(\mu-\lambda_{b}\right)\right] \\
\eta_{0}^{-} & =D\left[\left(\mu-\lambda_{a}\right)\left(\Xi_{-}-k^{2}\right)+k\left(\mu-\lambda_{b}\right)\left(\zeta_{-}+k \zeta_{+}\right)\right] \\
\eta_{0}^{+} & =D\left[\left(\mu-\lambda_{a}\right)\left(\Xi_{+}-k^{2}\right)+k\left(\mu-\lambda_{b}\right)\left(\zeta_{+}+k \zeta_{-}\right)\right] \\
\eta_{1} & =D\left[\left(\lambda_{a}-\mu\right)+k\left(\mu-\lambda_{b}\right)\right] \\
\eta_{1}^{-} & =D\left[k\left(\mu-\lambda_{b}\right)\left(\zeta_{-}-k\right)+\left(\mu-\lambda_{a}\right)\left(\zeta_{-}+k \zeta_{+}\right)\right] \\
\eta_{1}^{+} & =D\left[-\left(\mu-\lambda_{b}\right)\left(\zeta_{+}-k\right)-\left(\mu-\lambda_{a}\right)\left(\zeta_{+}+k \zeta_{-}\right)\right] \\
\eta_{2} & =D\left[\left(\lambda_{a}-\mu\right)+k\left(\mu-\lambda_{b}\right)\right] \\
\eta_{2}^{-} & =D\left[\left(\mu-\lambda_{b}\right)\left(\Xi_{-}-k^{2}\right)+\left(\mu-\lambda_{a}\right)\left(\zeta_{-}+k\left(1+\zeta_{-}\right)-k^{2} \zeta_{-}\right)\right] \\
\eta_{2}^{+} & =D\left[\left(\mu-\lambda_{b}\right)\left(\Xi_{+}-k^{2}\right)-\left(\mu-\lambda_{a}\right)\left(\zeta_{+}+k\left(1+\zeta_{+}\right)-k^{2} \zeta_{+}\right)\right]
\end{aligned}
$$


onde percebemos que $\eta_{0}=-\eta_{1,2}$. Similarmente temos as formas explicitas das variáveis auxiliares $\tau_{i}$ :

$$
\begin{aligned}
\tau_{0} & =2(1-k) D \sqrt{1+4 k} \\
\tau_{0}^{-} & =D\left[1-\sqrt{1+4 k}+k(\sqrt{1+4 k}-3)+k^{2}(\sqrt{1+4 k}-1)\right], \\
\tau_{0}^{+} & =D\left[\sqrt{1+4 k}\left(k^{2}-1\right)-1+k^{2}-k(2-\sqrt{1+4 k})\right], \\
\tau_{1} & =2 D(k-1) \sqrt{1+4 k} \\
\tau_{1}^{-} & =D\left[1-2 k-2 k^{2}-\sqrt{1+4 k}\right] \\
\tau_{1}^{+} & =D\left[-1-2 k+2 k^{2}-\sqrt{1+4 k}\right], \\
\tau_{2} & =2 D(k-1) \sqrt{1+4 k}, \\
\tau_{2}^{-} & =D\left[1-2 k^{3}-\sqrt{1+4 k}-2 k(\sqrt{1+4 k}-2)+k^{2}(1+\sqrt{1+4 k})\right], \\
\tau_{2}^{+} & =D\left[1-2 k^{3}-\sqrt{1+4 k}-2 k(\sqrt{1+4 k}+2)+k^{2}(\sqrt{1+4 k}-1)\right],
\end{aligned}
$$

Como $\Xi_{+}>\Xi_{-}$, para todos os valores de $k$, os termos que acompanham o maior autovalor irão dominar a evolução dos parâmetros. De fato, se $\eta_{i}<0$ teremos que $\ln a_{i}<0$ e o sistema estará na fase ativa, já se $\eta_{i}>0$ o sistema estará na fase absorvente. Isso nos permite afirmar que a condição crítica se traduz como $\eta_{i}=0$. Impondo $\eta_{0}^{+}=0$ temos

$$
\lambda_{b}^{*}=1+\frac{\left(1-\lambda_{a}\right)\left(\zeta_{+}+k-k^{2}\right)}{k \zeta_{+}+k^{2} \zeta_{-}}
$$

que pode ser escrita em uma forma mais enxuta:

$$
\lambda_{b}^{*}=\frac{\mu \zeta_{+}-\lambda_{a}}{\zeta_{+}-1}
$$

Obtemos a mesma expressão através de $\eta_{1}^{+}=0$ e $\eta_{2}^{+}=0$. Podemos então estudar o comportamento do sistema no ponto crítico. Nesse ponto temos que para todos valores de $k$ vale $\eta_{i}^{+}=0$. Para $k=1$ temos que $\Xi_{-}<1, \operatorname{logo} \Xi_{-}^{n} \rightarrow 0, \operatorname{logo}$ à medida que iteramos o GR todos os $\ln a_{n}^{++}, \ln a_{n}^{-}$e $\ln a_{n}^{--}$tendem, em modulo, à $\left(\lambda_{b}-\lambda_{a}\right)$. Isso nos diz que o ruído se mantem constante com a iteração do GR e é tão intenso quanto a separação entre $\lambda_{a}$ e $\lambda_{b}$.

Já para $k=3$ vale que $\Xi_{-}>1, \operatorname{logo} \ln a_{n}^{++}, \ln a_{n}^{-}$e $\ln a_{n}^{--}$crescem exponencialmente (em escala logarítmica!) com $\ln a_{n} \sim \Xi_{-}^{n}$. Isso se traduz em um ruído que se torna extremamente forte de maneira abrupta. Exibimos um gráfico da evolução dos parâmetros $\ln a_{n}$ na figura (A.1).

As condições sobre os parâmetros para que possamos iterar o GR sem preocupações são:

$$
\begin{array}{r}
\ln a_{n}^{++}+\ln a_{n}^{--} \geq 0, \\
\ln a_{n}^{++}+\ln a_{n}^{-} \leq 0,
\end{array}
$$

No caso $k=1$, para valores grandes de $n$ temos que $\ln a_{n}^{++} \approx-\ln a_{n}^{--}$, logo todas as relações valem, porém a determinação da taxa mais próxima de 1 se torna bastante ambígua. Já para $k=3$ temos que $\left|\ln a_{n}^{++}\right|<\ln a_{n}^{--}$e $\left|\ln a_{n}^{++}\right|>\ln a_{n}^{-}$, logo ambas condições sempre são válidas e o GR pode ser iterado indefinidamente (no ponto crítico). 


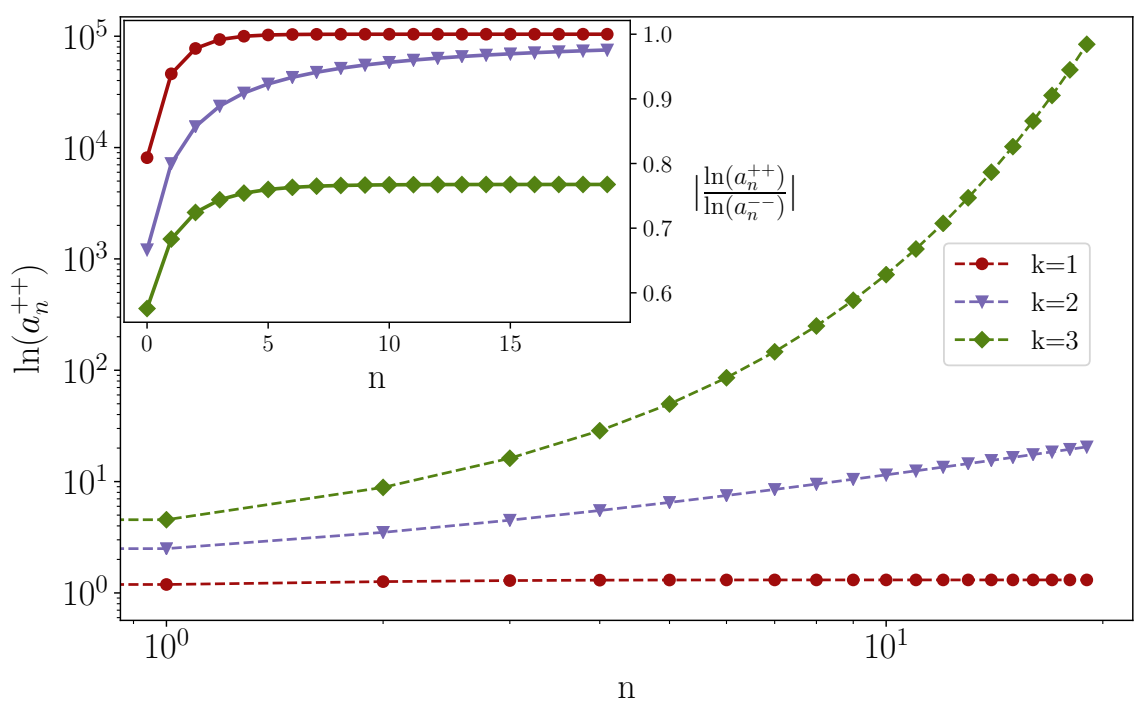

Figura A.1: Evolução da grandeza $\ln a_{n}^{++}$sob iteração do GR no ponto crítico para diferentes valores de $k$. No inset está a evolução da razão $\left|\ln a_{n}^{++} / \ln a_{n}^{--}\right|<1$, que é a condição que garante que possamos iterar o GR sem que ele falhe.

Vale realçar que caso a relação $a^{++}<1<a^{-}<a^{--}$for quebrada o tratamento de GR não fracassa imediatamente. Isso acontece quando a escala de tempo for dada por $\Omega=a^{u p}$ e esse intervalo for o alvo da renormalização pois a sequência consiste em intervalos alternantes de subida e descida, com apenas um tipo de intervalo de subida. Se este intervalo for renormalizado iremos englobar a sequência inteira e passos posteriores se tornam impossíveis.

Agora iremos voltar nossa atenção para os expoentes críticos que não foram obtidos diretamente através do GR. Para encontrar o expoente $\beta\left(\rho_{\text {est }} \sim \epsilon^{\beta}\right)$ precisamos relacionar as grandezas do sistema com a densidade $\rho$ diretamente. Como a equação logística não tem noção de espaço, fazer essa relação não é uma tarefa simples. Uma possível solução seria fazer um mapeamento em outro problema para recuperar a noção de dimensionalidade (como feito para desordem temporal aleatória, onde é feito um mapeamento no passeio aleatório com parede refletora [46]), porém a desordem aperiódica não se traduz de forma trivial em outros problemas. Outra forma de buscar essa relação é resolver a relação recursiva

$$
\rho_{n+1}^{-1}=a_{n} \rho_{n}^{-1}+c_{n}
$$

onde os parâmetros $a_{n}$ e $c_{n}$ variam de acordo com a sequência de Fibonacci. Vimos no capitulo 4 que a equação acima pode ser escrita em termos das condições iniciais como:

$$
\rho_{n}^{-1}=\mathbb{A}_{n} \rho_{0}^{-1}+\mathbb{C}_{n}
$$


onde

$$
\mathbb{A}_{n}=\prod_{i=0}^{n} a_{i}, \quad \mathbb{C}_{n}=\sum_{i=0}^{n} c_{i} \prod_{j=i+1}^{n} a_{j} .
$$

Na fase ativa temos que $\mathbb{A}_{n} \rightarrow 0$ (já que $a_{i}<1$ ), logo o termo transiente que depende da densidade inicial desaparece. As informações sobre a densidade estão, portanto, contidas no termo $\mathbb{C}_{n}$. Durante a renormalização os termos $c_{n}$ se combinam de forma não linear e, para os nossos fins, não tem sido relevantes, até agora. Este termo também pode ser reescrito da seguinte maneira:

$$
\mathbb{C}_{n}=\mathbb{A}_{n}\left[c_{a} \sum_{i \in A} \frac{1}{\mathbb{A}_{i}}+c_{b} \sum_{i \in B} \frac{1}{\mathbb{A}_{i}}\right],
$$

onde as somas em $i \in A$ e $i \in B$ significam somas sobre todos os índices que são um " $A$ " ou um " $B$ " na sequência de Fibonacci e $C_{a, b}$ é o valor que $c_{n}$ assume quando as taxas são do tipo " $A$ " ou " $B$ ", respectivamente. Explicitamente os primeiros termos dessas somas são:

$$
\begin{aligned}
\sum_{i \in A} \frac{1}{\mathbb{A}_{i}} & =\frac{1}{a_{A}}+\frac{1}{a_{A}}\left(\frac{1}{a_{B}}\right)^{k} \frac{1}{a_{A}}+\frac{1}{a_{A}}\left(\frac{1}{a_{B}}\right)^{k}\left(\frac{1}{a_{A}}\right)^{2}+\ldots, \\
\sum_{i \in B} \frac{1}{\mathbb{A}_{i}} & =\frac{1}{a_{A}}\left(\frac{1}{a_{B}}\right)+\frac{1}{a_{A}}\left(\frac{1}{a_{B}}\right)^{2}+\ldots
\end{aligned}
$$

As somas não convergem devido à natureza aperiódica da sequência de Fibonacci, porém elas devem convergir se realizarmos uma média sobre configurações iniciais, já que $\mathbb{C}_{n}$ deve convergir à densidade estacionária nesse caso.

Tendo em vista os resultados numéricos da sessão 4.5 podemos buscar a relação entre encontrar a evolução de $\rho$ realizando uma média sobre configurações e fazer o mesmo considerando taxas uniformes e iguais aos valores que elas assumiriam na média configuracional. Isso equivale relacionar a expreesão A.24 (após tirarmos a média configuracional) a sua forma no caso uniforme (utilizaremos um "til" para nos referir as grandezas do caso uniforme):

$$
\tilde{\mathbb{C}}_{n}=\sum_{i=0}^{n} \tilde{c}_{i} \prod_{j=i+1}^{n} \tilde{a}_{j}
$$

onde tanto $\tilde{c}_{i}$ como $\tilde{a}_{i}$ são uniformes e independem do índice $i$. A soma acima se torna um progressão geométrica com razão $a_{i}=\exp [(\langle\mu\rangle-\langle\lambda\rangle) \Delta t]$. Isso nos dá que no limite $n \rightarrow \infty$ :

$$
\tilde{\mathbb{C}}_{n}=\tilde{c}_{n} \frac{1}{1-\tilde{a}_{n}}=\frac{\langle\lambda\rangle}{\langle\lambda\rangle-\langle\mu\rangle}
$$

que é o valor estacionário de $\rho^{-1}$. Essa expressão é condizente com o resultado obtido se utilizássemos diretamente $\dot{\rho}=0$ na equação logística. Provar que a equação A.24 é equivalente a equação acima permanece como uma questão em aberto, porém evidências numéricas indicam que perto da criticalidade e no limite de $n$ grandes elas são equivalentes. 



\section{Apêndice B}

\section{O Caso $\mathrm{k}=2$}

Visto que a teoria de grupo de renormalização para a equação logística com desordem determinística aperiódica desenvolvida no capítulo 4 não funciona para o caso $k=2$, apresentamos nesse apêndice um tratamento para esse caso específico.

\section{B.1 Adaptação do GR}

O tratamento de GR não funciona para o caso $k=2$ pois temos que a multiplicidade algébrica do autovalor $\lambda_{1}=1$ da matriz de substituição $M$ definida como:

$$
M \equiv\left(\begin{array}{ccc}
k+1 & k & 0 \\
0 & 0 & 1 \\
k & 0 & k
\end{array}\right)
$$

é maior do que 1 já que também temos que $\Xi_{-}=1$. Nesse caso a matriz $M$ não pode ser decomposta como anteriormente. Temos então que achar o vetor de Jordan relacionado ao autovalor $\lambda_{1}=1^{1}$, que pode ser feito da seguinte maneira:

$$
\left(\boldsymbol{M}-\lambda_{1} \mathbb{1}\right) \overrightarrow{j_{1}}=\overrightarrow{v_{1}},
$$

que nos dá a vetor de Jordan $\vec{j}_{1}=(1,-3 / 2,-1 / 2)$, que completa o autoespaço da matriz $\boldsymbol{M}$. Com isso podemos resolver as equações provenientes do GR para a evolução das grandezas do modelo:

$$
\left(\begin{array}{c}
\ln \left(a_{n}^{++}\right) \\
\ln \left(a_{n}^{-}\right) \\
\ln \left(a_{n}^{--}\right)
\end{array}\right)=\left(\begin{array}{ccc}
(k+1) & k & 0 \\
0 & 0 & 1 \\
k & 0 & (k+1)
\end{array}\right)^{n}\left(\begin{array}{c}
\ln \left(a_{0}^{++}\right) \\
\ln \left(a_{0}^{-}\right) \\
\ln \left(a_{0}^{--}\right)
\end{array}\right)
$$

\footnotetext{
${ }^{1}$ Uma possível decomposição para esse tipo de matriz seria por SVD, porém o método que utilizamos é mais simples.
} 
e:

$$
\left.\left(\begin{array}{c}
\Delta t_{n}^{++} \\
\Delta t_{n}^{-} \\
\Delta t_{n}^{--}
\end{array}\right)=\left(\begin{array}{ccc}
(k+1) & k & 0 \\
0 & 0 & 1 \\
k & 0 & (k+1)
\end{array}\right)\right)^{n}\left(\begin{array}{c}
\Delta t_{0}^{++} \\
\Delta t_{0}^{-} \\
\Delta t_{0}^{--}
\end{array}\right) .
$$

Usando as propriedades

$$
\boldsymbol{M}^{n} \overrightarrow{v_{1}}=\lambda_{1}^{n} \overrightarrow{v_{1}}, \quad \boldsymbol{M}^{n} \overrightarrow{j_{1}}=\lambda_{1}^{n} \overrightarrow{j_{1}}+n \lambda_{1}^{n-1} \overrightarrow{v_{1}},
$$

podemos aplicar facilmente $\boldsymbol{M}^{n}$ às condições iniciais se as decompusermos no autoespaço expandido de $\boldsymbol{M}$.

Disso temos:

$$
\begin{aligned}
\ln \left(a_{n}^{++}\right) & =\frac{1}{9}\left[\ln \left(a_{0}^{++}\right)\left(5+4 \Xi_{+}^{n}+6 n\right)+2 \ln \left(a_{0}^{-}\right)\left(-1+\Xi_{+}^{n}+6 n\right)+2 \ln \left(a_{0}^{--}\right)\left(-1+4^{n}-3 n\right)\right], \\
\ln \left(a_{n}^{-}\right) & =\frac{1}{9}\left[2 \ln \left(a_{0}^{++}\right)\left(-1+\Xi_{+}^{n}-3 n\right)+\ln \left(a_{0}^{-}\right)\left(8+\Xi_{+}^{n}-12 n\right)+\ln \left(a_{0}^{--}\right)\left(-1+\Xi_{+}^{n}+6 n\right)\right], \\
\ln \left(a_{n}^{--}\right) & =\frac{1}{9}\left[2 \ln \left(a_{0}^{++}\right)\left(-4+4 \Xi_{+}^{n}-3 n\right)+4 \ln \left(a_{0}^{-}\right)\left(-1+\Xi_{+}^{n}-3 n\right)+\ln \left(a_{0}^{--}\right)\left(4+4 \Xi_{+}^{n}+6 n\right)\right] ;
\end{aligned}
$$

e expressões similares para os intervalos de tempo. Estamos em posição de encontrar o passo de crossover na fase ativa, assim como fizemos para os outros casos de $k$ na seção 4 , impondo a condição $\ln \left(a_{n^{*}}^{--}\right)=0$. Isso nos leva a uma equação transcendental com termos que dependem do passo de iteração em leis de potência com $\Xi_{+}^{n^{*}}$. Tal equação pode ser resolvida numericamente e, se utilizarmos as relações $\xi_{t} \sim\left\langle\Delta t_{n^{*}}\right\rangle \sim \epsilon^{-\nu_{\|}}$, podemos encontrar o expoente $\nu_{\|}$para $k=2$. Um gráfico ilustrando essa análise numérica está representado na figura (B.1) e dela extraímos a estimativa $\nu_{\|}=1.04(2)$, utilizando distâncias à criticalidade $\epsilon$ pequenas para acentuar o comportamento em lei de potência e "emudecer" a dependência linear.

Outro resultado interessante é que se impusermos a condição de criticalidade, que consiste em nulificar todos os termos que contêm potências do autovalor $\Xi_{+}$no sistema de equações acima, usando que $k=2$ obtemos o valor crítico $\lambda_{b}^{*}$ :

$$
\lambda_{b}^{*}=2 \mu-\lambda_{a},
$$

que é idêntico ao valor previsto pela equação (4.5), se utilizarmos o valor numérico do autovalor $\zeta_{+}=2$ para o caso $k=2$. 


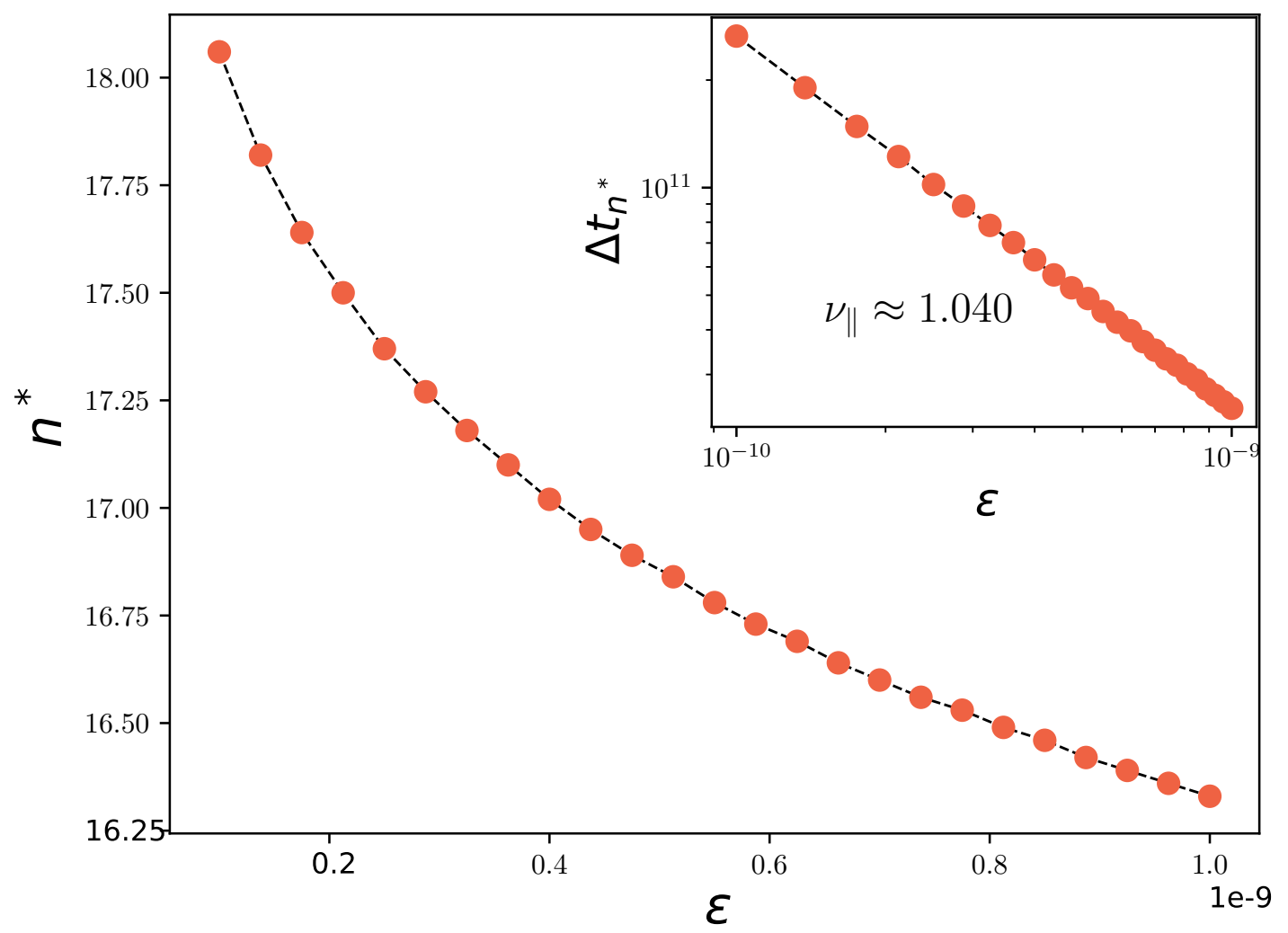

Figura B.1: Passo de crossover obtido através da iteração numérica da equação transcendental obtido impronto a condição $\ln \left(a_{n^{*}}^{--}\right)=0$. No inset está um gráfico da distância a criticalidade $\epsilon$ contra o tamanho médio dos intervalos de tempo $\Delta t_{n^{*}}$ no passo $n^{*}$, do qual obtemos a estimativa $\nu_{\|}=1.04$ ajustando $\ln (\Delta t)=-\nu_{\|} \ln (\epsilon)+$ cte. 



\section{Bibliografia}

[1] P. Grassberger, "On the critical behavior of the general epidemic process and dynamical percolation," Mathematical Biosciences, vol. 63, no. 2, pp. 157 - 172, 1983.

[2] A.-L. Barabási and H. E. Stanley, Fractal Concepts in Surface Growth. Cambridge University Press, 1995.

[3] H. Haken, Synergetics: an introduction : nonequilibrium phase transitions and self-organization in physics, chemistry, and biology. No. v. 3 in Springer series in synergetics, Springer, 1983.

[4] S. Salinas, Introdução a Física Estatística Vol. 09. EDUSP, 1997.

[5] P. Grassberger, "Are damage spreading transitions generically in the universality class of directed percolation?," Journal of Statistical Physics, vol. 79, pp. 13-23, Apr 1995.

[6] K. A. Takeuchi, M. Kuroda, H. Chaté, and M. Sano, "Directed percolation criticality in turbulent liquid crystals," Phys. Rev. Lett., vol. 99, p. 234503, Dec 2007.

[7] R. M. Ziff, E. Gulari, and Y. Barshad, "Kinetic phase transitions in an irreversible surface-reaction model," Phys. Rev. Lett., vol. 56, pp. 2553-2556, Jun 1986.

[8] S. Okuma, Y. Tsugawa, and A. Motohashi, "Transition from reversible to irreversible flow: Absorbing and depinning transitions in a sheared-vortex system," Phys. Rev. B, vol. 83, p. 012503, Jan 2011.

[9] D. S. Fisher, "Critical behavior of random transverse-field ising spin chains," Phys. Rev. B, vol. 51, pp. 6411-6461, Mar 1995.

[10] T. N. Nguyen, P. A. Lee, and H.-C. zur Loye, "Design of a random quantum spin chain paramagnet: Sr3cupt0.5ir0.5o6," Science, vol. 271, pp. 489-491, 011996.

[11] D. Shechtman, I. Blech, D. Gratias, and J. W. Cahn, "Metallic phase with long-range orientational order and no translational symmetry," Phys. Rev. Lett., vol. 53, pp. 1951-1953, Nov 1984.

[12] L. Bindi, C. Lin, C. Ma, and P. Steinhardt, "Collisions in outer space produced an icosahedral phase in the khatyrka meteorite never observed previously in the laboratory," Scientific Reports, vol. 6, p. 38117, 122016. 
[13] H. Barghathi, D. Nozadze, and T. Vojta, "Contact process on generalized fibonacci chains: Infinitemodulation criticality and double-log periodic oscillations," Physical Review E, vol. 89, 012014.

[14] N. de Bruijn, "Algebraic theory of penrose's non-periodic tilings of the plane. i," Indagationes Mathematicae (Proceedings), vol. 84, no. 1, pp. 39 - 52, 1981.

[15] A. L. Mackay, "Crystallography and the penrose pattern," Physica A: Statistical Mechanics and its Applications, vol. 114, no. 1, pp. 609 - 613, 1982.

[16] J. M. Luck, "Cantor spectra and scaling of gap widths in deterministic aperiodic systems," Phys. Rev. $B$, vol. 39, pp. 5834-5849, Mar 1989.

[17] U. Grimm and M. Baake, "Aperiodic Ising Models," arXiv e-prints, pp. cond-mat/9604116, Apr 1996.

[18] H. K. Janssen, "On the nonequilibrium phase transition in reaction-diffusion systems with an absorbing stationary state," Zeitschrift für Physik B Condensed Matter, vol. 42, pp. 151-154, Jun 1981.

[19] P. Grassberger, "On phase transitions in schlögl's second model," Zeitschrift für Physik B Condensed Matter, vol. 47, pp. 365-374, Dec 1982.

[20] D. Stauffer and A. Aharony, Introduction To Percolation Theory. Taylor \& Francis, 1994.

[21] S. R. Broadbent and J. M. Hammersley, "Percolation processes: I. crystals and mazes," Mathematical Proceedings of the Cambridge Philosophical Society, vol. 53, no. 3, p. 629-641, 1957.

[22] H. Hinrichsen, "Non-equilibrium critical phenomena and phase transitions into absorbing states," $A d-$ vances in Physics, vol. 49, p. 815-958, Nov 2000.

[23] G. Odor, "Universality classes in nonequilibrium lattice systems," Review of Modern Physics, vol. 76, p. $663,082004$.

[24] I. Jensen, "Low-density series expansions for directed percolation: I. a new efficient algorithm with applications to the square lattice," Journal of Physics A: Mathematical and General, vol. 32, pp. 52335249 , jan 1999.

[25] C. A. Voigt and R. M. Ziff, "Epidemic analysis of the second-order transition in the ziff-gulari-barshad surface-reaction model," Phys. Rev. E, vol. 56, pp. R6241-R6244, Dec 1997.

[26] I. Jensen, "Critical behavior of the three-dimensional contact process," Phys. Rev. A, vol. 45, pp. R563R566, Jan 1992.

[27] J. Marro and R. Dickman, Nonequilibrium Phase Transitions in Lattice Models. Aléa-Saclay, Cambridge University Press, 2005. 
[28] A. B. Harris, "Effect of random defects on the critical behaviour of ising models," Journal of Physics C: Solid State Physics, vol. 7, pp. 1671-1692, may 1974.

[29] J. M. Luck, "A classification of critical phenomena on quasi-crystals and other aperiodic structures," Europhysics Letters (EPL), vol. 24, pp. 359-364, nov 1993.

[30] W. Kinzel, "Phase transitions of cellular automata," Zeitschrift für Physik B Condensed Matter, vol. 58, pp. 229-244, Sep 1985.

[31] T. Vojta and R. Dickman, "Spatiotemporal generalization of the harris criterion and its application to diffusive disorder," Phys. Rev. E, vol. 93, p. 032143, Mar 2016.

[32] T. E. Harris, "Contact interactions on a lattice," Ann. Probab., vol. 2, pp. 969-988, 121974.

[33] D. Landau and K. Binder, A Guide to Monte Carlo Simulations in Statistical Physics. Cambridge University Press, 2015.

[34] M. de Oliveira and T. Tomé, Dinâmica Estocástica e Irreversibilidade Vol. 35. EDUSP, 2001.

[35] I. Jensen and R. Dickman, "Time-dependent perturbation theory for nonequilibrium lattice models," Journal of Statistical Physics, vol. 71, pp. 89-127, Apr 1993.

[36] M. M. S. Sabag and M. J. de Oliveira, "Conserved contact process in one to five dimensions," Phys. Rev. E, vol. 66, p. 036115, Sep 2002.

[37] A. Grübler, The rise and fall of infrastructures: dynamics of evolution and technological change in transport. Contributions to economics, Physica-Verlag, 1990.

[38] C. Perez, Technological Revolutions and Financial Capital. E. Elgar Pub., 2003.

[39] P. Chaikin and T. Lubensky, Principles of Condensed Matter Physics. Cambridge University Press, 2000.

[40] A. J. Noest, "New universality for spatially disordered cellular automata and directed percolation," Phys. Rev. Lett., vol. 57, pp. 90-93, Jul 1986.

[41] A. G. Moreira and R. Dickman, "Critical dynamics of the contact process with quenched disorder," 1996.

[42] I. Webman, D. B. Avraham, A. Cohen, and S. Havlin, "Dynamical phase transitions in a random environment," Philosophical Magazine B, vol. 77, no. 5, pp. 1401-1412, 1998.

[43] R. Dickman and A. G. Moreira, "Violation of scaling in the contact process with quenched disorder," Phys. Rev. E, vol. 57, pp. 1263-1268, Feb 1998.

[44] M. M. de Oliveira and S. C. Ferreira, "Universality of the contact process with random dilution," Journal of Statistical Mechanics: Theory and Experiment, vol. 2008, p. P11001, nov 2008. 
[45] I. Jensen, "Temporally disordered bond percolation on the directed square lattice," Phys. Rev. Lett., vol. 77, pp. 4988-4991, Dec 1996.

[46] T. Vojta and J. A. Hoyos, "Infinite-noise criticality: Nonequilibrium phase transitions in fluctuating environments," EPL (Europhysics Letters), vol. 112, 072015.

[47] F. Iglói and C. Monthus, "Strong disorder rg approach of random systems," Physics Reports, vol. 412, no. 5, pp. $277-431,2005$.

[48] F. J. Oliveira, M. S. Faria, and A. P. Vieira, "Strong-disorder renormalization group study of aperiodic quantum ising chains," Journal of Statistical Mechanics: Theory and Experiment, vol. 2012, p. P03007, mar 2012 . 